\title{
THERMAL EXPANSION OF COPPER AND SOME OF ITS IMPORTANT INDUSTRIAL ALLOYS
}

\author{
By Peter Hidnert
}

ABSTRACT

Data on the thermal expansion of 128 samples of copper and its important alloys of various compositions, heat treatments, mechanical treatments, etc., are presented. The specimens contained from 56 to 100 per cent copper and were prepared in a number of ways-cast, cast and cold-rolled, extruded, extruded and cold worked, hot-rolled and cold worked. Most of the samples were examined from room temperature to about $300^{\circ} \mathrm{C}$. (Several specimens were cooled to $-50^{\circ} \mathrm{C}$ and then heated to $+300^{\circ} \mathrm{C}$.)

Practically all available information on the thermal expansion of copper and its alloys is briefly reviewed.

A description of the apparatus and the preparation of the samples, etc., are given.

Definite mathematical relations were found to exist between the coefficients of expansion and the copper content of most of the alloys investigated (Series II, III, $\mathrm{V}, \mathrm{VI}$ ). In general, the coefficient of expansion increases with a decrease in the copper content. The addition of lead or tin has a decided effect on the coefficient; the former element generally decreases and the latter increases the coefficient.

CAST AND COLD-ROLLEDD COPPER-ZINC AlLOYS (SERIES II AND III).-In the case of alloys containing 62 per cent copper, it was found that the coefficients did not materially differ in cast or cold-rolled specimens, and for alloys containing $9 \circ$ per cent copper a similar agreement existed. For alloys with a copper content from about 62 to $9 \circ$ per cent the cold-rolled alloys have greater coefficients than the castings, and for alloys containing more than 90 per cent copper the reverse is true. The coefficients of the inside sections of the castings are generally slightly less than those of the outside sections. A relation exists between the density and thermal expansion of the cold-rolled copper-zinc alloys (Series II).

CAst and Cold-Roliend COPper-Tin AlLoys (SERIES V and VI).-The coeffcients of the cold-rolled tin alloys are less than those of the castings. Cold-rolling and drawing, therefore, cause a diminution in the values of the coefficients.

Hot RolLed AND EXTRuded SPECIMENS (SERIES I, IV, AND VII).-Owing to the large number of varying elements in the hot-rolled and extruded samples, it was impossible to determine the exact effect of each constituent element. In general, however, the coefficients are greater than the extrapolated values obtained from the quadratic equations of the copper-zinc alloys (Series II and III).

The differences between the various series of samples are discussed in the section "Comparison of Results" and presented graphically in Figs. 39 to 43 .

The appendix gives average coefficients of expansion of all the samples investigated. 


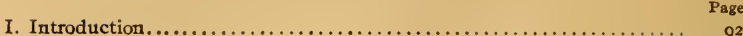

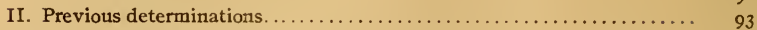

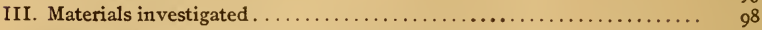

IV. Apparatus and evaluation of constants.................. ror

V. Experimental and derived results ........................ 107

I. Series I. Copper: Electrolytic, nickeliferous, arsenical........ I07

2. Series II. Cold-rolled copper-zinc alloys................ Io9

3. Series III. Sections of copper-zinc castings .............. II6

4. Series IV. Extruded and hot-rolled copper-zinc alloys........ I25

5. Series V. Cold-rolled copper-tin alloys................. ${ }_{132}^{2}$

6. Series VI. Sections of copper-tin castings................ $\mathbf{r}_{33}$

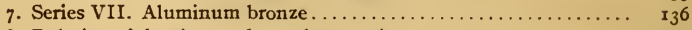

8. Relation of density to thermal expansion................ I $_{3} 8$

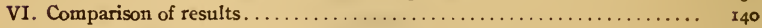

VII. Summary and conclusions. . . . . . . . . . . . . . . $\ldots \ldots \ldots \ldots \ldots \ldots$

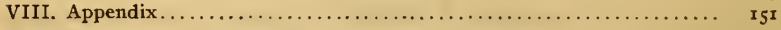

\section{INTRODUCTION}

A general demand for reliable information on the thermal expansion of copper and its alloys, caused the Bureau, with the cooperation of the American Brass Co., to undertake a comprehensive investigation on this subject. An attempt has been made to determine how the coefficients of expansion vary with temperature, chemical composition, heat treatment, mechanical treatment, etc. In structural work and in the design and construction of various apparatus, such as steam and pressure gages, thermostats, automatic valves, etc., many questions relating to expansion arise. The following article should answer many questions of expansivity in so far as these refer to apparatus constructed of these alloys.

Most of the samples were examined from room temperature to about $300^{\circ} \mathrm{C}$. (Several specimens were cooled to $-50^{\circ} \mathrm{C}$ and then heated to $+300^{\circ} \mathrm{C}$.) None of the determinations were made on alloys that had been annealed after cold working. The alloys investigated contain various percentages of copper (from 56 to roo per cent), zinc (o to 40 per cent), and tin (o to ro per cent). The percentages of other elements contained are relatively small. The samples are divided into seven series, according to chemical composition and treatment.

The samples and photomicrographs were prepared by the technical department of the American Brass Co., which also furnished the chemical composition. The author wishes to express his appreciation for valuable suggestions, comments, and data on 
the micrographs and the preparation of the samples, given by W. H. Bassett and F. G. Smith of this company.

\section{PREVIOUS DETERMINATIONS}

Some of the work by previous observers on the thermal expan sion of copper and copper alloys will be briefly reviewed here.

Matthiessen ${ }^{1}$ divided the physical properties of alloys into two classes, namely, (I) Those which do not indicate their chemical nature, and (2) those which do indicate their chemical nature. $\mathrm{He}$ investigated the property of thermal expansion, in order to determine to which of these classes this property belongs, as well as to find the law which regulates the expansion of alloys.

His method by which the expansion of small quantities of metals and alloys could be determined was to weigh the body in water at different temperatures. The sample was slightly gilded to prevent the action of water on it. Before each weighing the water was boiled in order to expel absorbed air.

He found that copper does not behave, in one respect, like glass. The glass rods which he examined "do not return directly to their original length after being heated to $100^{\circ}$ and cooled rapidly; copper, however, does so; for no differences in the coefficients were observed after heating the rod to $100^{\circ}$, determining its expansion, allowing it to stand over night, and redetermining the coefficients."

The following formulas applicable between $0^{\circ}$ and $100^{\circ} \mathrm{C}$ are given for the linear and the cubical thermal expansion of copper:

$$
L_{\mathrm{t}}=L_{\mathrm{o}}\left(\mathrm{I}+\mathrm{IO}^{-4} \times 0.148 \mathrm{I} t+\mathrm{IO}^{-6} \times 0.0185 t^{2}\right)
$$

and

$$
V_{t}=V_{0}\left(\mathrm{I}+10^{-4} \times .4463 t+10^{-6} \times .0555^{2}\right)
$$

The corresponding formulas for a copper-zinc alloy containing $7 \mathrm{I}$ per cent copper are

$$
L_{\mathrm{t}}=L_{\mathrm{o}}\left(\mathrm{I}+1 \mathrm{IO}^{-} \times 0.1720 t+10^{-6} \times 0.0186 t^{2}\right)
$$

and $\quad V_{\mathrm{t}}=V_{\mathrm{o}}\left(\mathrm{I}+\mathrm{IO}^{-4} \times .5 \mathrm{I} 6 \mathrm{I} t+1 \mathrm{I0}^{-6} \times .055^{-6} t^{2}\right)$.

These equations represent the mean of two determinations on the same sample. The results were as follows (if $V_{\mathrm{o}}=\mathrm{I}$ ):

$$
\text { First heating, } \quad V_{100}=1.005723 \text {. }
$$

Second heating, $V_{100}=1.0057 \mathrm{I} 6$.

Matthiessen states that "a difference in the crystalline form will in all probability cause a slight difference in the coefficients of expansion. It is well known that alloys crystallize much more 
readily, in most cases, than the component metals, and not always in the same form."

He reached the conclusion that apparently the determinations of the thermal expansion of alloys give in general no indication as to their chemical nature.

Benoit ${ }^{2}$ used Fizeau's method for determinations of the thermal expansion of a number of brasses and bronzes from 0 to about $80^{\circ} \mathrm{C}$. The results are summarized in Tabie $\mathrm{I}$, in which $t^{\circ}$ represents any temperature from o to about $80^{\circ} \mathrm{C}$.

TABLE 1.-Coefficients of Expansion of Some Brasses and Bronzes

\begin{tabular}{|c|c|c|c|c|c|c|c|c|}
\hline \multirow{2}{*}{ Alloy } & \multicolumn{6}{|c|}{ Composition } & \multicolumn{2}{|c|}{$\begin{array}{l}\text { Average coefficients of expansion from } \\
\qquad 0^{\circ} \text { to } t^{\circ} \mathrm{C}\end{array}$} \\
\hline & $\begin{array}{l}\text { Cop- } \\
\text { per }\end{array}$ & Zinc & Leać & Tin & Iron & $\begin{array}{l}\text { Phos- } \\
\text { phorus }\end{array}$ & $\begin{array}{l}\text { According to mer- } \\
\text { cury thermometer }\end{array}$ & $\begin{array}{l}\text { According to hydro- } \\
\text { gen thermometer }\end{array}$ \\
\hline Brass I................. & $\begin{array}{l}\text { P. ct. } \\
59.48\end{array}$ & $\begin{array}{l}\text { P. ct. } \\
37.95\end{array}$ & $\begin{array}{r}\text { P. ct. } \\
1.89\end{array}$ & $\begin{array}{r}\text { P. ct. } \\
0.36\end{array}$ & $\begin{array}{l}\text { P. ct. } \\
0.27\end{array}$ & P. ct. & $10^{-2}(18666+6.58 t)$ & $10^{-9}(18759+5.55 t)$ \\
\hline Brass II. . . . . . . . . . & 59.15 & 38.25 & 2.06 & .30 & .19 & & $10^{-9}(18745+6.37 t)$ & $10^{-9}(18839+5.33 t)$ \\
\hline Brass III............. & 63.41 & 33.74 & 2.02 & .22 & .38 & & $10^{-8}(18361+6.21 t)$ & $10^{-9}(18453+5.19 t)$ \\
\hline Brass IV............ & 73.75 & 24.18 & .57 & 1.52 & Trace & & $10^{-9}(17850+5.55 t)$ & $10^{-9}(17939+4.56 t)$ \\
\hline Bronze I. ........... & 81.20 & 8.60 & .17 & 9.87 & ......... & ........ & $10^{-9}(17465+5.93 t)$ & $10^{-9}(17552+4.96 t)$ \\
\hline Bronze $\mathbf{u} a \ldots \ldots \ldots$ & & & & ........ & & ........ & $10^{-9}(17451+6.50 t)$ & $10^{-9}(17538+5.54 t)$ \\
\hline $\begin{array}{l}\text { Phosphor bronze, } \\
\text { poor in phos- } \\
\text { phorus, hard } b . . .\end{array}$ & 97.6 & & & 2.2 & & 0.2 & $10^{-9}(16582+5.54 t)$ & $10^{-9}(16664+4.62 t)$ \\
\hline $\begin{array}{l}\text { Phosphor bronze, } \\
\text { poor in phos- } \\
\text { phorus, annealed } b\end{array}$ & 97.6 & & . & 2.2 & & .2 & $10^{-9}(16492+5.99 t)$ & $10^{-9}(16575+5.08 x)$ \\
\hline $\begin{array}{l}\text { Phosphor bronze, } \\
\text { rich in phos- } \\
\text { phorus, hard } b . . .\end{array}$ & 94.6 & & & 4.7 & & .7 & $10^{-9}(16909+5.90 t)$ & $10^{-9}(16994+4.96 t)$ \\
\hline $\begin{array}{l}\text { Phosphor bronze, } \\
\text { rich in phos- } \\
\text { phorus, annealed } b\end{array}$ & 94.6 & & & 4.7 & & .7 & $10^{-9}(16886+6.04 t)$ & $10^{-9}(16971+5.110)$ \\
\hline
\end{tabular}

a Same composition as the preceding, before fusion.

$\checkmark$ The composition is approximate.

TABLE 2.-Expansion of Copper and Two of Its Alloys

\begin{tabular}{|c|c|c|c|c|c|}
\hline \multirow[b]{2}{*}{ Material } & \multicolumn{5}{|c|}{ Linear expansion trom- } \\
\hline & $\begin{array}{l}+16 \text { to } \\
-191^{\circ} \mathrm{C}\end{array}$ & $\begin{aligned} & 16 \text { to } \\
+ & 250^{\circ} \mathrm{C}\end{aligned}$ & $\begin{array}{l}16 \text { to } \\
375^{\circ} \mathrm{C}\end{array}$ & $\begin{array}{l}16 \text { to } \\
500^{\circ} \mathrm{C}\end{array}$ & $\begin{array}{l}16 \text { to } \\
625^{\circ} \mathrm{C}\end{array}$ \\
\hline & $\mathbf{m m}$ & $\mathrm{mm}$ & $\mathbf{m m}$ & mm & $\mathrm{mm}$ \\
\hline Copper................................. & -2.917 & +4.011 & +6.335 & +8.784 & +11.360 \\
\hline Bronze $(84 \mathrm{Cu}, 9 \mathrm{Zn}, 6 \mathrm{Sn}) \ldots \ldots \ldots \ldots \ldots \ldots$ & -3.117 & 4.259 & 6.730 & 9.335 & .............. \\
\hline Brass $(62 \mathrm{Cu}, 38 \mathrm{Zn}) \ldots \ldots \ldots \ldots \ldots \ldots$ & -3.403 & 4.637 & 7.506 & & (.............. \\
\hline
\end{tabular}

2 Benoit, Jour. de Phys., 8, p. 45r; r889. 
Henning ${ }^{3}$ determined the linear expansion of one copper and two copper alloys by comparing the change of length of these bodies at various temperatures with the known expansion of platinum as determined by Scheel. Table 2 gives the linear expansion (or change in length) in millimeters of $\mathrm{I}$-meter rods.

Dittenberger and Gehrcke ${ }^{4}$ investigated the thermal expansion of copper to $625^{\circ} \mathrm{C}$, which may be represented by the quadratic function

$$
10^{2} \lambda=16 \text { o70 } t+4.030 t^{2} .
$$

After each heating, the rod of length $487 \mathrm{~mm}$ showed a permanent elongation of 0.01 to $0.02 \mathrm{~mm}$.

These investigators also made observations on two copperalloy rods. The expansion of the first rod, which contained 6r.5 per cent copper, 37.9 per cent zinc, and 0.4 per cent lead, is in agreement with the formula

$$
\mathrm{ro}^{9} \lambda=\mathrm{I} 7487 t+8.767 t^{2}
$$

between $\mathrm{O}$ and $427^{\circ} \mathrm{C}$. On maintaining this specimen at $500^{\circ} \mathrm{C}$ for five hours, it was found that the rod increased in length. The increase at constant temperature was approximately proportional to the time. The point at which this growth at constant temperature begins, is near the melting point of zinc $\left(4 \mathrm{r} 9^{\circ} \mathrm{C}\right)$.

The second rod, which contained 84.I per cent copper, 8.7 per cent zinc, 6.2 per cent tin, and 0.7 per cent lead, did not show this phenomenon, evidently because its zinc content is less. The equation

$$
10^{\circ} \lambda=17044 t+4.34 t^{2}
$$

represents the expansion between $\mathrm{o}$ and $500^{\circ} \mathrm{C}$.

Dorsey ${ }^{5}$ used a modified form of the Pulfrich interferometer in determining the thermal expansion of copper at low temperatures. He obtained the following results on a sample of commercial seam-

\begin{tabular}{|c|c|c|c|}
\hline Temperature & $\begin{array}{l}\text { Instantaneous } \\
\text { coefflcients } \times 10^{8}\end{array}$ & Temperature & $\begin{array}{l}\text { Instantaneoug } \\
\text { coeffleients } \times 10^{8}\end{array}$ \\
\hline Degrees absolute & & Degrees absolute & \\
\hline 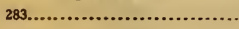 & 1635 & $183 . \ldots \ldots \ldots \ldots \ldots \ldots$ & 1468 \\
\hline $263 . \ldots \ldots \ldots \ldots$ & 1613 & 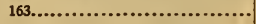 & 1437 \\
\hline $243 . . . \ldots \ldots \ldots \ldots$ & 1610 & 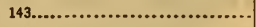 & 1305 \\
\hline $223 . . . \ldots \ldots \ldots \ldots . . . .$. & 1595 & $123 . . . \ldots \ldots \ldots \ldots \ldots \ldots \ldots \ldots \ldots \ldots \ldots \ldots \ldots$ & 1206 \\
\hline 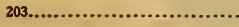 & 1500 & $103 . \ldots \ldots \ldots \ldots \ldots \ldots \ldots \ldots \ldots \ldots \ldots \ldots \ldots \ldots \ldots \ldots$ & 1039 \\
\hline
\end{tabular}
less tubing containing 99.9 per cent copper (density =8.91).

TABLE 3.-Coefficients of Expansion of Copper

Henning, Ann. d. Phys., 327 (22, fourth series), p. 631; 1907.

- Dittenberger and Gehrcke, Die Thätigkeit der Physikalisch-Technischen Reichanstalt im Jabre, rgor p. Ir2. (See also Dittenberger, Zs. d. Vereines Deutscher Ingenieure, 46, p. r532; rgo2.)

- Dorsey, Phys. Rev., 25 (No. 2), D. 88; 1907. 
Turner and Levy ${ }^{6}$ investigated the annealing of copper with special reference to dilatation. They state "It is common knowledge that hard copper becomes perfectly annealed by heating to $500^{\circ} \mathrm{C}$; that the heating need not be for any lengthened period, and the rate of cooling afterward is unimportant."

An extensometer was employed, which was made in the metallurgical department of the University of Birmingham. Two expansion curves of hard-drawn and of annealed copper from $18^{\circ}$ to about $600^{\circ} \mathrm{C}$ are shown, but no definite quantitative data are given. Turner and Levy observed "that both the heating and cooling curves are quite regular, there being no break such as would be caused by the slightest abrupt change of volume at a critical temperature. There was nothing observed which would serve to indicate at exactly what temperature hard copper passes into the soft variety."

These observers also examined five hard-drawn copper alloys, four of which, "namely, 70:30 brass, 66:34 brass, gun metal, and phosphor bronze gave perfectly regular and uniform curves as the temperature rose, and no indication was afforded as to the point at which the hard metal became annealed." They did not obtain a satisfactory curve for the fifth sample, 60:40 brass.

"The conclusion to be drawn from these experiments would appear to be that the alterations which take place when hard copper is by annealing converted into the soft variety are unaccompanied by any change in linear dimensions. It is known that the separation of a constituent as of graphite from cast iron or pearlite from steel, is accompanied by marked dilatometric changes. Le Chatelier ${ }^{7}$ has shown that a dimorphic transformation, such as that which ferrous sulphide undergoes between 100 and $15^{\circ}$, is accompanied by a marked change of volume. Allotropic changes in an element are also usually accompanied by marked alterations of volume, as in the case of pure iron at about $880^{\circ} \mathrm{C}$. It is evident therefore, that such changes in the properties of copper and of copper alloys as are caused by mechanical work or annealing, respectively, are of a different order to those which are due to allotropic or dimorphic transformations, or to the separation or rearrangement of constituents. The results here recorded lead us to believe that mechanical work produces only internal rearrangement

6 Turner and Levy, Proc. Roy. Soc., London, 80 (series A), D. 1 ; 1908.

7 Metallographist, 1903 , p. 23; Bull. de la Société d' Encouragement pour 1 'Industrie Nationale; September, 1902 . 


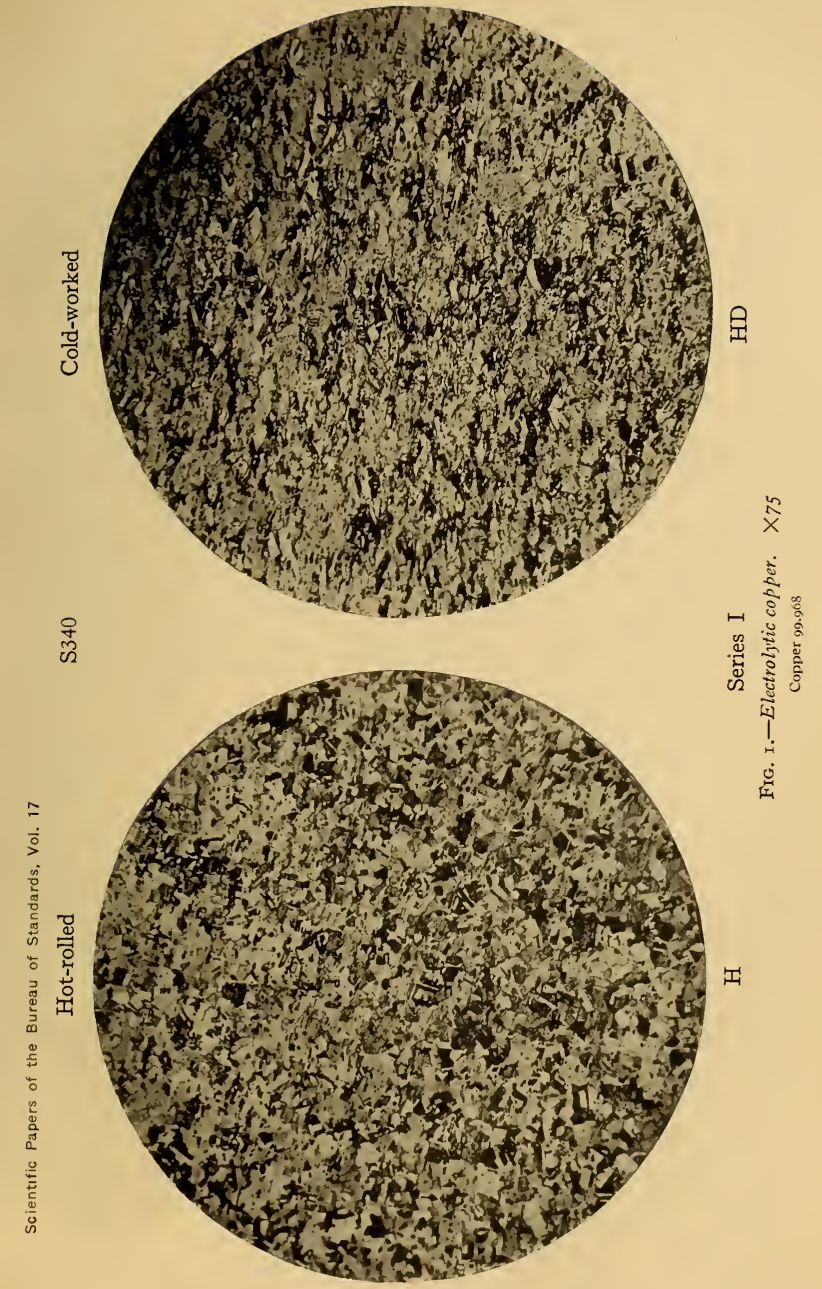


of the metallic grains or molecules, but does not lead to any chemical or physical changes such as are correctly regarded as allotropic. We have met with no evidence to support the view that allotropic change results from mechanical work."

Price and Davidson ${ }^{8}$ reported Bureau of Standards observations ${ }^{9}$ on the thermal expansion of 17 samples of rolled brass cut longitudinally and of 12 samples cut transversely to the direction of rolling. The specimens varied from 0.256 to 0.034 inch in thickness. The various thicknesses were obtained by cold-rolling. The chemical composition of these specimens was as follows:

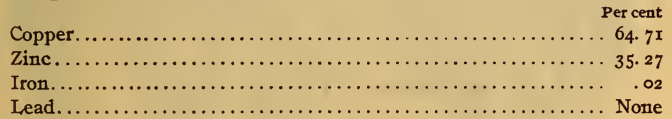

Observations on the expansion of the 29 samples were made from room temperature to about $300^{\circ} \mathrm{C}$.

Several curves are shown, but no attempt was made to determine the coefficients of expansion, their relation to the percentage reduction in thickness due to rolling, nor the differences between the coefficients of corresponding longitudinal and transverse samples. It is hoped to compute and discuss the coefficients of expansion of these brasses in a future publication.

Merica and Schad ${ }^{10}$ investigated the thermal expansion of alpha and of beta brass between o and $600^{\circ} \mathrm{C}$ in relation to the mechanical properties of heterogeneous brasses of the Muntz metal type.

The expansion curves for alpha brass are regular, but those of beta show a transformation point at about $450^{\circ}$, due to a change of beta into beta prime. Alpha brass usually showed a slight permanent elongation after heating to $600^{\circ} \mathrm{C}$ and cooling, but in the case of beta brass a shrinkage always took place. The quadratic equations given with the curves do not, however, best fit the observations in each case.

The average coefficients of expansion of a number of brasses over different termperature intervals are given in the table on next page.

\footnotetext{
${ }^{8}$ Price and Davidson, Transactions of the American Institute of Metals, 10, p. 133; 19 r6.

$\checkmark$ Observations made by L. W. Schad and Peter Hidnert of the Bureau of Standards.

10 Merica and Schad, Journal of the American Institute of Metals, 11 (No. 3), p. 396, 1917; and B. S. Scientific Papers, No. $32 x$; 1918.
} 
TABLE 4.-Coefficients of Expansion of Alpha and Beta Brasses

\begin{tabular}{|c|c|c|c|c|c|c|c|c|c|c|c|c|}
\hline \multirow{2}{*}{ Specimen } & \multirow{2}{*}{ Phase } & \multicolumn{5}{|c|}{ Chemical analysis } & \multicolumn{6}{|c|}{ Avorage coefficients $\times 10^{6}$ from- } \\
\hline & & $\begin{array}{l}\text { Cop- } \\
\text { per }\end{array}$ & Zinc & Tin & Lead & Iron & $\begin{array}{r}20 \text { to } \\
100^{\circ} \mathrm{C}\end{array}$ & $\begin{array}{r}100 \text { to } \\
200^{\circ} \mathrm{C}\end{array}$ & $\begin{array}{r}200 \text { to } \\
300^{\circ} \mathrm{C}\end{array}$ & $\begin{array}{r}300 \text { to } \\
400^{\circ} \mathrm{C}\end{array}$ & $\begin{array}{r}400 \text { to } \\
450^{\circ} \mathrm{C}\end{array}$ & $\begin{array}{l}500 \text { to } \\
600^{\circ} \mathrm{C}\end{array}$ \\
\hline 215A... & Alpha... & $\begin{array}{r}\text { P. ct. } \\
65.6\end{array}$ & $\begin{array}{r}\text { P. ct. } \\
32.9\end{array}$ & $\begin{array}{c}\text { P. ct. } \\
1.3\end{array}$ & $\begin{array}{c}\text { P. ct. } \\
0.2\end{array}$ & $\begin{array}{c}\text { P. ct. } \\
0.1\end{array}$ & 19.2 & 20.0 & 22.0 & 22.5 & 23.5 & 24.5 \\
\hline $216 \mathrm{C} \ldots \ldots \ldots$ & Beta.... & 54.5 & 43.9 & 1.3 & .1 & .2 & 21.6 & 21.8 & 22.8 & 29.6 & 35.0 & 30.5 \\
\hline 250A.......... & Alpha... & 53.5 & 45.6 & .9 & Tr. & Tr. & 20.1 & ......... & ....... & ........ & ........ & ........ \\
\hline $252 \mathrm{~A} \ldots \ldots$ & Beta.... & 54.7 & 44.5 & .7 & .1 & .1 & 22.8 & 19.4 & 23.5 & 27.5 & 39.2 & 26.9 \\
\hline $256 \mathrm{~A} \ldots \ldots \ldots .$. & Alpha... & 65.3 & 34.5 & .23 & .2 & Tr. & 18.7 & 20.0 & 22.0 & 22.5 & 23.0 & 23.7 \\
\hline 259 A.......... & Alpha... & 64.6 & 35.4 & .06 & .04 & $<.04$ & 22.8 & 22.2 & 21.9 & 22.2 & 23.4 & 23.6 \\
\hline 261F.......... & Beta.... & 55.5 & 44.5 & .07 & .05 & $<.04$ & 20.0 & 21.0 & 23.6 & 28.0 & 35.0 & 27.0 \\
\hline
\end{tabular}

\section{MATERIALS INVESTIGATED}

The samples investigated are grouped into seven series as given in Table 5 .

TABLE 5.-Classification of Materials

\begin{tabular}{|c|c|c|}
\hline Series & $\begin{array}{l}\text { Copper con- } \\
\text { tent range }\end{array}$ & $\begin{array}{c}\text { Number of } \\
\text { samples }\end{array}$ \\
\hline 1. Copper: Electrolytic, nickeliferous, arsenical................... & $\begin{array}{c}\text { Per cent } \\
99.38-99.97\end{array}$ & 4 \\
\hline 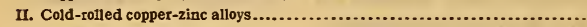 & $62.1-97.0$ & 18 \\
\hline III. Sections of copper-zinc castings. ............................ & $62.1-97.0$ & 72 \\
\hline rV. Extruded and hot-rolled copper-zinc alloys. .................... & $56.4-61.4$ & 12 \\
\hline V. Cold-rolled copper-tin alloys............................. & $89.7-95.4$ & 4 \\
\hline 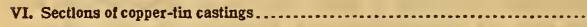 & $89.7-95.4$ & 16 \\
\hline 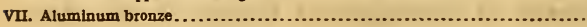 & 92.2 & 2 \\
\hline
\end{tabular}

Other details (commercial names, heat treatments, etc.) relating to these specimens will be given later. However, the following typical photomicrographs are shown and briefly explained in this section, for they are considered as partial definitions of the materials investigated.

SERIES I: COPPER (Fig. I).-The micrograph of $\mathrm{S} 340 \mathrm{H}$ shows the normal crystalline character of very pure copper due to selfannealing during hot-rolling. It also shows the distribution of cuprous oxide in lengthwise streaks. The micrograph of $\mathrm{S}_{34} \mathrm{OHD}$ shows principally the elongation of the grains due to cold working; i. e., the structure of typical hard-drawn copper.

SERIES II AND III: Cold-Rolled AND CAST COPPER-ZINC Alloys (Figs. 2 to 9).-(a) Alpha Brass.-S320 shows the structure of cast alpha brass. The grains are practically pure alpha, which agrees with the well-known equilibrium diagrams. The color shading 


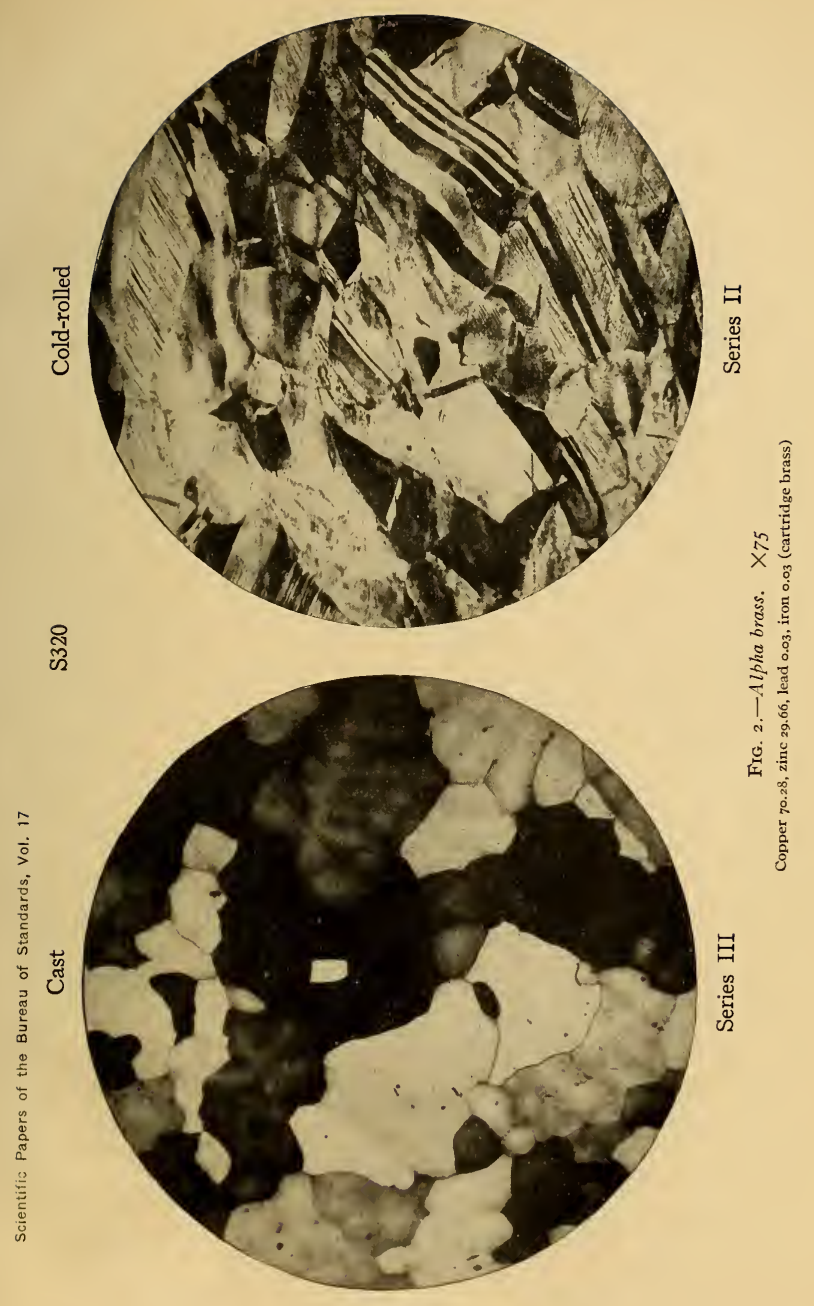




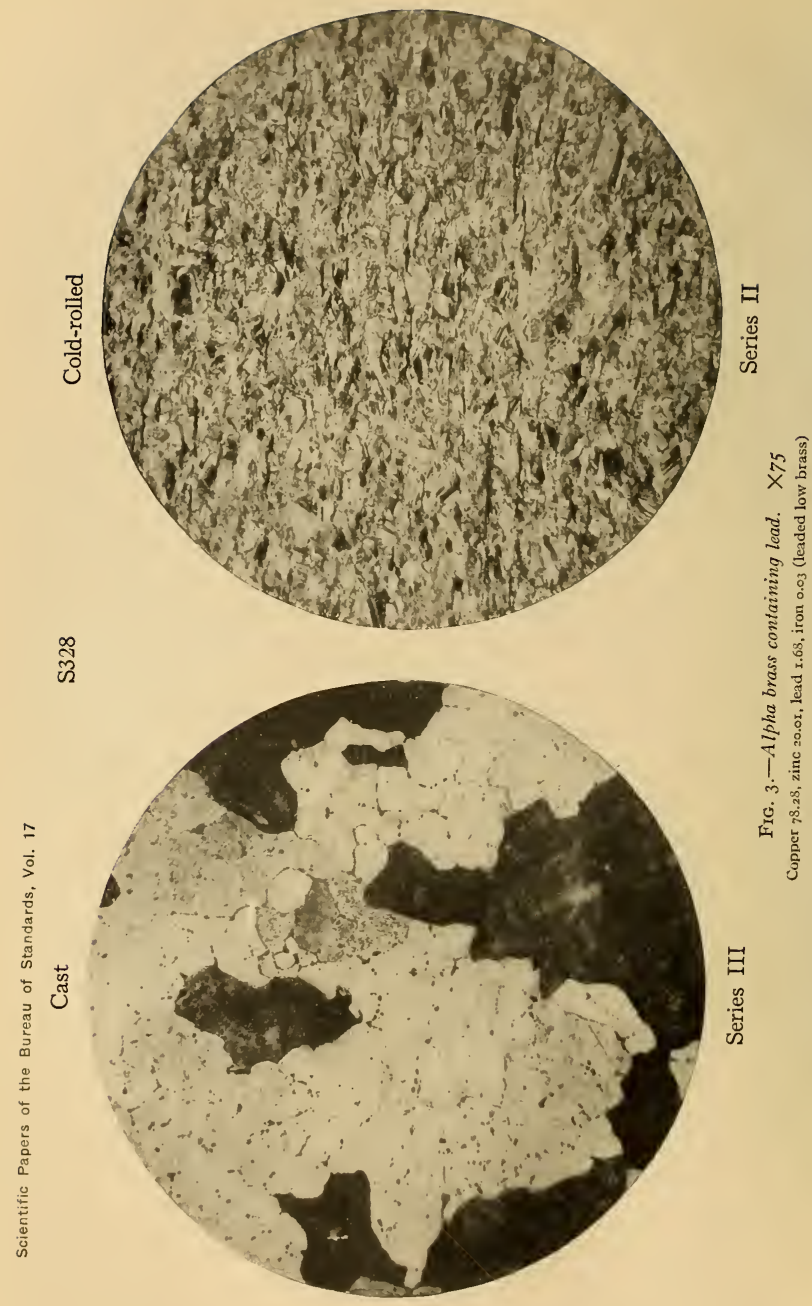




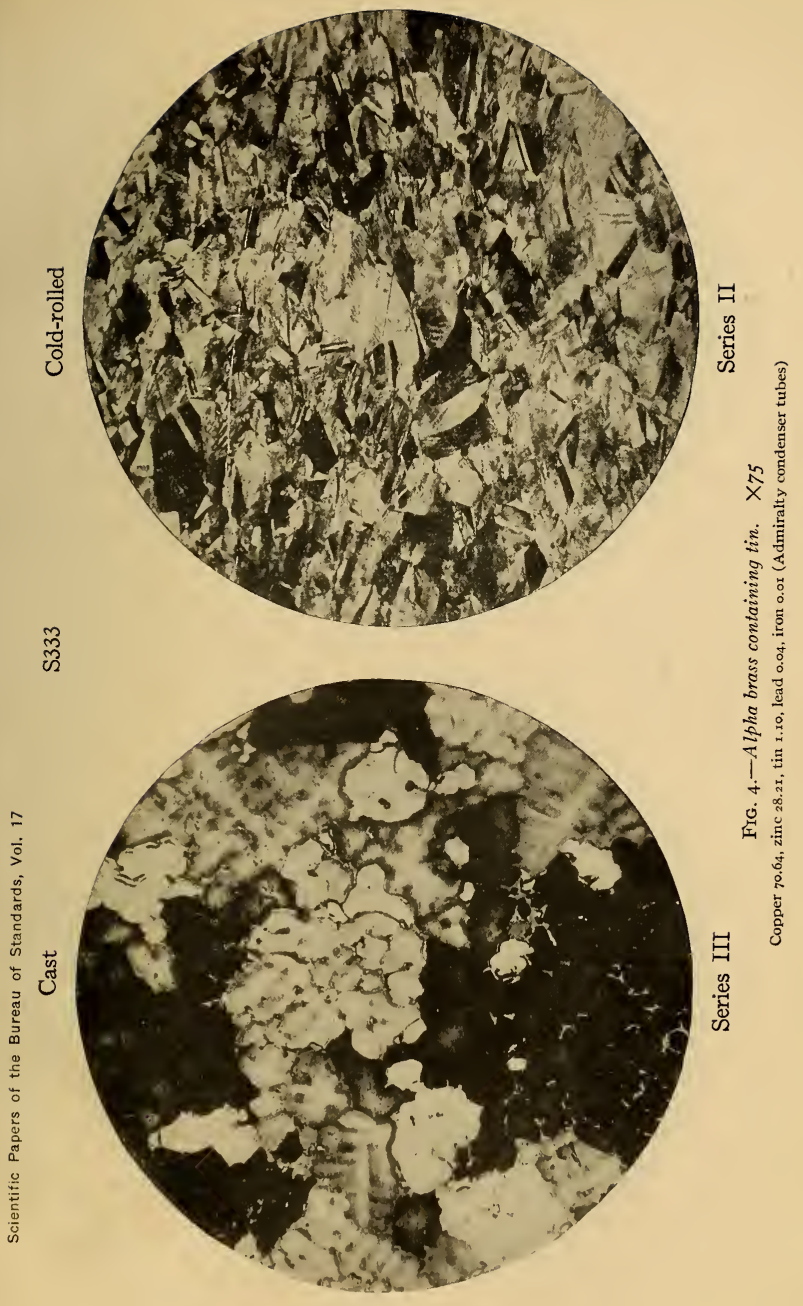




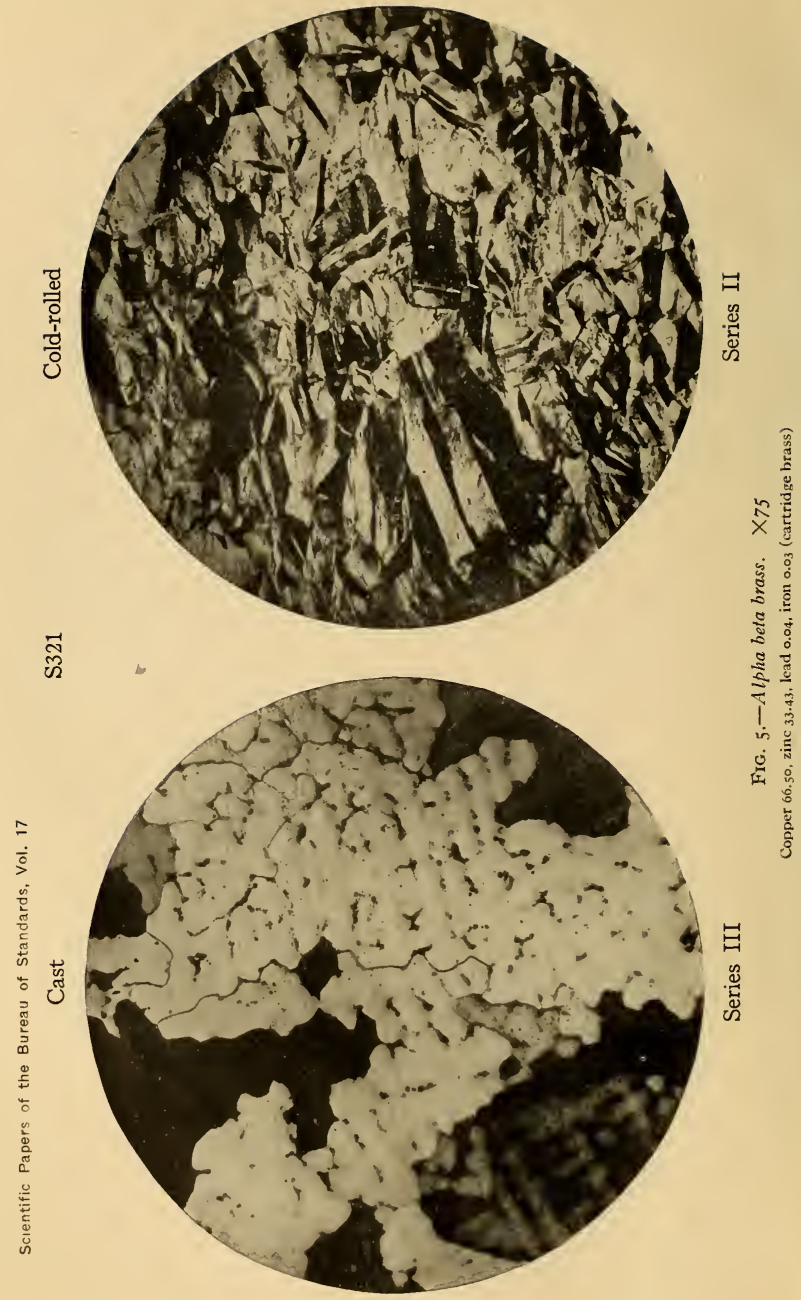




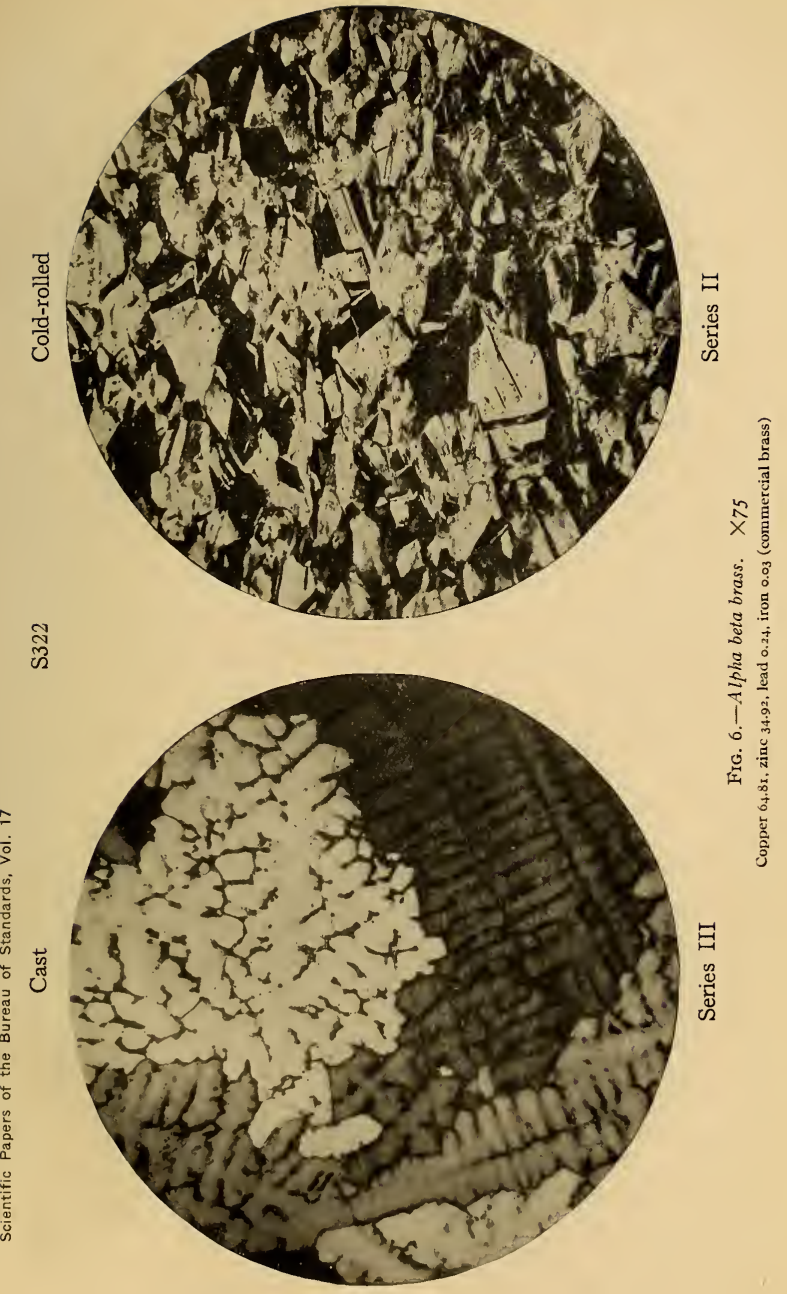




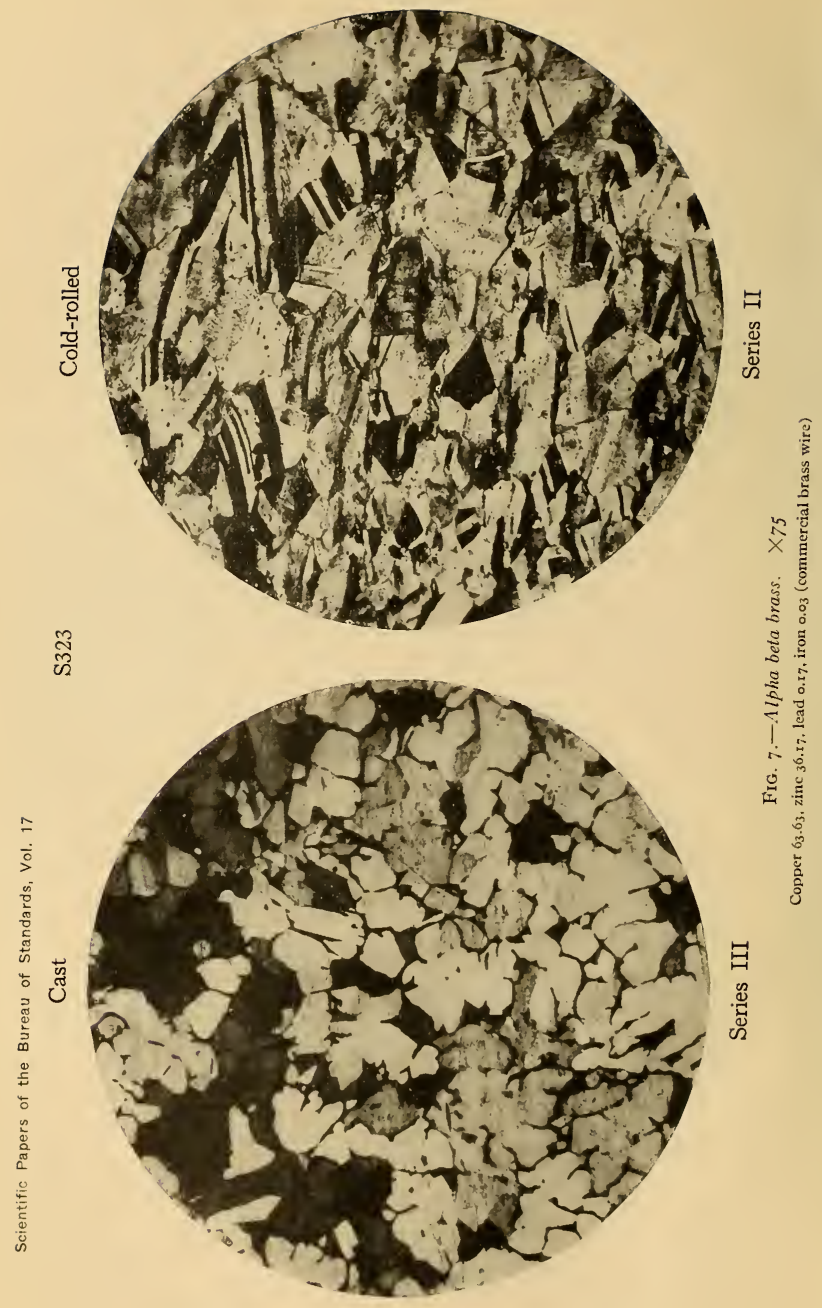




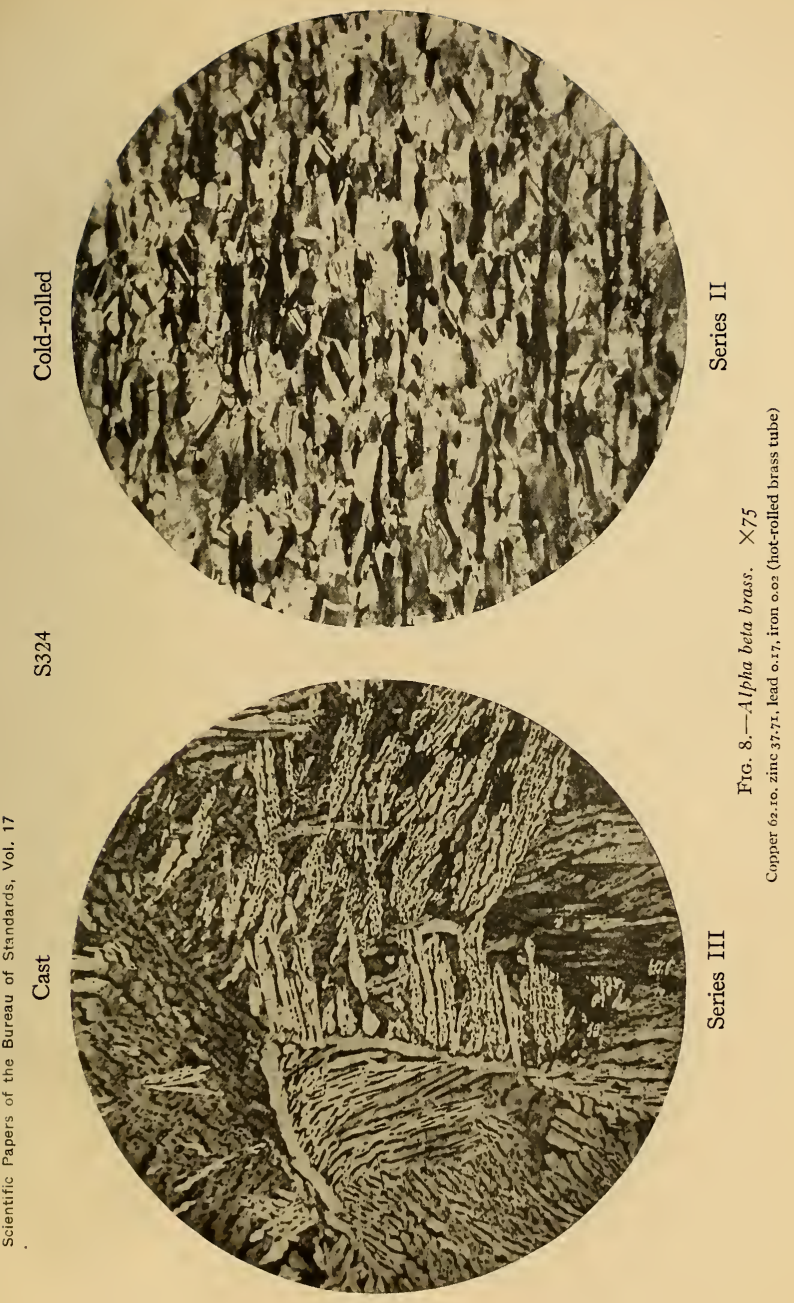




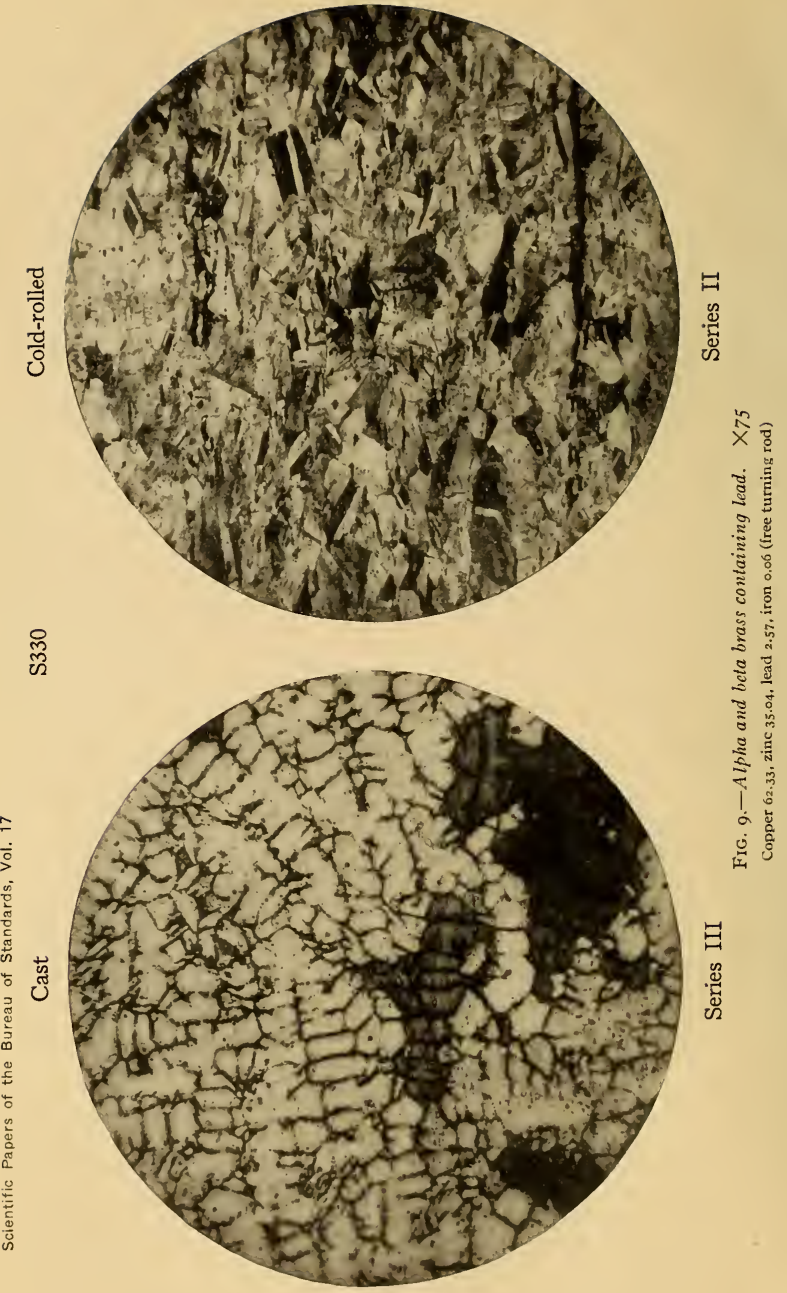


of dendritic form indicates lack of homogeneity within the grains. The micrograph of the cold-rolled sample shows twinned alpha crystals which are the result of annealing and cold working. The elongated appearance is due to cold-drawing as the last operation.

(b) Alpha Brass Containing Lead.-S328 shows a structure similar to the casting of $\mathrm{S}_{32} \mathrm{O}$, the principal difference being that part of the lead can be seen as small dark dots mostly along borders of the grain. The corresponding micrograph of the cold-rolled sample shows the elongated twinned alpha crystals with streaks of lead scattered among them.

(c) Alpha Brass Containing Tin. $-\mathrm{S}_{33} 3$ shows a structure of alpha grains similar to $\mathrm{S}_{320}$. Small islands of a tin-rich alloy can be seen segregated from the alpha. The micrograph of the cold-rolled alloy shows elongated twinned alpha crystals. Annealing and cold working caused the tin to diffuse and become absorbed in the alpha grains.

(d) Alpha Beta Brass. - The structure of cast brass in which there is a varying amount of beta depending on the zinc content is shown in the micrographs of $\mathrm{S}_{32} \mathrm{I}$ to $\mathrm{S}_{324}$, inclusive. In micrograph $\mathrm{S}_{32} \mathrm{x}$ the alpha dendrites (referred to in the micrograph of the casting of $\mathrm{S}_{320}$ ) are bordered with islands of beta, in $\mathrm{S}_{322}$ the beta nearly envelops the alpha dendrites, in $\mathrm{S}_{32} 3$ there are no dendrites on account of the larger proportion of beta, and in $\mathrm{S}_{32} 4$ there is a new grain formation in which the grains are relatively large and consist of mixed alpha and beta surrounded by a network of alpha.

The changes in the structure due to annealing and cold working may be seen from a comparison of the micrographs of the cast and cold-rolled alloys ( $\mathrm{S}_{32} \mathrm{I}$ to $\mathrm{S}_{324}$, inclusive). In the cold-rolled alloys $S_{32}$ and $S_{322}$ the beta, which could be seen in the castings, has diffused and none but alpha crystals can be seen. Only a small amount of beta, appearing as dark streaks, can be seen in the cold-rolled alloys of $\mathrm{S}_{32} 3$ and $\mathrm{S}_{324}$.

(e) Alpha and Beta Brass Containing Lead.-The structure of a cast alpha and beta brass containing lead is shown in micrograph S33o. The proportion of zinc is great enough so that in the cold-rolled alloy $\mathrm{S}_{33}$ o (like $\mathrm{S}_{323}$ ) the beta is not all diffused by the cold-rolling and annealing. A small proportion of the lead can be seen as dots in the alpha crystals. (This alloy will be compared with $\mathrm{S}_{343}$ later.) 
Series IV: Extruded and Hot-Rolled Copper-Zinc Alloys. (Figs. ro to 15 ).-(a) Alpha-Beta Brass.-The micrographs of $\mathrm{S}_{34} \mathrm{I}$ and $\mathrm{S}_{342}$ show typical structural differences between hot-rolled and extruded alloys having nearly the same composition. Both alloys have the alpha and beta Muntz structure, but the distribution of the phases is entirely different, due to the different methods of hot-working.

(b) Extruded Alpha and Beta Brass Containing Lead.-The micrograph of $\mathrm{S}_{343} \mathrm{E}$ shows elongated grain of alpha and beta. Some of the undissolved lead probably accompanies the beta.

The micrograph of $\mathrm{S}_{343} \mathrm{ED}$ shows a greater proportion of beta than casting $S_{33}$ (a leaded brass of practically the same composition) of Series III, principally on account of the lesser amount of cold working and annealing the former received. The fact that the extruded alloy carries a slightly greater amount of zinc and lead has a slight bearing on the amount of beta phase. From a comparison of the micrographs of $\mathrm{S}_{343}$ and $\mathrm{S}_{33} \mathrm{o}$, the structural differences in the two leaded brasses, due to extrusion and cold-rolling, may be observed.

(c) Alpha and Beta Brass Containing Tin.-The structural differences between the hot-rolled $\left(\mathrm{S}_{344}\right)$ and extruded $\left(\mathrm{S}_{345}\right)$ brasses (having nearly the same composition) are shown in Figs. I 3 and I4. These alloys are of the same type as $\mathrm{S}_{34} \mathrm{I}$ and $\mathrm{S}_{342}$ and have the same structural character. The small tin content has no apparent effect on the structure.

(d) Alpha and Beta Bronze Containing Tin and Iron.-The structure of a typical manganese bronze is shown in the micrographs of $S_{346}$, both extruded and drawn. It is an alloy of the same general type as $\mathrm{S}_{342}$ and $\mathrm{S}_{345}$, but on account of the greater proportion of zinc the beta crystals predominate. It consists principally of beta grains through which are scattered needles and globules of alpha.

Series V and VI: Cold-Rolled and Cast Copper-Tin ALLoys (Fig. 16).-The micrograph of the cast alpha tin bronze (S408) shows dendrites of alpha surrounded by beta. Within the beta there are small areas of delta or alpha and delta complex.

The corresponding micrograph of the cold-rolled sample shows elongated alpha crystals. The tin-rich parts (beta) of the castings have been completely diffused by annealing and cold working, which produced a homogeneous alloy.

SERIES VII: ALUMinum BRonze (Fig. I7).-The micrograph of the alpha aluminum bronze $\left(\mathrm{S}_{347} \mathrm{H}\right)$ shows the crystalline 


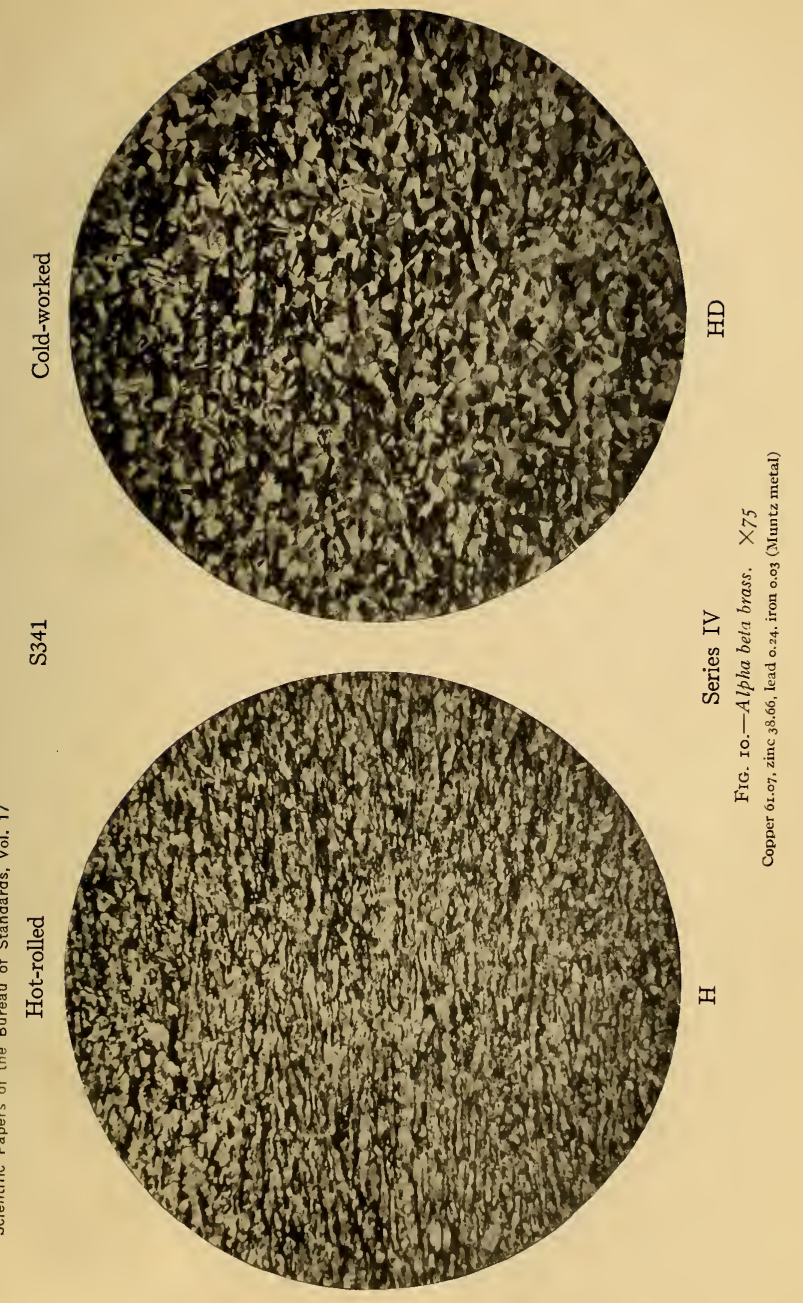




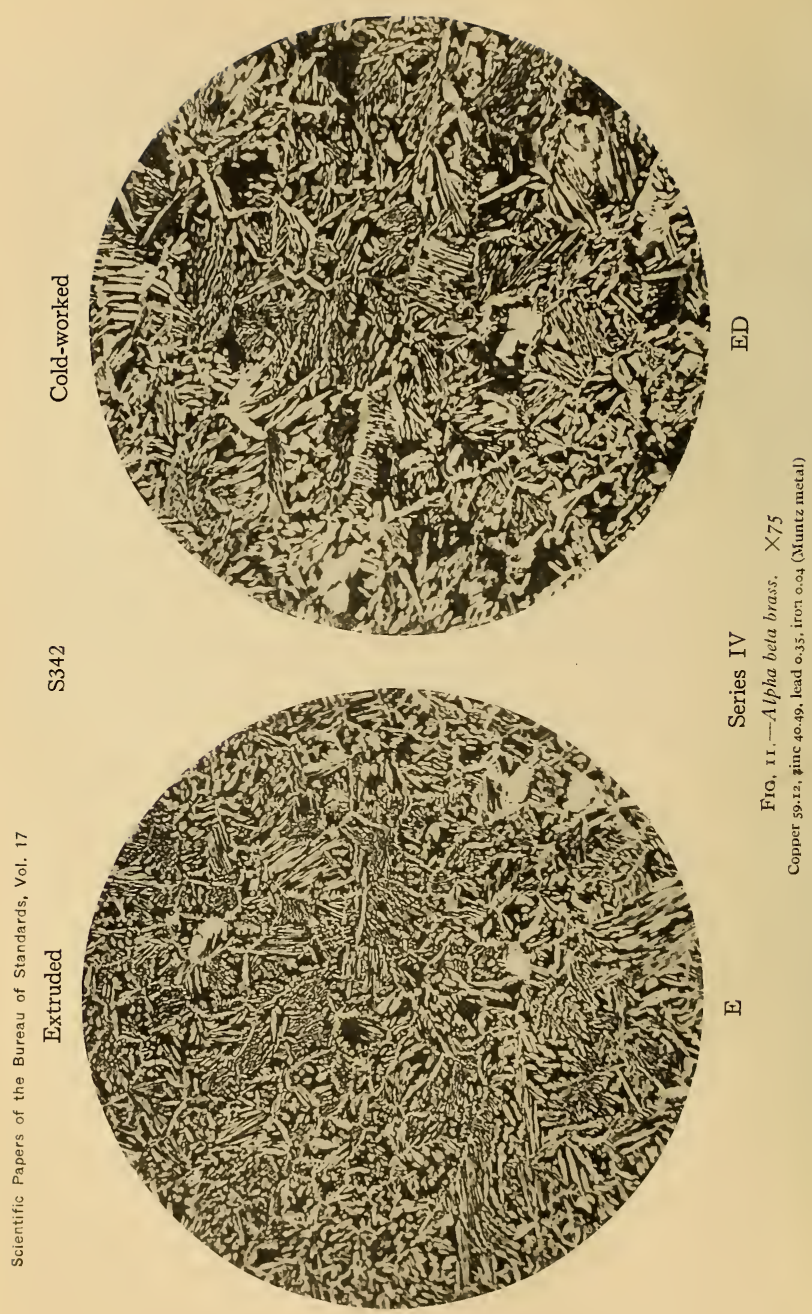




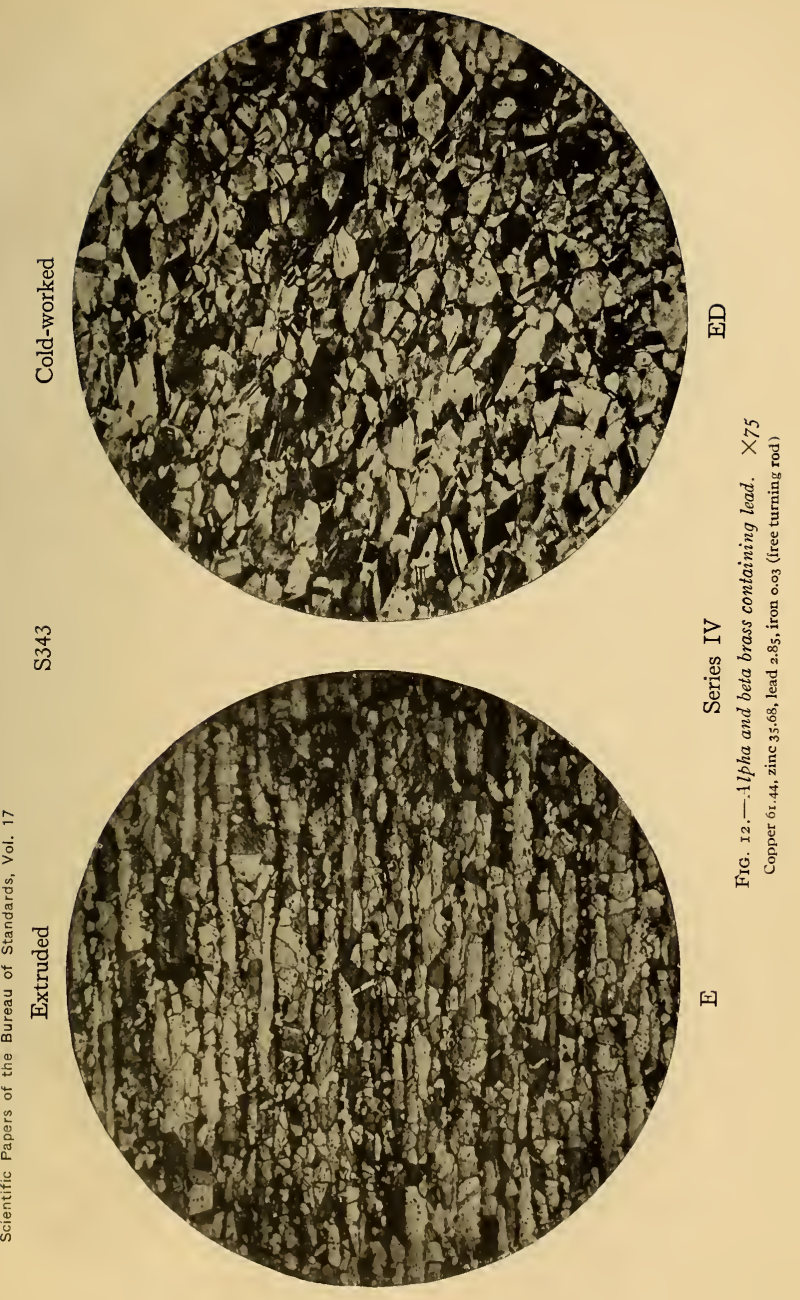




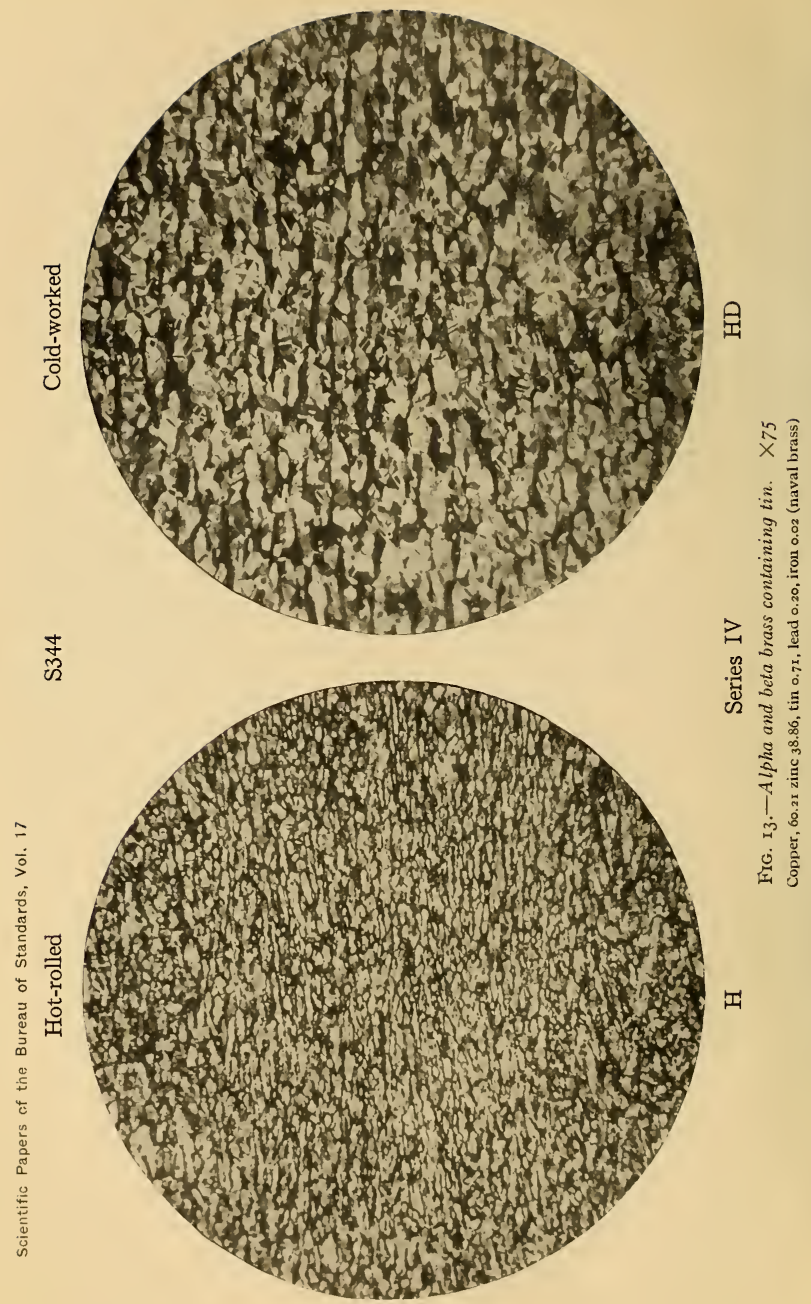




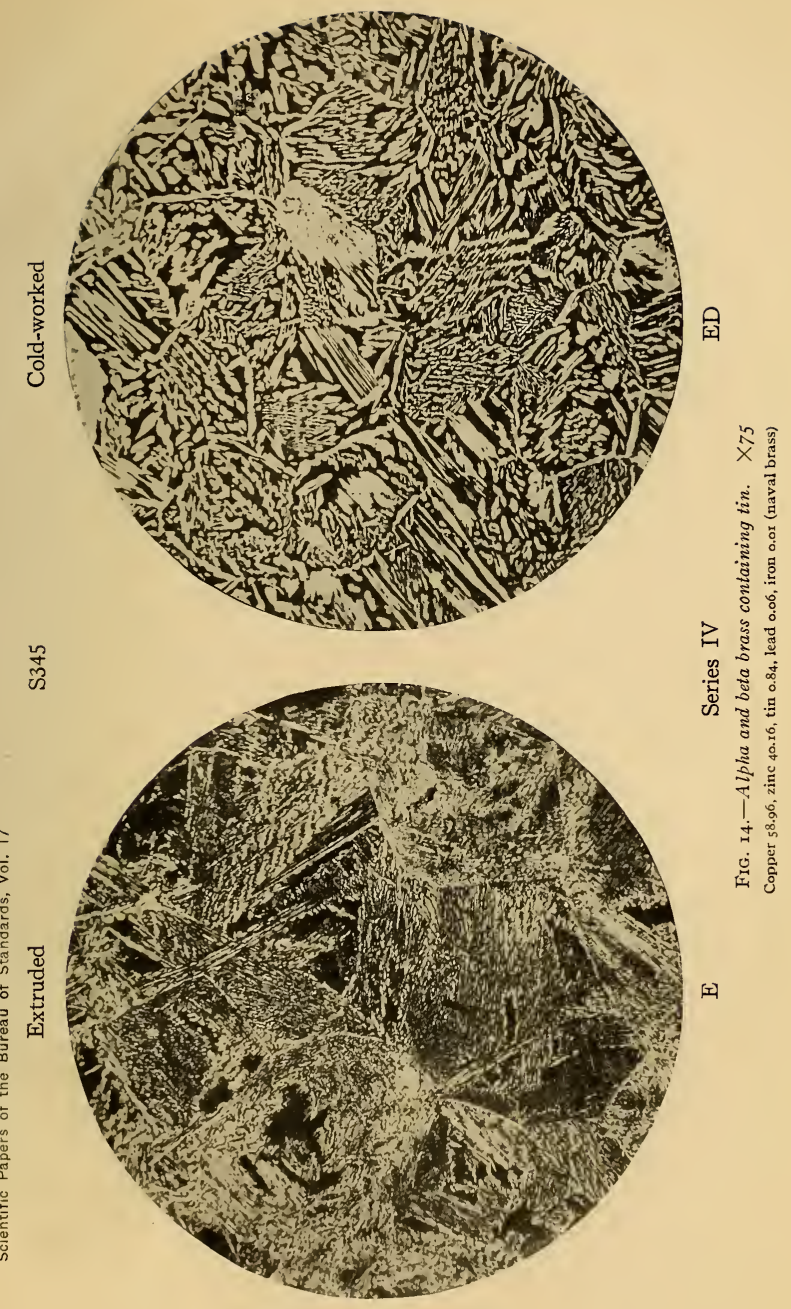




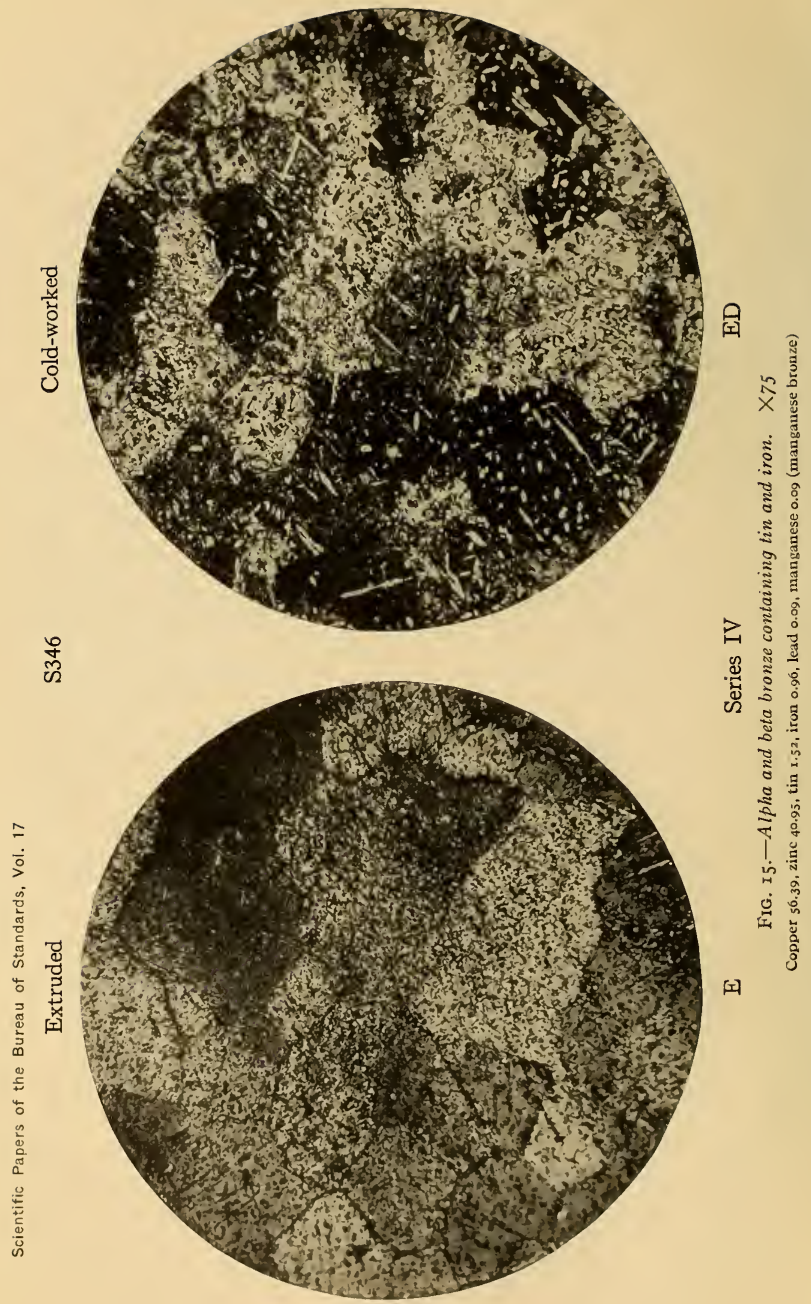




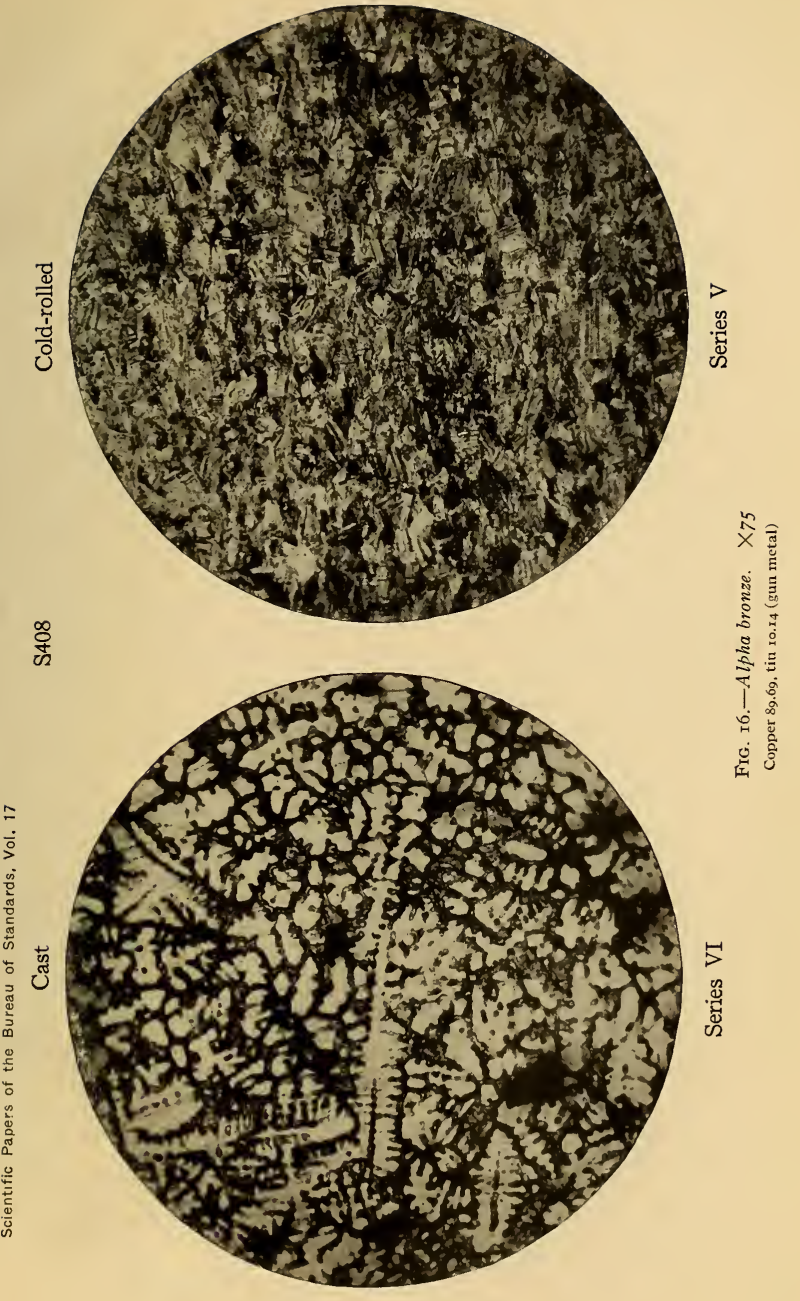




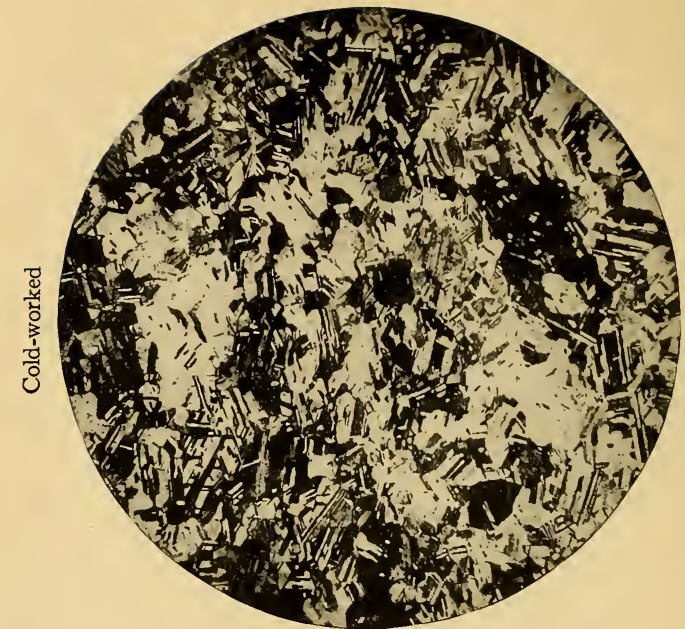

箈

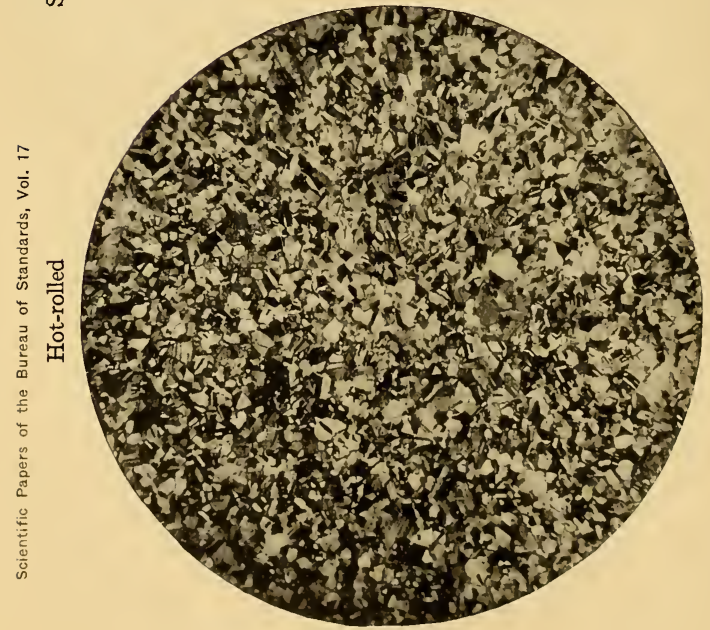


character due to self-annealing during hot-rolling. In this respect it is similar to copper.

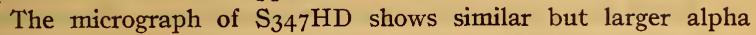
crystals. This alloy was drawn only slightly and the consequent elongation of the grains can not be seen.

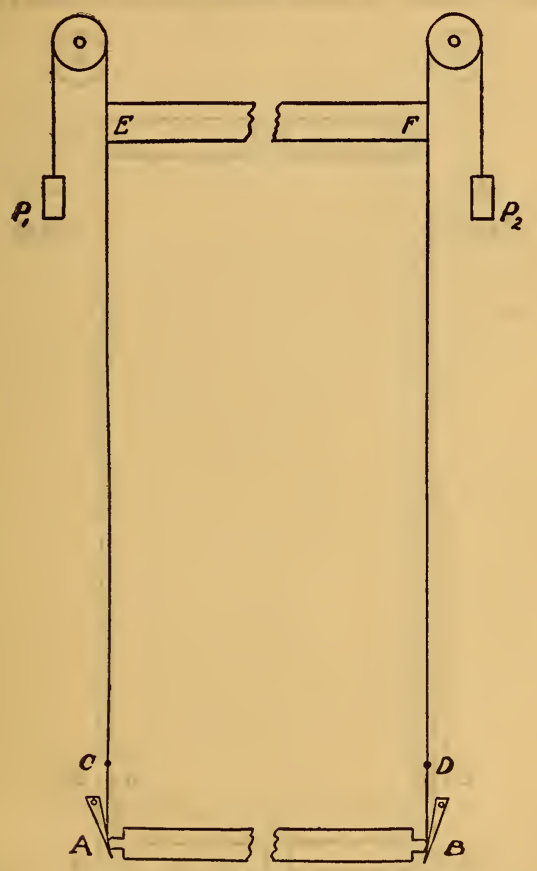

FIG. 18.-Diagrammatic representation of specimen and contact wires

\section{APPARATUS AND EVALUATION OF CONSTANTS}

The apparatus employed was essentially the same as that used for the determination of the thermal expansion of molybdenum. ${ }^{11}$

Each specimen was supported horizontally in a return flow bath. The method of arrangement ${ }^{12}$ is shown diagramatically in

11 B. S. Scientific Papers, No. 332; 1919.

${ }^{12}$ A. W. Gray, J. Wash. Acad. Sci., 9, p. 248 ; 19 r2. 
Fig. I 8. $A B$ represents the specimen, and $C$ and $D$ are points on the I mil tungsten wires $A C E$ and $B D F$, which points represent the foci of two horizontal micrometer microscopes. These wires are in contact with the ends of the specimen $A B$, and are stretched upward to a rigid bar $E F$ (shown in part). Each wire passes over a pulley, and supports a small weight, $P$, at its upper end. $A C$

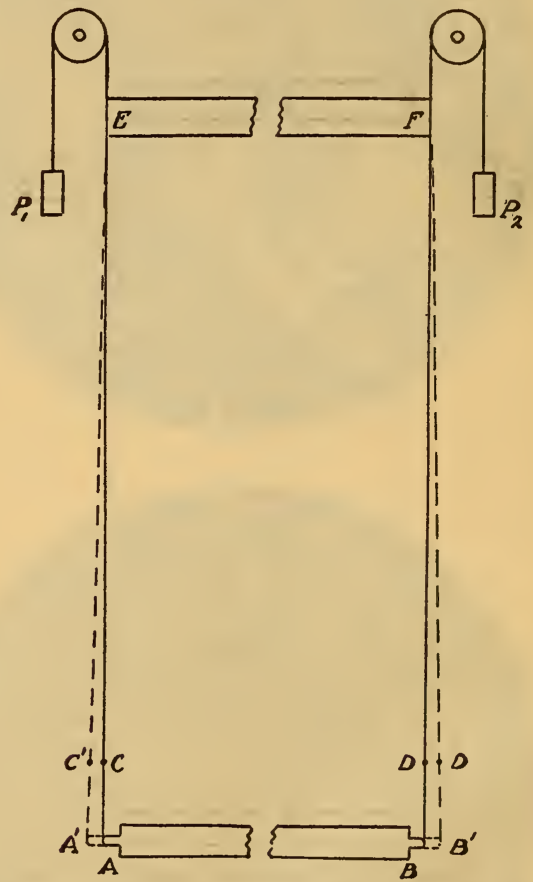

FIG. 19.-Diagrammatic representation of expanded specimen

is $\frac{1}{10}$ the distance of $A E$, and, similarly, $B D$ is $\frac{1}{10}$ the distance of $B F$. $E F$ is a hollow invar bar which is kept at room temperature.

The length changes of $A B$ were measured indirectly. The distance, $C D$, was compared with a standard bar kept at the same temperature as $E F$. If the temperature of the specimen is increased, it expands as shown in Fig. 19. $A^{\prime} B^{\prime}$ represents the 
length of the specimen at some increased temperature, and $\left(A A^{\prime}+B B^{\prime}\right)$ represents the true expansion. The microscopes first measured the distance $C D$ and then $C^{\prime} D^{\prime}$. The difference between $C^{\prime} D^{\prime}$ and $C D$, which is equal to $\left(C C^{\prime}+D D^{\prime}\right)$, gives the apparent expansion, from which the true expansion $\left(A A^{\prime}+B B^{\prime}\right)$ may be determined. Since $A C$ is $\frac{1}{10}$ of $A E$, and triangle $C^{\prime} C E$

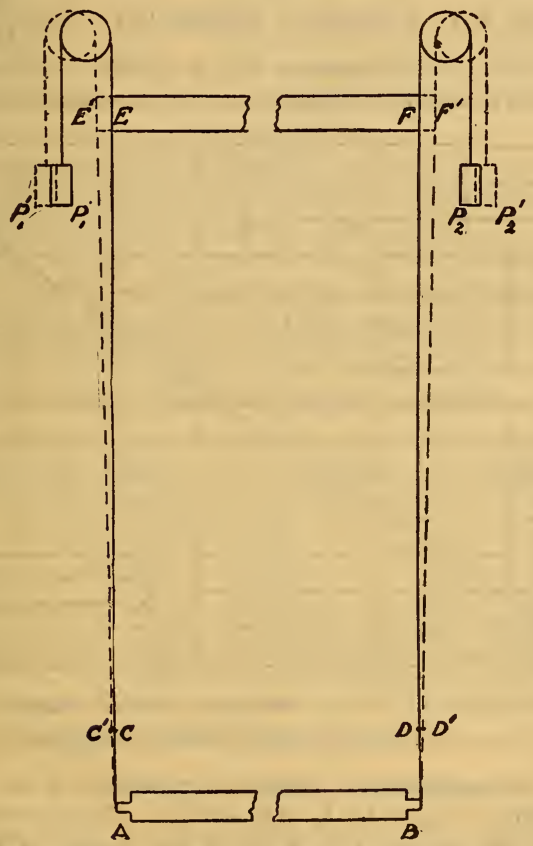

FIG. 20.-Diagrammatic representation of expanded bar EF

is similar to triangle $A^{\prime} A E$, then $\frac{C C^{\prime}}{A A^{\prime}}=\frac{9}{10}$ or $A A^{\prime}=\frac{10}{9} C C^{\prime}$. Similarly, $B B^{\prime}=\frac{10}{9} D D^{\prime}$. The true expansion is therefore equal to $\frac{10}{9}$ of the observed or apparent expansion.

If the temperature of $E F$ varies from the assumed constant temperature, it is necessary to apply a correction to the observed length of $C D$. If the temperature of the upper hollow bar, $E F$, 
increases its temperature above the standard temperature and expands an amount equal to $E E^{\prime}+F F^{\prime}$, then the wires will incline as shown in Fig. 20. The microscopes will sight the points $C^{\prime}$ and $D^{\prime}$ instead of the points $C$ and $D$. It is necessary, therefore, to subtract the distance, $C C^{\prime}+D D^{\prime}$, from the observed distance, $C^{\prime} D^{\prime}$, in order to obtain the distance, $C D$. Since $A C$ is $\frac{1}{10}$ of $A E$, and triangle $A C C^{\prime}$ is similar to triangle $A E E^{\prime}$, then $\frac{C C^{\prime}}{E E^{\prime}}=\frac{1}{10}$ or $C C^{\prime}$ is $\frac{1}{10} E E^{\prime}$. In like manner $D D^{\prime}$ is $\frac{1}{10} F F^{\prime} . C C^{\prime}+D D^{\prime}$, the correction to be applied (added when the temperature is below the

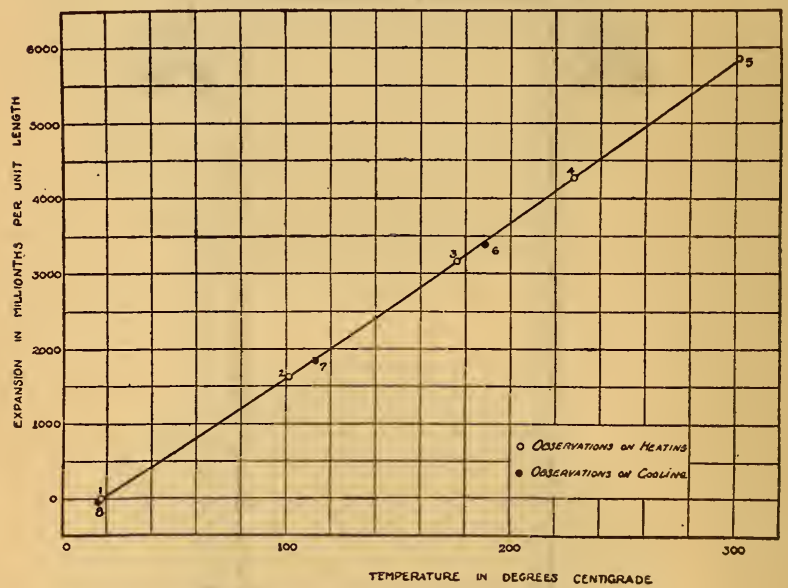

FIG. 21.-Linear expansion as a function of temperature

standard temperature and subtracted when above the standard temperature), is equal to $\frac{1}{10}\left(E E^{\prime}+F F^{\prime}\right)$. The correction to be applied to the length, $C D$, is $\frac{1}{10}$ of the change of $E F$. This correction is usually very small.

The return flow bath was filled with oil or pentane, the liquid used depending on the temperature desired. Between room temperature and $300^{\circ} \mathrm{C}$, "Renown" engine oil was used, while for low temperatures pentane was employed. An electric resistance coil surrounded by, and in contact with, the liquid was used for heating. Cooling below room temperature was effected by the expansion of compressed air within a coil of copper tubing immersed in the 
bath containing pentane. The liquid surrounding the specimen was kept in circulation by means of a propeller. The temperature variation over the entire specimen was probably not greater than $0.1^{\circ} \mathrm{C}$ during an observation.

The length changes were determined with a movable comparator consisting of two micrometer microscopes rigidly clamped on an invar bar at a distance from each other equal to the length of the specimen $(30 \mathrm{~cm})$. The microscopes were so arranged that they could first be sighted on a standard length bar kept at nearly constant temperature and then on the I mil wires which were in contact with the ends of the specimen.

The temperatures were determined by means of a copper-constantan thermoelement and a potentiometer calibrated respectively by the heat and electrical divisions of this Bureau.

In order to indicate how the observations were used in deriving empirical equations of expansion, the observations on a single specimen ( $\mathrm{S}_{34 \mathrm{I}}$ ) are given in the following table. The accompanying curve (Fig. 2r) shows the results graphically.

TABLE 6.-Expansion Observations on a Sample.

\begin{tabular}{|c|c|c|c|c|c|}
\hline Observatlon number & $\begin{array}{c}\text { Tem- } \\
\text { perature }\end{array}$ & $a \Delta l$ & Observation number & $\underset{\text { perature }}{\text { Tem- }}$ & $a \Delta t$ \\
\hline 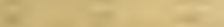 & $\cdot \mathbf{C}$ & $\times 10^{-6}$ & & $\cdot \mathbf{C}$ & $\times 10^{-0}$ \\
\hline 1................................. & 17.5 & 0 & $5 \ldots \ldots . . . .$. & 301.2 & 5864 \\
\hline $2, \ldots \ldots \ldots \ldots$ & 101.3 & 1621 & $6 \ldots . .$. & 188.5 & 3380 \\
\hline $3 \ldots \ldots \ldots \ldots \ldots \ldots \ldots \ldots \ldots \ldots \ldots \ldots \ldots \ldots$ & 175.8 & 3159 & $7 \ldots \ldots \ldots \ldots$ & 112.6 & 1838 \\
\hline $4 \ldots \ldots \ldots \ldots \ldots$ & 228.1 & 4283 & $8 . \ldots \ldots \ldots \ldots \ldots$ & 15.9 & -47 \\
\hline
\end{tabular}

a $\Delta l$ represents the change per unit length from the length at the initial temperature $x 7.5^{\circ} \mathrm{C}$.

If it is assumed that the specimen expands in accordance with a second degree equation of the form

$$
\Delta l=(t-17.5) a+(t-17.5)^{2} b,
$$

where $t$ represents any temperature between $\mathrm{I} 7.5$ and $30 \mathrm{r} .2^{\circ} \mathrm{C}$, then from the values of $\Delta l$, obtained from the observations on heating, it is possible to derive the following empirical equation by the method of least squares:

$$
\Delta l=19.02(t-17.5) 1^{-8}+0.00590(t-17.5)^{2} 1^{-6} .
$$

Table 7 gives a comparison of the observed values with those computed from this empirical formula.

$20183^{\circ}-21-2$ 
TABLE 7.--Results on Heating

\begin{tabular}{|c|c|c|c|}
\hline Temperature, degrees centigrade & $\begin{array}{c}\text { Observed } \\
\Delta l\end{array}$ & $\underset{\Delta l}{\text { Computed }}$ & Realduais \\
\hline & $\times 10^{-6}$ & $\times 10^{-6}$ & $\times 10^{-6}$ \\
\hline 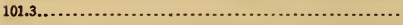 & 1621 & 1635 & -14 \\
\hline $175.8 \ldots \ldots \ldots \ldots \ldots \ldots$ & 3159 & 3159 & 0 \\
\hline $228.1 \ldots \ldots \ldots \ldots \ldots$ & 4283 & 4267 & +16 \\
\hline $301.2 \ldots \ldots \ldots \ldots \ldots$ & 5864 & 5871 & -7 \\
\hline
\end{tabular}

The probable error is

$$
0.6745 \sqrt{\frac{501 \times 10^{-12}}{4-2}}= \pm \mathrm{II} \times 10^{-6} \text {. }
$$

The deviations of the observed values taken on cooling, from this empirical equation representing the heating curve, are given in the following table, where $\Delta l$ represents the change per unit length from the length at the initial temperature $17.5^{\circ} \mathrm{C}$.

TABLE 8.-Results on Cooling

\begin{tabular}{|c|c|c|c|}
\hline Temperature, degrees centigrade & $\begin{array}{c}\text { Observed } \\
\Delta l\end{array}$ & $\underset{\Delta l}{\text { Compuled }}$ & $\begin{array}{l}\text { Devla- } \\
\text { tions }\end{array}$ \\
\hline 301.2. & $\begin{array}{l}\times 10^{-6} \\
5864\end{array}$ & $\begin{array}{l}\times 10^{-6} \\
5871\end{array}$ & $\begin{array}{l}\times 10^{-0} \\
-7\end{array}$ \\
\hline $188.5 \ldots$ & 3380 & 3425 & -45 \\
\hline $112.6 \ldots \ldots \ldots \ldots \ldots \ldots \ldots \ldots \ldots \ldots$ & 1838 & 1862 & -24 \\
\hline 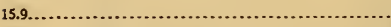 & -47 & -30 & -17 \\
\hline
\end{tabular}

From inspection of the preceding table, it is evident that the observations on cooling lie below the heating curve and that the specimen at the end of the test was about 0.002 per cent shorter than at the beginning.

The first derivative of the empirical equation of expansion

gives

$$
\Delta l=19.02(t-\mathrm{I} 7.5) 10^{-6}+0.00590(t-\mathrm{I} 7.5)^{2} \mathrm{IO}^{-6}
$$

$$
\frac{d}{d t}[\Delta l]=19.02 \times 10^{-6}+0.01180(t-17.5) 10^{-6}
$$

and represents the tangent to the expansion curve. This tangent also represents the rate of expansion or instantaneous coefficient, $a_{\imath}$, at any temperature, $t$, within the proper limits.

From inspection of the preceding linear equation and the following table which gives the instantaneous coefficients computed for every $50^{\circ}$ from 50 to $250^{\circ} \mathrm{C}$, it is evident that the rate of expansion increases with temperature. 
TABLE 9.-Relation between Coefficient of Expansion and Temperature

\begin{tabular}{|c|c|c|c|}
\hline Temperature, degrees centigrade & $\begin{array}{l}\text { Instantane- } \\
\text { ous coeffi- } \\
\text { clents }\end{array}$ & Temperature, degrees centigrade & $\begin{array}{l}\text { Instantane- } \\
\text { ous coeft- } \\
\text { clents }\end{array}$ \\
\hline & $\times 10^{-6}$ & & $\times 10^{-0}$ \\
\hline 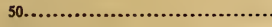 & 19.40 & $200 \ldots \ldots \ldots$. & 21.17 \\
\hline 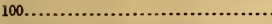 & 19.99 & 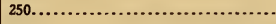 & 21.76 \\
\hline 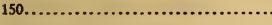 & 20.58 & & \\
\hline
\end{tabular}

The equation

$$
\Delta l=19.02(t-\mathrm{x} 7.5) 1 \mathrm{1}^{-6}+0.00590(t-\mathrm{I} 7.5)^{2} \mathrm{I}^{-6}
$$

may be transformed into the following:

$$
L_{t}=L_{0}\left(\mathrm{I}+\mathrm{I} 8.8 \mathrm{I} t \times 10^{-6}+0.00590 t^{2} \times 10^{-6}\right),
$$

where $L_{t}$ is the length of the specimen at any temperature, $t$, between 17.5 and $301.2^{\circ} \mathrm{C}$ and $L_{0}$ the length at $0^{\circ} \mathrm{C}$.

\section{EXPERIMENTAL AND DERIVED RESULTS}

\section{SERIES I.-COPPER: ELECTROLYTIC, NICKELIFEROUS, ARSENICAL}

In this series there are four samples of copper. The method of working of these samples before the thermal expansion tests is given in the following table. The specimen marked " $H$ " was hot-rolled and those marked " $H D$ " were drawn, annealed, and finished hard after being hot-rolled.

\begin{tabular}{|c|c|}
\hline $\begin{array}{l}\text { Laboratory } \\
\text { number }\end{array}$ & Method of working \\
\hline \$340H...... & Hot-rolled in one heat from wire bar to $3 / 8$-inch diameter. \\
\hline S340HD...... & $\begin{array}{l}\text { Hot-rolled in one heat from wire bar to } 3 / 8 \text {-inch diameter, drawn to } 0.300 \text { inch, annealed, } \\
\text { and finished hard at } 1 / 4 \text { inch. }\end{array}$ \\
\hline S339ED...... & $\begin{array}{l}\text { Hot-rolled to } 5 / 8 \text {-inch diameter, cold-drawn to } 0.300 \text { inch, annealed, and finished hard } \\
\text { at } 1 / 4 \text { inch. }\end{array}$ \\
\hline S338HD...... & Same method as S339HD. \\
\hline
\end{tabular}

TABLE 10.-Treatment Before Expansion Tests

Table I I gives the composition, the temperature range of the thermal expansion test, the values of $a$ and $b$ of the general quadratic equation

$$
L_{t}=L_{0}\left(\mathrm{I}+a t+b t^{2}\right),
$$

where $L_{t}$ is the length at any temperature within the specified range, the probable error of $L_{t}$, and the instantaneous coefficients at every $50^{\circ}$ from 50 to $250^{\circ} \mathrm{C}$. 
TABLE 11.-Summary of Values of Series I

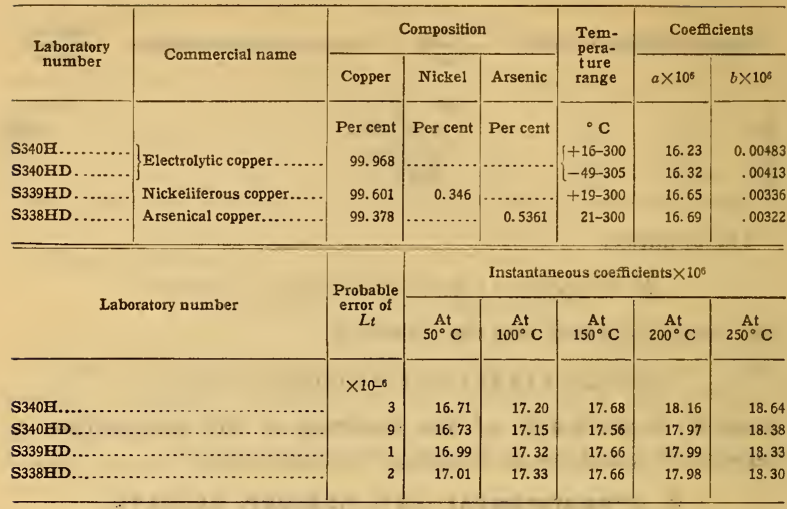

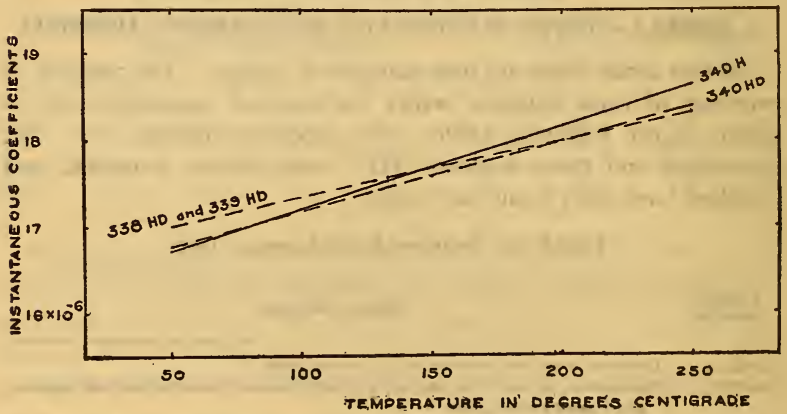

FIG. 22.-Coefficients of expansion of Series I

The curves in Fig. 22 show graphically the relation between the instantaneous coefficients and the temperature from 50 to $250^{\circ} \mathrm{C}$.

ELECTROLYTIC COPPER.-These samples were prepared from high-grade electrolytic copper wire bar.

The instantaneous coefficients of the drawn sample of electrolytic copper are less (nearly over the whole temperature range) than those of the hot-rolled specimen. The maximum difference in the coefficients is $0.26 \times 10^{-6}$ and occurs at $250^{\circ} \mathrm{C}$. 
In general, annealing and drawing of the hot-rolled bar caused a slight lowering of the values of the coefficients.

NiCKELIFEROUS AND ARSENICAL COPPER.-The instantaneous coefficients of the cold-drawn nickeliferous and arsenical copper samples are practically equal, and somewhat larger than those of the drawn electrolytic copper rod (to $200^{\circ} \mathrm{C}$ ). The substitution of small amounts of nickel or arsenic tends to raise the instantaneous coefficients.

The cooling curves of $\mathrm{S}_{340 H D}, \mathrm{~S}_{339 H D}$, and $\mathrm{S}_{33} \mathrm{HD}$ lie below the heating curves, and the cooling curve of $\mathrm{S} 34 \mathrm{OH}$ lies above. The maximum variation between the heating and cooling curves is \pm 50 millionths per unit length. After cooling to room temperature, the variation in length from the original length was found to be as follows. The minus (-) sign indicates a decrease in length.

TABLE 12.-Changes in Length After Test

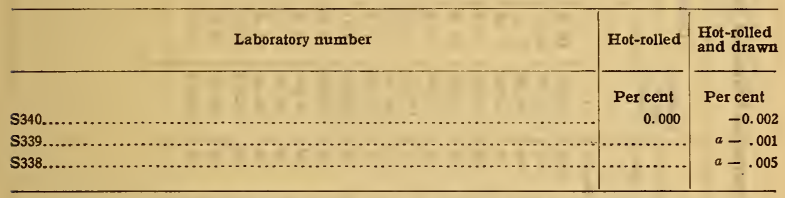

a The maximum deviation between the heating and cooling curves did not exceed this value.

\section{SERIES II.-COLD-ROLLED COPPER-ZINC ALLOYS}

Series II includes 16 samples of copper-zinc alloys, cold-rolled from 2 -inch chill castings to twenty-one thirty-second inch, colddrawn to $0.300-i n c h$, annealed, and finished hard at one-fourthinch, and 2 samples ( $\mathrm{S}_{332}$ and $\mathrm{S}_{333}$ ) similarly rolled from chill castings of $15 / 8$-inch diameter.

This series may be subdivided into four groups of alloys: (a) Alpha brass, $\mathrm{S}_{31} 3$ to $\mathrm{S}_{320}$, inclusive; (b) alpha beta brass, $\mathrm{S}_{32 \mathrm{I}}$ to $S_{324}$, inclusive; $(c)$ leaded brass (alpha or alpha beta), $S_{327}$ to $\mathrm{S}_{330}$, inclusive; $(d)$ alpha brass containing tin, $\mathrm{S}_{332}$ and $\mathrm{S}_{333}$.

The following table gives the composition, the temperature range of the thermal expansion test, the values of $a$ and $b$ of the general quadratic equation

$$
L_{\mathrm{t}}=L_{\mathrm{o}}\left(\mathrm{I}+a t+b t^{2}\right) \text {, }
$$

where $L_{t}$ is the length at any temperature within the specified range, the probable error of $L_{t}$, and the instantaneous coefficients at every $50^{\circ}$ from 50 to $250^{\circ} \mathrm{C}$. 


\begin{tabular}{|c|c|c|}
\hline \multirow{5}{*}{ 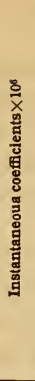 } & 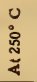 & 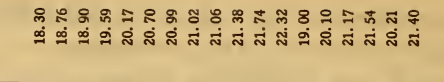 \\
\hline & ن & 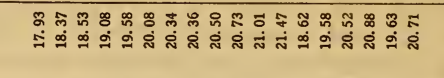 \\
\hline & 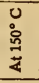 & 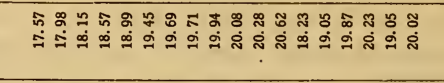 \\
\hline & $\begin{array}{l}0 \\
\vdots \\
\vdots\end{array}$ & 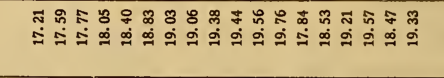 \\
\hline & $\begin{array}{l}0 \\
: \\
\stackrel{8}{*}\end{array}$ & 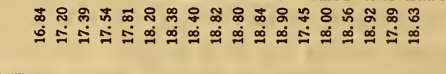 \\
\hline \multicolumn{2}{|c|}{ 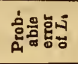 } & 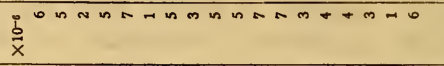 \\
\hline \multirow{2}{*}{ 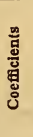 } & $\underset{\substack{x \\
0}}{0}$ & 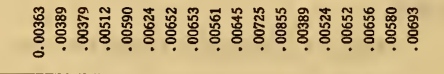 \\
\hline & $\underset{\substack{x \\
\theta}}{\stackrel{x}{x}}$ & 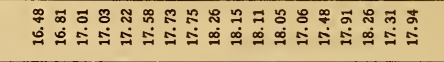 \\
\hline \multicolumn{2}{|c|}{ 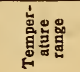 } & 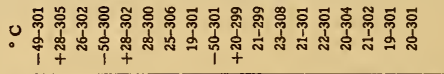 \\
\hline \multirow{4}{*}{ 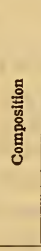 } & 氜 & 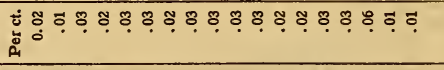 \\
\hline & 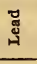 & 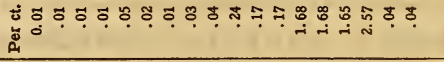 \\
\hline & 苞 & 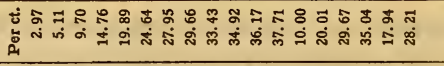 \\
\hline & 芯 & 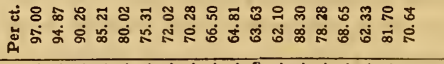 \\
\hline \multicolumn{2}{|c|}{ 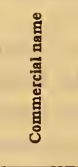 } & 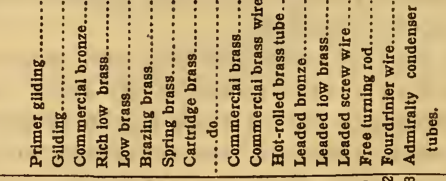 \\
\hline \multicolumn{2}{|c|}{ b额的点 } & 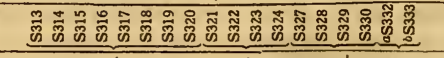 \\
\hline \multicolumn{2}{|c|}{ 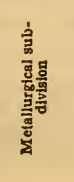 } & 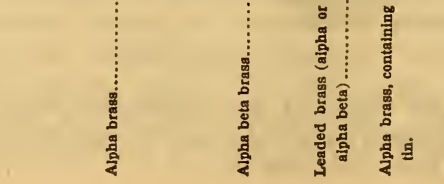 \\
\hline
\end{tabular}


The observations on three of the above alloys were plotted, and the curves obtained are shown in Fig. 23.

From inspection of the previous table, it is seen that, in general, the coefficients increase with a decrease in the copper content of these copper-zinc alloys. If the values of the instantaneous coeffi-

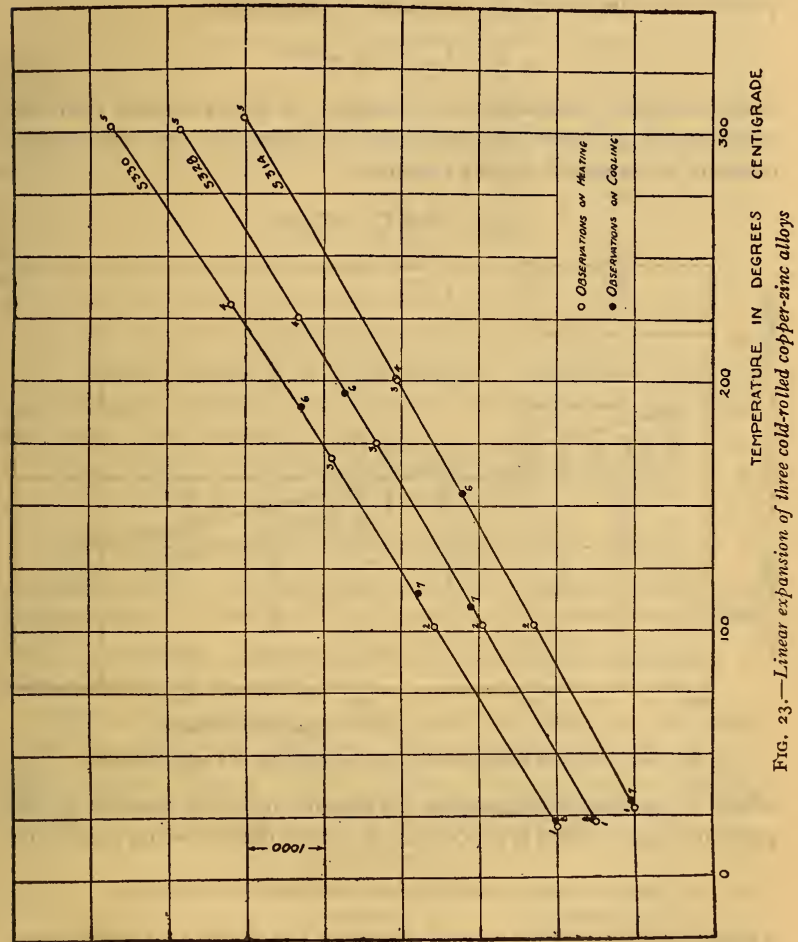

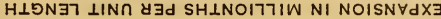

cients at $50^{\circ} \mathrm{C}$ are plotted against the copper content, the curve shown in Fig. 24 is obtained. It is obvious that it is possible to derive a mathematical relation between the instantaneous coefficient at $50^{\circ} \mathrm{C}$ and the copper (or zinc) content of these alloys, if it is assumed that the other elements present are impurities which 
may be neglected. Since the leaded brasses ( $\mathrm{S}_{327}$ to $\mathrm{S}_{330}$, inclusive) and the brasses containing tin ( $\mathrm{S}_{332}$ and $\mathrm{S}_{333}$ ) contain lead and tin, respectively, which were added intentionally, it was decided to ignore these alloys in deriving the relation between copper content and expansivity. The instantaneous coefficients computed from the quadratic equation of expansion

$$
L_{t}=L_{o}\left(\mathbf{1}+a t+b t^{2}\right)
$$

may be called "experimental" values. If it is assumed that the relationship between the coefficient of expansion and the copper content is expressed by the equation

$$
a_{50}=A+B \mathrm{Cu}+\mathrm{C} \mathrm{Cu}^{2}
$$

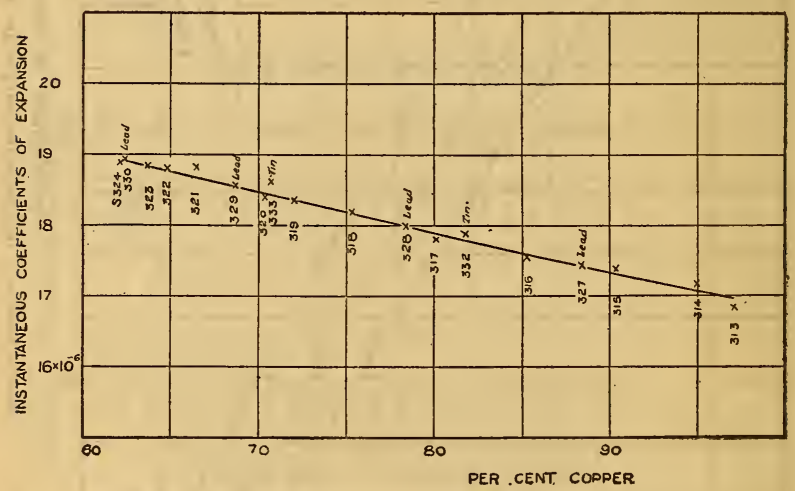

FIG. 24.-Relation between instantaneous coefficient and copper content

where $a_{50}$ is the instantaneous coefficient at $50^{\circ} \mathrm{C}$ and $\mathrm{Cu}$ is the per cent copper, then it is possible to derive the following equation:

$$
a_{50}=\left(22.923-0.06833 \mathrm{Cu}+0.0000695 \mathrm{Cu}^{2}\right) \mathrm{IO}^{-8},
$$

where $\mathrm{Cu}$ is the copper content between the limits 62.I and 97 per cent.

The following is a comparison of the experimental values of the instantaneous coefficients of expansion at $50^{\circ} \mathrm{C}$ with those comcomputed from this formula. The residuals show that the equation holds. 
TABLE 14.-Comparison of Experimental and Computed Coefficients at $50^{\circ} \mathrm{C}$

[The probable error of $a_{30}$ is $\pm 0.06 \times 10^{-6}$.]

\begin{tabular}{|c|c|c|c|c|}
\hline \multirow{2}{*}{ Laboratory number } & \multirow{2}{*}{ Copper } & \multicolumn{2}{|c|}{ Coefficients } & \multirow{2}{*}{ Residuals } \\
\hline & & $\underset{\text { Experimen- }}{\text { tal } a_{50}}$ & $\underset{a_{s 0}}{\text { Computed }}$ & \\
\hline$\Rightarrow+x^{\circ}$ & Per cent & $\times 10^{-6}$ & $\times 10^{-6}$ & $\dot{\times 10^{-6}}$ \\
\hline S313.............. & 97.00 & 16.84 & 16.95 & -0.11 \\
\hline S314............... & 94.87 & 17.20 & 17.07 & +.13 \\
\hline S315............ & 90.26 & 17.39 & 17.32 & .07 \\
\hline 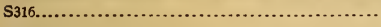 & 85.21 & 17.54 & 17.61 & -.07 \\
\hline 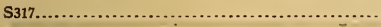 & 80.02 & 17.81 & 17.90 & -.09 \\
\hline S318...................... & 75.31 & 18.20 & 18.17 & +.03 \\
\hline 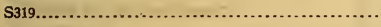 & 72.02 & 18. 38 & 18.36 & .02 \\
\hline 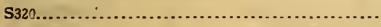 & 70.28 & 18.40 & 18.46 & -.06 \\
\hline \$321...................... & 66.50 & 18. 82 & 18.69 & +.13 \\
\hline 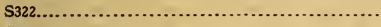 & 64.81 & 18.80 & 18.79 & .01 \\
\hline 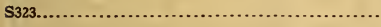 & 68.63 & 18.84 & 18.86 & -.02 \\
\hline 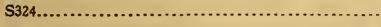 & 62.10 & 18.90 & 18.95 & -.05 \\
\hline
\end{tabular}

In a similar manner the instantaneous coefficients, $a_{100}, a_{150}$, $a_{200}$, and $a_{250}$, at $100, \mathrm{I} 50,200$, and $250^{\circ} \mathrm{C}$, respectively, were computed and the equations derived are

$$
\begin{aligned}
& a_{100}=\left(24.673-0.08794 \mathrm{Cu}+0.0001252 \mathrm{Cu}^{2} \pm 0.05\right) \mathrm{IO}^{-6} \\
& a_{150}=\left(25.790-.091 \mathrm{Iu}+.0000775 \mathrm{Cu}^{2} \pm .08\right) \mathrm{IO}^{-6} \\
& a_{200}=\left(23.406-.00386 \mathrm{Cu}-.000542 \mathrm{I} \mathrm{Cu}^{2} \pm .13\right) \mathrm{IO}^{-6} \\
& a_{250}=\left(28.68 \mathrm{I}-.1145 \mathrm{I} \mathrm{Cu}+.0000874 \mathrm{Cu}^{2} \pm .16\right) \mathrm{IO}^{-6} .
\end{aligned}
$$

The last term in the parenthesis of each equation represents the probable error.

Fig. 25 represents graphically the instantaneous coefficients at every $50^{\circ}$ from 50 to $250^{\circ} \mathrm{C}$.

A change in temperature causes a greater change in the value of the instantaneous coefficient of a copper-zinc alloy of low

\begin{tabular}{|c|c|c|c|c|c|c|c|}
\hline \multirow{2}{*}{ Laboratory number } & \multicolumn{4}{|c|}{ Composition } & \multicolumn{2}{|c|}{ Coefficients $\times 10^{6}$} & \multirow{2}{*}{$\begin{array}{c}\text { Change } \\
\left(a_{100}-a_{50}\right)\end{array}$} \\
\hline & Copper & Zinc & Lead & Iron & $a_{50}$ & $a_{100}$ & \\
\hline & Per cent & Per cent & Per cent & Per cent & & & $\times 10^{-6}$ \\
\hline 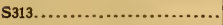 & 97.00 & 2.97 & 0.01 & 0.02 & 16.84 & 17.21 & 0.37 \\
\hline S320......................... & 70.28 & 29.66 & .03 & .03 & 18.40 & 19.06 & .66 \\
\hline
\end{tabular}
copper content than in that of an alloy of higher copper content, as is apparent from Fig. 25 and the following comparison:

TABLE 15 
The change in the rate of expansion or instantaneous coefficient of $\mathrm{S}_{320}$ from 50 to $100^{\circ} \mathrm{C}$ is nearly twice as large as that for $\mathrm{S}_{31}$ 3. This change increases with a decrease in the copper content (and a corresponding increase in the per cent zinc) of the alloy.

The average residuals of the alpha beta brasses $\left(\mathrm{S}_{321}\right.$ to $\mathrm{S}_{324}$, inclusive) above $100^{\circ} \mathrm{C}$, exceed the corresponding probable errors, which indicates that this group of alloys is not in as close agreement with the empirical equations as the group of alpha brasses ( $\mathrm{S}_{3} \mathrm{I}_{3}$ to $\mathrm{S}_{320}$, inclusive).

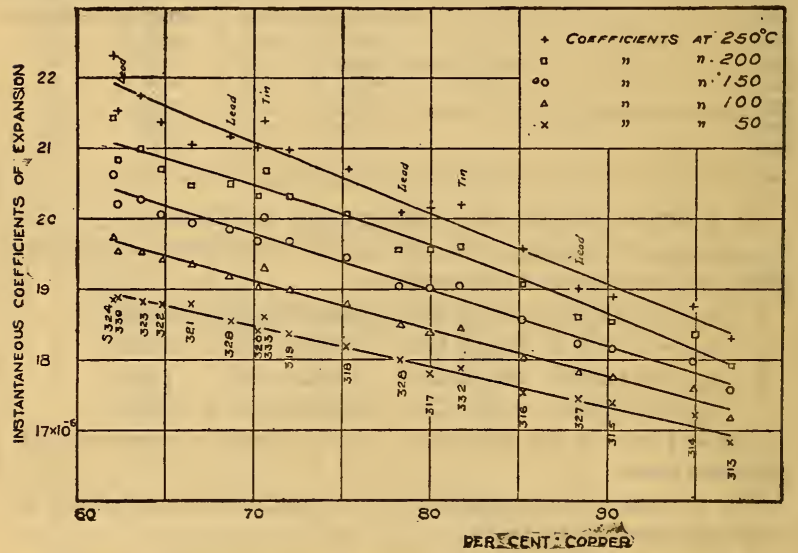

FrG. 25.-Relations between instantaneous coefficients and copper content

The two copper alloys $\left(\mathrm{S}_{332}\right.$ and $\left.\mathrm{S}_{333}\right)$ containing tin, which was added intentionally, have coefficients which are greater than the theoretical values of alloys of corresponding copper content (but without tin), as may be seen from Fig. 25 and the following comparison: 
TABLE 16.-Comparison of Experimental and Theoretical Coefficients

A. S332 (COPPER 81.70, TIN 0.31)

\begin{tabular}{|c|c|c|c|c|c|}
\hline \multirow[b]{2}{*}{ - } & \multicolumn{5}{|c|}{ Instantaneous coefficients $\times 10^{5}$} \\
\hline & At $50^{\circ} \mathrm{C}$ & At $100^{\circ} \mathrm{C}$ & At $150^{\circ} \mathrm{C}$ & At $200^{\circ} \mathrm{C}$ & At $250^{\circ} \mathrm{C}$ \\
\hline 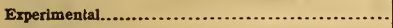 & 17.89 & 18.47 & 19.05 & 19.63 & 20.21 \\
\hline 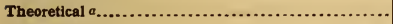 & 17.80 & 18.32 & 18.86 & 19.47 & 19.91 \\
\hline 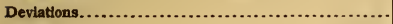 & .09 & .15 & .19 & .16 & .30 \\
\hline
\end{tabular}

B. S333 (COPPER 70.64, TIN 1.10)

\begin{tabular}{|c|c|c|c|c|c|}
\hline Experimental & 18.63 & 19. 33 & 20.02 & 20.71 & 21.40 \\
\hline 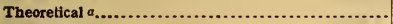 & 18.44 & 19.09 & 19.74 & 20.43 & 21.03 \\
\hline 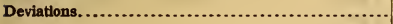 & .19 & .24 & .28 & .28 & .37 \\
\hline
\end{tabular}

a These valucs rcfer to a cold-rolled copper-zinc alloy of correspondirig copper content (but without tin).

The deviations are greater than the probable errors, and are attributable to the large amounts of tin. It should be noted that for the alloy containing I.Io per cent tin ( $\left.\mathrm{S}_{333}\right)$, the observed values deviate from the theoretical curves of instantaneous coefficients more than those of the alloy containing less tin $\left(\mathrm{S}_{332}\right)$.

The four leaded brasses containing from 1.65 to 2.57 per cent lead, which was intentionally added, have instantaneous coefficients that are less than the theoretical values of alloys of corresponding copper content (but without appreciable amounts of lead). The average deviations at 150,200 , and $250^{\circ} \mathrm{C}$ are $-0.10 \times 10^{-6},-0.17 \times 10^{-6}$, and $-0.20 \times 10^{-6}$, respectively, which exceed the probable errors and are due to the added lead.

From the equations of instantaneous coefficients it is possible to predict the coefficients of a cold-rolled copper-zinc alloy, the copper content of which varies from 62.1 to 97 per cent. There is a remarkable uniformity between the coefficients of expansion and the copper content of these alloys. This uniformity might be better if copper and zinc were the only two elements to vary.

In general, it was found that the cooling curves from the maximum temperature (about $300^{\circ} \mathrm{C}$ ) to room temperature did not coincide exactly with the heating curves. At any given temperature the variation did not exceed \pm 70 millionths per unit length. In each case the maximum variation occurred at room temperature; that is, the cooling curve deviated more from the heating curve as the temperature decreased from about $300^{\circ} \mathrm{C}$ (the maximum temperature) to room temperature. The following table shows the deviations at room temperature or the changes 
in length after test. The plus $(+)$ sign indicates an increase in length, and the minus (-) sign a decrease in length.

TABLE 17.-Change in Length Due to Heat Treatment Received During Test

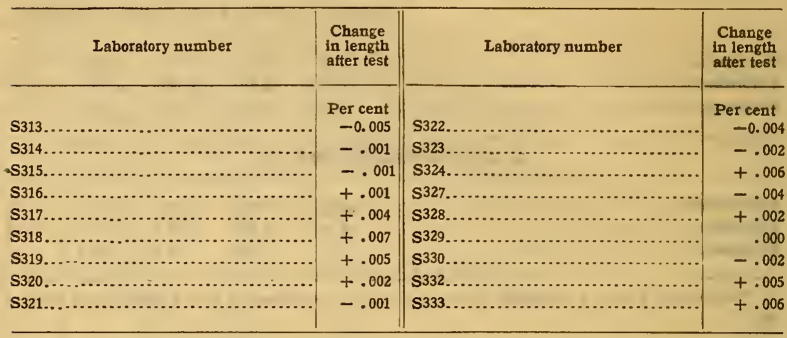

As a general rule, materials fail to return to their original dimensions after heating unless they are well annealed before test. This means that the cooling curve does not coincide with the

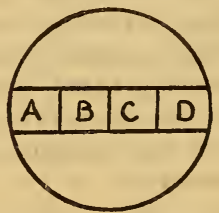

FIG. 26.-Cross section of copper-zinc casting

heating curve, and may lie above or below the heating curve, or may intersect it, depending on the material.

Since the specimens of Series II were in the hard condition (not annealed), it is not surprising to find that these samples did not return to their original lengths and that the cooling curves did not coincide with the heating curves. It should be remembered, however, that the deviations between the heating and cooling curves are very small.

\section{SERIES III: SECTIONS OF COPPER-ZINC CASTINGS}

Series III includes 72 samples cut from i 8 castings of copper-zinc alloys, the compositions of which correspond to those of Series II. From each casting, four specimens were cut as shown in the diagram (Fig. 26). 
$A$ and $D$ represent outside sections, and $B$ and $C$ inside sections. All the samples except $\mathrm{S}_{33} 2$ and $\mathrm{S}_{333}$ (cut from $\mathrm{r} \frac{5}{8}$-inch castings) were cut from 2 -inch castings. It should be noted that the samples of Series II were obtained from castings similar to those of Series III, which castings were treated as described in the first paragraph of Series II (p. ro9). $\mathrm{S}_{3} \mathrm{I}_{3} \mathrm{~A}, \mathrm{~S}_{3} \mathrm{I}_{3} \mathrm{~B}, \mathrm{~S}_{3} \mathrm{I}_{3} \mathrm{C}$, and $\mathrm{S}_{3} \mathrm{I}_{3} \mathrm{D}$ of Series III have the same chemical composition as $\mathrm{S}_{3} \mathrm{I}_{3}$ of Series II, and in like manner for the other specimens of this series.

The following table gives the composition, the temperature range of the thermal expansion test, the values of $a$ and $b$ of the general quadratic equation

$$
L_{\mathrm{t}}=L_{\mathrm{o}}\left(\mathrm{I}+a t+b t^{2}\right),
$$

the probable error of $L_{t}$, and the instantaneous coefficients at every $50^{\circ}$ from 50 to $250^{\circ} \mathrm{C}$. 


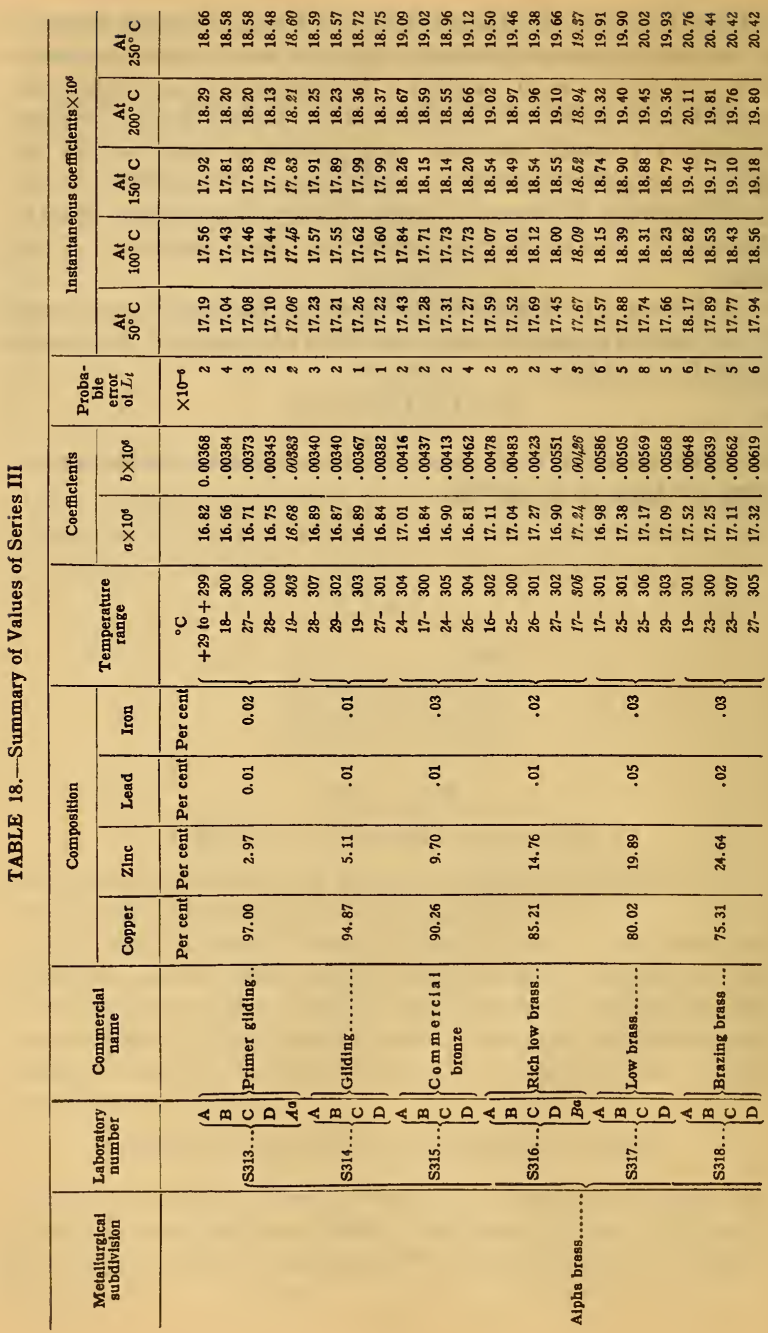




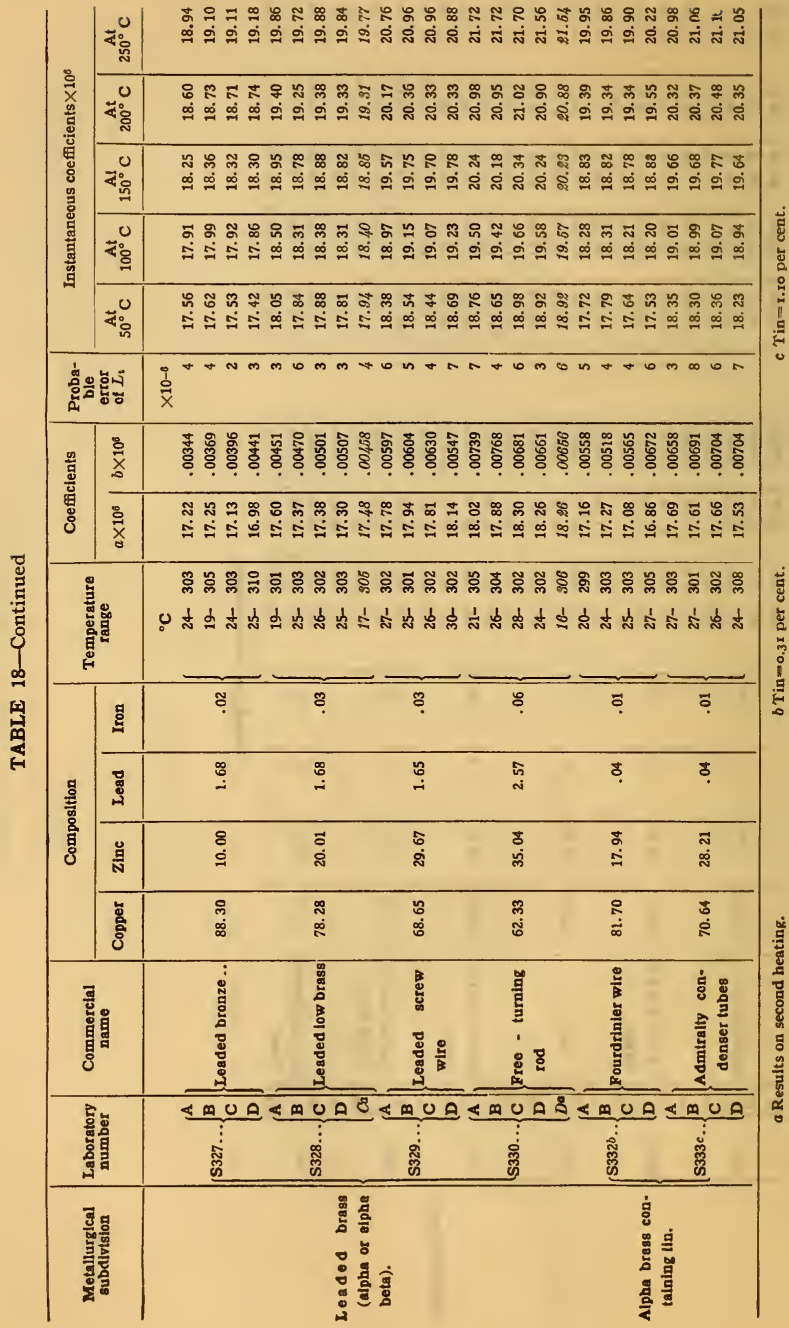


The observations on four of the above samples were plotted, and the curves obtained are shown in Fig. 27.

Similar to Series II, the coefficients of this series, in general, increase with a decrease in the copper content of the casting.

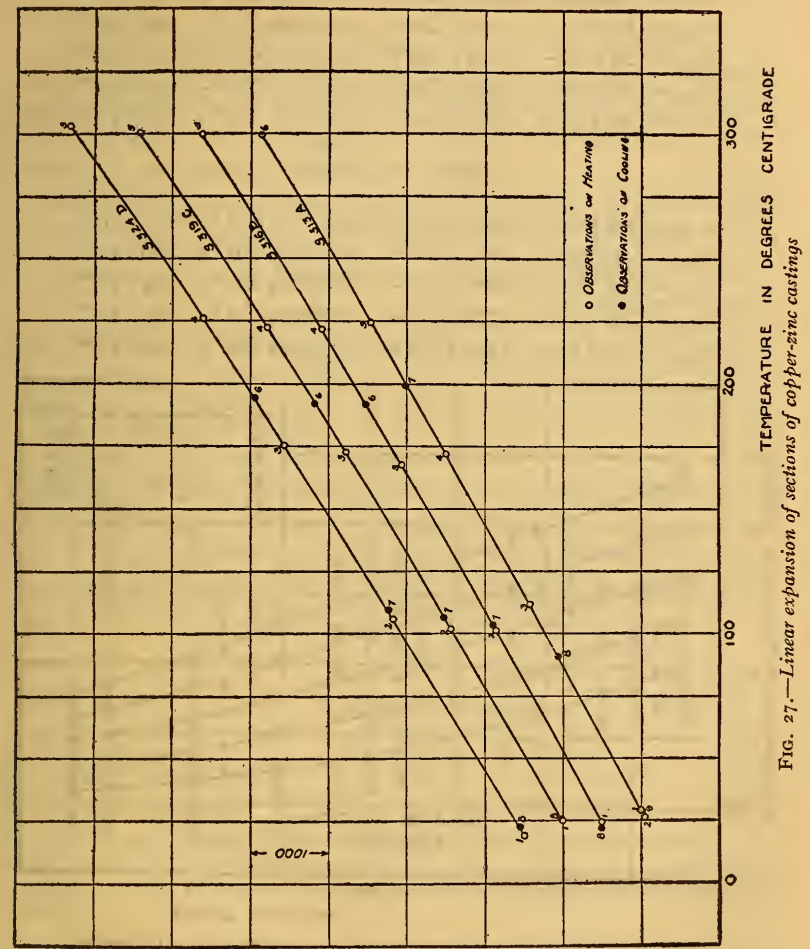

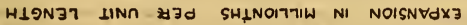

The following mathematical relations between the instantaneous coefficients and the copper content of the castings were derived. In deducing these equations, the sections of the four leaded castings, $\mathrm{S}_{327}$ to $\mathrm{S}_{330}$, and those of the two castings containing tin, $S_{332}$ and $S_{333}$, were neglected, for these samples contained $20183^{\circ}-21-3$ 
large amounts of lead and tin, respectively, which were added intentionally.

\section{OUTSIDE SECTIONS}

$$
\begin{aligned}
& a_{50}=\left(29.39 \mathrm{I}-0.23978 \mathrm{Cu}+0.00 \mathrm{II} 74 \mathrm{I} \mathrm{Cu}{ }^{2} \pm 0.07\right) \mathrm{IO}^{-6} \\
& a_{100}=\left(29.023-.20604 \mathrm{Cu}+.0009006 \mathrm{Cu}^{2} \pm .06\right) \mathrm{IO}^{-6} \\
& a_{150}=\left(28.646-. \mathrm{I} 72 \mathrm{I} 2 \mathrm{Cu}+.0006263 \mathrm{Cu}^{2} \pm .05\right) \mathrm{IO}^{-6} \\
& a_{200}=\left(29.250-.16345 \mathrm{Cu}+.0005 \mathrm{IO} \mathrm{Cu}^{2} \pm .06\right) \mathrm{IO}^{-6} \\
& a_{250}=\left(28.543-. \mathrm{I} 2 \mathrm{IO} 4 \mathrm{Cu}+.000 \mathrm{I} 830 \mathrm{Cu}^{2} \pm .08\right) \mathrm{IO}^{-6}
\end{aligned}
$$

\section{INSIDE SECTIONS}

$$
\begin{aligned}
& a_{50}=\left(29.533-0.24272 \mathrm{Cu}+0.001 \mathrm{I} 87 \mathrm{I} \mathrm{Cu}^{2} \pm 0.07\right) \mathrm{IO}^{-6} \\
& a_{100}=\left(29.37 \mathrm{I}-.2 \mathrm{I} 524 \mathrm{Cu}+.0009569 \mathrm{Cu}^{2} \pm .06\right) \mathrm{IO}^{-6} \\
& a_{150}=\left(29.207-. \mathrm{I} 8780 \mathrm{Cu}+.0007269 \mathrm{Cu}^{2} \pm .04\right) \mathrm{IO}^{-6} \\
& a_{200}=\left(29.704-.17729 \mathrm{Cu}+.0006029 \mathrm{Cu}^{2} \pm .05\right) \mathrm{IO}^{-6} \\
& a_{250}=\left(29.237-.14192 \mathrm{Cu}+.0003222 \mathrm{Cu}^{2} \pm .06\right) \mathrm{IO}^{-6}
\end{aligned}
$$

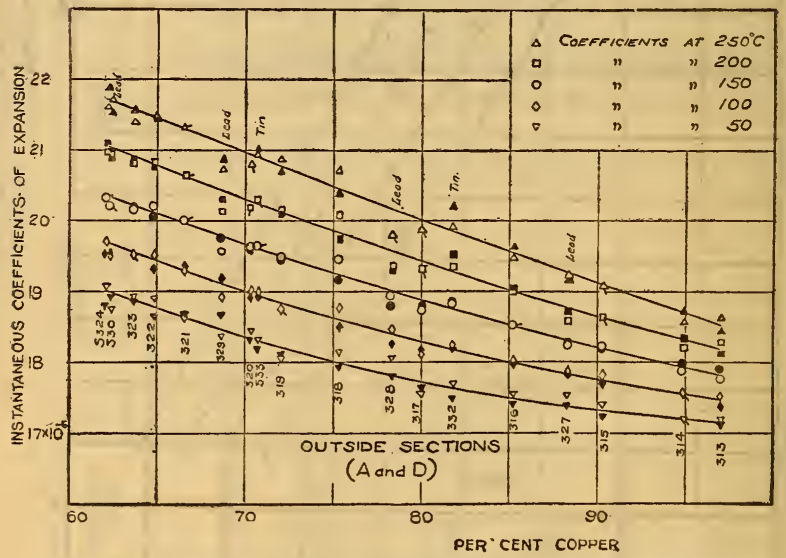

FIG. 28.-Relations between instantaneous coefficients and copper content

The light symbols represent the observed values of sections $A$ and the dark symbols thase of sections $D$. Where the values of two sections $(A$ and $D$ ) are equal or nearly so, a tagged symbol was employed as shown

These equations apply for copper-zinc castings, the copper content of which varies from 62.I to 97 per cent. In each case the last term of the parenthesis represents the probable error in the value of the coefficient as determined from the corresponding equation. 
Fig. 28 represents graphically the instantaneous coefficients of the outside sections at every $50^{\circ}$ from 50 to $250^{\circ} \mathrm{C}$, and Fig. 29 the coefficients of the inside sections.

In general, the residuals of this series are not as large as those of Series II.

From an examination of Figs. 28 and 29 it is seen, as was the case for the cold-rolled alloys of Series II, that the instantaneous coefficient of a copper-zinc casting of high copper content is not affected by a temperature change as much as that of a casting of low copper content.

In Series II the average residuals of the cold-rolled alpha beta brasses ( $\mathrm{S}_{32 \mathrm{I}}$ to $\mathrm{S}_{324}$, inclusive) exceed the probable errors.

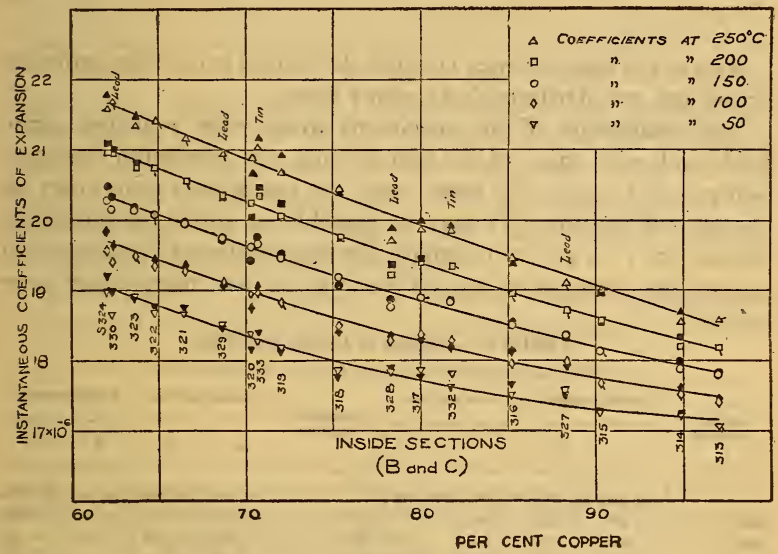

FIG. 29.-Relations between instantaneous coefficients and copper content

The light symbols represent the observed values of sections $B$, and the dark symbols those of sections $C$. Where the values of two sections $(B$ and $C$ ) are equal or nearly so, a tagged symbol was employed as shown

The residuals of the alpha beta castings of Series III, however, are generally less than the probable errors, which shows that this group of castings is in close agreement with the derived quadratic equations.

The instantaneous coefficients of the two castings ( $\mathrm{S} 332$ and $\mathrm{S}_{333}$ ) which contain tin were found to be usually greater (deviations somewhat more than the probable errors) than the theoretical values of alloys of corresponding copper content (but without tin). 
Most of the instantaneous coefficients of the leaded castings, $\mathrm{S}_{327}$ to $\mathrm{S}_{330}$, are less than the theoretical values. The average deviations are as follows:

TABLE 19.-Deviations of Leaded Castings

\begin{tabular}{|c|c|c|}
\hline \multirow{2}{*}{ Temperature, degrees centigrade } & \multicolumn{2}{|c|}{$\begin{array}{l}\text { Average deviations } \\
\times 10^{4}\end{array}$} \\
\hline & $\begin{array}{l}\text { Outside } \\
\text { sections }\end{array}$ & $\begin{array}{l}\text { Inside } \\
\text { sections }\end{array}$ \\
\hline $50 \ldots \ldots \ldots \ldots \ldots$ & 0.14 & 0.13 \\
\hline $100 \ldots \ldots \ldots \ldots \ldots . . . . .$. & .10 & .08 \\
\hline 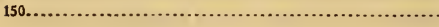 & .10 & .07 \\
\hline 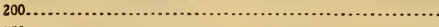 & .16 & .07 \\
\hline 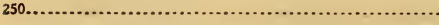 & .23 & .13 \\
\hline
\end{tabular}

As was the case in Series II, these deviations exceed the probable errors and are attributable to added lead.

The coefficients of the specimens which were reheated agree fairly well with those of the first heating, the maximum variation being $\pm 0.15 \times 10^{-8}$. In most cases the coefficients were lower on the second heating. It may be possible to apply the equations (given on p. I 22) to calculate the instantaneous coefficients of copper-zinc castings on second heatings without introducing large eríors.

TABLE 20.-Change in Length after Test

\begin{tabular}{|c|c|c|c|c|c|c|c|c|c|}
\hline \multirow{2}{*}{$\begin{array}{l}\text { Laboratory } \\
\text { number }\end{array}$} & \multicolumn{2}{|c|}{ Outside sections } & \multicolumn{2}{|c|}{ Inside sections } & \multirow{2}{*}{$\begin{array}{l}\text { Laboratory } \\
\text { number }\end{array}$} & \multicolumn{2}{|c|}{ Outside sections } & \multicolumn{2}{|c|}{ Inside sections } \\
\hline & A & D & B & C & & $\mathbf{A}$ & D & B & C \\
\hline & Per cent & Per cent & Per cent & Per cent & & Per cent & Per cent & Per cent & Per cent \\
\hline S313.......... & 0.000 & $|-0.001|$ & 0.000 & $a 0.000$ & S322.. & $a-0.002$ & $a-0.002$ & $a 0.000$ & -0.001 \\
\hline \$314......... & -.001 & $a+.001$ & -.001 & $a .000$ & S323... & -.003 & $a-.003$ & -.002 & -.002 \\
\hline$\$ 315 \ldots$ & $a .000$ & .000 & .000 & $a .000$ & S324.. & -.001 & -.001 & -.004 & $a-.002$ \\
\hline S316... & .000 & .002 & +.006 & $a .000$ & S327... & -.003 & $a .000$ & .000 & -.002 \\
\hline \$317.... & -.003 & .000 & $a .004$ & .000 & \$328... & .000 & 0.000 & $a-.001$ & a. 000 \\
\hline S318..... & .000 & .000 & .000 & -.001 & S329... & $a-.003$ & $a .000$ & 0.000 & $a-.002$ \\
\hline s319..... & $a .000$ & $a, 000$ & $3-.003$ & .000 & $\mathbf{S} 330 \ldots$ & .000 & -.002 & -.002 & -.001 \\
\hline S320..... & $a+.002$ & .001 & .000 & +.002 & S332.... & $a+.002$ & .000 & $a .000$ & +.002 \\
\hline \$321.......... & $a .000$ & -.001 & -.002 & -.002 & \$333........ & a. 000 & +.001 & .000 & $a .004$ \\
\hline
\end{tabular}

a The maximum deviation between the heating and cooling curves did not exceed this value.

The cooling curves of this series, as in Series II, did not coincide exactly with the heating curves. Unlike Series II, however, the maximum variation did not always occur at room temperature. At any given temperature from room temperature to $300^{\circ} \mathrm{C}$ the variation did not exceed \pm 70 millionths per unit length (except 
$\mathrm{S}_{320 \mathrm{C}}$, which showed a variation of $+\mathrm{r} 30$ millionths at $206^{\circ} \mathrm{C}$ ). The preceding table gives the differences between the lengths after cooling to room temperature and the original lengths of the specimens of this series.

The heating and cooling curves of the four samples which were reheated coincided. These specimens, therefore, returned to the same lengths they had before the second heating. The first heating evidently had an annealing effect.

\section{SERIES IV: EXTRUDED AND HOT-ROLLED COPPER-ZINC ALLOYS}

In this series there are eight specimens of extruded copper-zinc alloys, the copper content of which varies from 56.4 to 6 I. .4 per cent, and four samples of hot-rolled alloys.

EXTRUDED.-Three specimens were extruded at 0.265 inch, and three having corresponding compositions were extruded at 0.265 inch, drawn to 0.256 inch, annealed, and finished hard at onefourth inch. The remaining two specimens $\left(\mathrm{S}_{343} \mathrm{E}\right.$ and $\left.\mathrm{S}_{343} \mathrm{ED}\right)$ containing 6 I.4 per cent copper were extruded at nine-sixteenths inch. One of these was then drawn to 0.300 inch, annealed, and finished hard at one-fourth inch. The specimens marked "E" were extruded, and those marked "ED" were drawn, annealed, and finished hard after being extruded.

HOT-ROLLED.-The method of working these samples before the thermal expansion tests is given in the following table:

TABLE 21.-Treatment Before Expansion Tests

\begin{tabular}{l|l}
\hline $\begin{array}{c}\text { Laboratory } \\
\text { number }\end{array}$ & Method of working \\
\hline S341H....... & $\begin{array}{l}\text { Hot-rolled from } 21 / 2 \text { inches square in one heat to } 3 / 8 \text {-inch diameter. } \\
\text { Hot-rolled from } 21 / 2 \text { inches square in one heat to } 3 / 8 \text {-inch diameter, drawn to } 0.256 \text { inch, an- } \\
\text { nealed, and finlshed hard at } 1 / 4 \text { inch. } \\
\text { S341H.D.... }\end{array}$ \\
S344H....... & $\begin{array}{l}\text { Hot-rolled from } 21 / 2 \text { inches square to } 1 / 2 \text {-inch diameter. } \\
\text { Hot-rolled from } 21 / 2 \text { inches square to } 1 / 2 \text {-inch diameter, cold-drawn to } 0.256 \text { inch, annealed, } \\
\text { and finished hard at } 1 / 4 \text { inch. }\end{array}$ \\
\hline
\end{tabular}

The specimens marked " $\mathrm{H}$ " were hot-rolled, and those marked "HD" were drawn, annealed, and finished hard after being hotrolled.

Table 22 gives the composition, the temperature range of the thermal expansion test, the values of $a$ and $b$ of the general quadratic equation

$$
L_{t}=L_{0}\left(\mathrm{I}+a t+b t^{2}\right) \text {, }
$$

the probable error of $L_{t}$, and the instantaneous coefficients at every $50^{\circ}$ from 50 to $250^{\circ} \mathrm{C}$. 
TABLE 22.-Summary of Values of Series IV

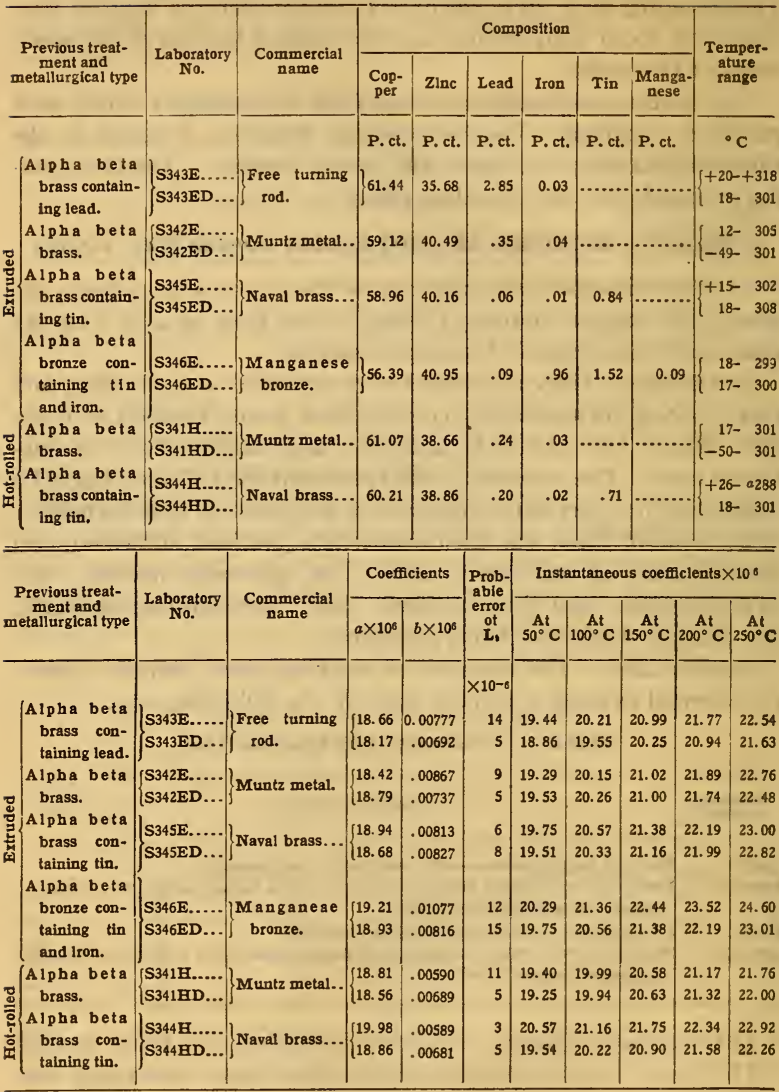

a Before test, specimen was bcated to $200^{\circ} \mathrm{C}$ and cooled to room temperature, after which the test was carried to $524^{\circ} \mathrm{C}$ in an electric furnace. Coefficients, however, apply only within the range given in the table.

Curves showing the relation between the instantaneous coefficients and the temperature from 50 to $250^{\circ} \mathrm{C}$ are given in Fig. 30 . 
The large number of varying elements makes it impossible to definitely determine the effect of each on the value of the coefficient of expansion. In general, a decrease in the copper content causes an increase in the coefficient.

AlPHA BETA BRAss. $-S_{342} E$ and $S_{342 E D}$.-The drawn specimen has greater coefficients below I40 (approximately), and smaller coefficients above $140^{\circ} \mathrm{C}$ than the extruded sample. At about $140^{\circ} \mathrm{C}$ the coefficients of these specimens are equal, and therefore the temperature-coefficient curves intersect at that temperature. At 50 and $250^{\circ} \mathrm{C}$ the differences are 0.24 and $0.28 \times 10^{-6}$, respectively. Annealing and drawing seem to have

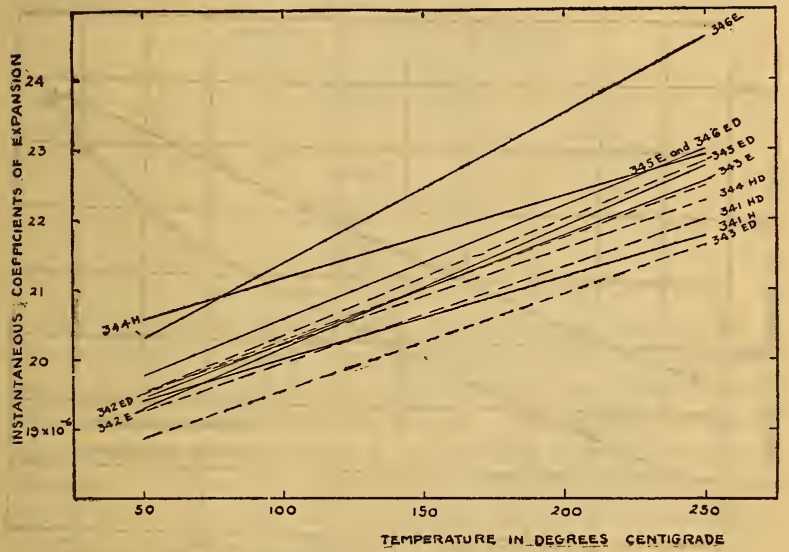

FIG. 30.-Coefficients of expansion of Series IV

much less effect on the coefficients of this extruded alloy than on the alloy with 6I.4 per cent copper. The latter alloy has 2.5 per cent more lead than the former. The curve of $\mathrm{S}_{343} \mathrm{E}$ (copper 61.4 per cent) lies between these two curves. The maximum variation of the former from either of the other two curves occurs at $250^{\circ} \mathrm{C}$ and is $0.22 \times 10^{-6}$.

$S_{34 I} H$ and $S_{34 I} H D$.-At about $140^{\circ} \mathrm{C}$ the rates of expansion of the hot-rolled and the drawn samples are the same. Below this temperature the instantaneous coefficients of the drawn sample are less than those of the hot-rolled, and above this temperature the latter is less than the former. The maximum difference in the coefficients is $0.24 \times 10^{-6}$. 
Alpha Beta Brass Containing Lead. $-S_{343} E$ and $S_{343} E D$.The drawn sample has lower instantaneous coefficients of expansion than the extruded. At $50^{\circ} \mathrm{C}$ the difference in the coefficients is $0.58 \times 10^{-8}$. This difference increases with increase of temperature, and is equal to $0.91 \times 10^{-6}$ at $250^{\circ} \mathrm{C}$. Annealing and drawing of this alloy, therefore, caused a marked diminution in the instantaneous coefficients.

Alpha Beta Brass Containing Tin.- $345 E$ and $S_{345} E D$.These specimens differ in composition from the preceding ones of this series in the following respects:

(a) They contain considerably less lead.

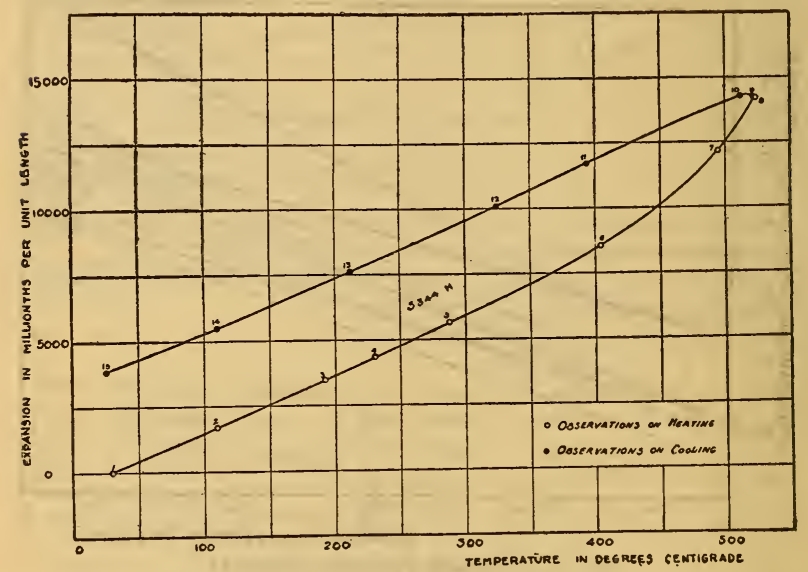

FIG. 31.-Thermal expansion of hot-rolled brass

(b) They contain an appreciable amount of tin.

The coefficients of the drawn sample are less than those of the extruded. At $250^{\circ} \mathrm{C}$ the difference in the coefficients is $0.18 \times 10^{-6}$. This difference increases very slowly with decrease in temperature and is equal to $0.24 \times 10^{-6}$ at $50^{\circ} \mathrm{C}$. For this alloy, annealing and drawing also caused a diminution in the instantaneous coefficients, but considerably less effect than was produced in the alloy with 61.4 per cent copper.

$S_{344 H}$ and $S_{344 H D}$.- These two samples also contain tin.

The instantaneous coefficients of the drawn sample are less than those of the hot-rolled. At $50^{\circ} \mathrm{C}$ the difference in the coefficients 
is $1.03 \times 10^{-6}$. This difference decreases with temperature and is $0.66 \times \mathrm{IO}^{6}$ at $250^{\circ} \mathrm{C}$. Annealing and drawing of the hot-rolled specimen containing $0.7 \mathrm{I}$ per cent tin caused the greatest change in the values of the instantaneous coefficients of hot-rolled samples of Series I and IV, probably due to the amount of tin contained in the alloy.

The hot-rolled specimen $\left(\mathrm{S}_{344} \mathrm{H}\right)$ was heated to $524^{\circ} \mathrm{C}$ in an electric air furnace. The observations were plotted, and the curves shown in Fig. 3I were obtained. It was impossible to derive a second degree equation applicable over the entire temperature range. Average coefficients of expansion are given in the following table:

TABLE 23.-Coefficients of Expansion

\begin{tabular}{|c|c|}
\hline $\begin{array}{c}\text { Temperature } \\
\text { interval }\end{array}$ & $\begin{array}{c}\text { Average } \\
\text { coefficient }\end{array}$ \\
\hline${ }^{\circ} \mathrm{C}$ & $\times 10^{-6}$ \\
$30-100$ & 20.7 \\
$100-200$ & 21.7 \\
$200-300$ & 23.0 \\
$300-400$ & 24.9 \\
$400-500$ & 40.8 \\
\hline
\end{tabular}

The coefficients increase with temperature. Above $400^{\circ} \mathrm{C}$ the coefficient increased very rapidly. The rate of expansion between 400 and $500^{\circ} \mathrm{C}$ was equal to about two times the rate between room temperature and $100^{\circ} \mathrm{C}$. The sudden increase in the coefficient indicates that a polymorphic change occurred in the alloy. It should be noted that the average coefficients from IOO to $200^{\circ}$ and 200 to $300^{\circ} \mathrm{C}$ are practically equal to the instantaneous coefficients at $\mathrm{I} 5^{\circ}$ and $25^{\circ} \mathrm{C}$, respectively.

The observations on cooling lie considerably above the heating curve. The average coefficients of contraction are as follows:

TABLE 24.-Coefficients of Contraction

\begin{tabular}{|c|c|}
\hline $\begin{array}{c}\text { Temperature } \\
\text { interval }\end{array}$ & $\begin{array}{c}\text { Average } \\
\text { coefficient }\end{array}$ \\
\hline${ }^{\circ} \mathrm{C}$ & $\times 10^{-6}$ \\
$500-400$ & 21.6 \\
$400-300$ & 23.0 \\
$300-200$ & 22.0 \\
$200-100$ & 20.8 \\
$100-30$ & 19.0 \\
\hline
\end{tabular}


On cooling to room temperature, this specimen was found to be 0.39 per cent longer than before the test.

After the test, another micrograph was made of this sample (Fig. 32). This record shows how completely the structure has been changed from that of the hot-rolled rod before the test. (See micrograph Fig. 13.) The change indicates that the grains have become equiaxed, in other words, the metal has been thoroughly annealed. The rate of expansion increased abruptly at about $400^{\circ} \mathrm{C}$, due to the beginning of this change in structure.

AlPha-Beta Bronze Containing Tin ANd Iron.-S346E and

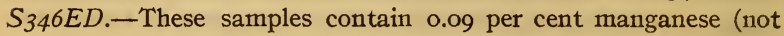
present in the other samples of this series) and comparatively large percentages of iron and tin.

The instantaneous coefficients of the drawn sample are considerably less than those of the extruded. At $50^{\circ} \mathrm{C}$ the difference in the coefficients is $0.54 \times 10^{-6}$. The difference increases very rapidly with increase in temperature, as shown in Fig. 30 and by the large differential rate of expansion $d a_{t}=a-a^{\prime}+2 t\left(b-b^{\prime}\right)$, where $a$ and $b$ are the coefficients in the expansion equation of the extruded specimen and $a^{\prime}$ and $b^{\prime}$ the coefficients of the drawn sample. The differential rate of expansion for these specimens is

$$
\begin{aligned}
d a_{t} & =[0.28+2 t(0.0026 \mathrm{I})] \mathrm{ro}^{-6} \\
& =(0.28+0.00522 t) \mathrm{IO}^{-6} .
\end{aligned}
$$

At $250^{\circ} \mathrm{C}$ the difference in the coefficients is $1.59 \times 10-{ }^{\circ}$. Annealing and drawing of this alloy produced the greatest changes in the coefficients of the alloys of this series. It is interesting to note that this treatment on the extruded alloy, $\mathrm{S}_{346 \mathrm{E}}$, produced a sample the coefficients of which are practically equal to those of $\mathrm{S}_{345} \mathrm{E}$ (curves of $\mathrm{S}_{346 \mathrm{ED}}$ and $\mathrm{S}_{345} \mathrm{E}$ coincide), which specimen contains less copper, lead, iron, and tin (and no manganese).

The cooling curves of $\mathrm{S}_{343} \mathrm{E}, \mathrm{S}_{343} \mathrm{ED}$, and $\mathrm{S}_{34} \mathrm{IH}$ lie below the heating curves, and those of $\mathrm{S}_{342 \mathrm{E}}, \mathrm{S}_{345} \mathrm{E}, \mathrm{S}_{345} \mathrm{ED}, \mathrm{S}_{34} 6 \mathrm{E}$, and $\mathrm{S}_{344} \mathrm{H}$ lie above the heating curves. The cooling curves of the other specimens in the series intersect the heating curves. The maximum variation between the cooling and heating curves occurred at room temperature, except for the following two specimens: 


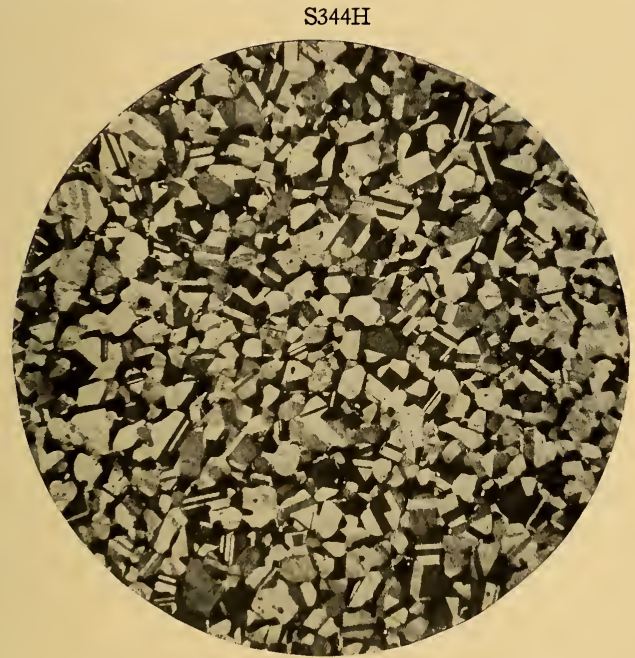

FIG. 32.-Alpha beta brass containing tin, after heating to $524^{\circ} \mathrm{C} . \quad \times 75$ Copper 60.21, zinc 38.86, tin 0.71 , lead 0.20 , iron 0.02 (naval brass) 
TABLE 25

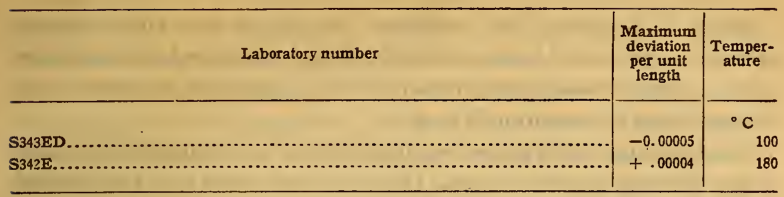

After cooling to room temperature, the variation in length from the original length was found to be as follows:

TABLE 26.--Changes in Length After Test

\begin{tabular}{l} 
Laboratory number \\
\hline
\end{tabular}

$a$ Specimen heated to $524^{\circ} \mathrm{C}$.

For the drawn specimens the deviations of the cooling curves from the heating curves are less than the corresponding deviations for the extruded samples. Annealing and drawing of the extruded alloys evidently tend to make the cooling curves approach the heating curves.

The differences in the changes in length at room temperature (see preceding table) between the extruded and drawn samples are comparable to the corresponding differences in the coefficients of the extruded and drawn samples. For $S_{342}$ and $S_{345}$ the differences in both cases are small, but for $S_{343}$ and $S_{346}$ the reverse is true. In the latter $\left(\mathrm{S}_{346}\right)$, the difference in the changes of length between the extruded and drawn samples is $0.026-0.002=0.024$ per cent, which is the greatest difference in this series. The greatest difference in the coefficients of expansion between the extruded and drawn samples was observed in this alloy. 


\section{SERIES V: COLD-ROLLED COPPER-TIN ALLOYS}

Series V includes four samples of copper tin alloys (alpha bronzes), cold-rolled from $\mathrm{r} 5 / 8$-inch chilled castings to twenty-one thirty-seconds inch round, cold-drawn to 0.300 inch, annealed, and finished hard at one-fourth inch.

The following table gives the composition, the temperature range of the thermal expansion test, the values of $a$ and $b$ of the general quadratic equation

$$
L_{\mathrm{t}}=L_{\mathrm{o}}\left(\mathrm{I}+a t+b t^{2}\right),
$$

the probable error of $L_{\mathrm{t}}$, and the instantaneous coefficients at every $50^{\circ}$ from 50 to $250^{\circ} \mathrm{C}$.

TABLE 27.-Summary of Values of Series V

\begin{tabular}{|c|c|c|c|c|c|c|c|c|c|c|c|c|c|}
\hline \multirow{2}{*}{$\begin{array}{c}\text { Labora- } \\
\text { tory } \\
\text { number }\end{array}$} & \multirow[b]{2}{*}{$\begin{array}{c}\text { Commerciaj } \\
\text { name }\end{array}$} & \multicolumn{3}{|c|}{ Composition } & \multirow{2}{*}{$\begin{array}{c}\text { Temper- } \\
\text { ature } \\
\text { range }\end{array}$} & \multicolumn{2}{|c|}{ Coefficients } & \multirow{2}{*}{ 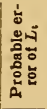 } & \multicolumn{5}{|c|}{ Instantaneous coefficients $\times 100$} \\
\hline & & 岕 & 면 & 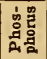 & & $\underset{\ddot{x}}{x}$ & $\underset{\substack{x \\
:}}{0}$ & & ${ }_{50^{\circ} \mathrm{C}}^{\text {At }}$ & $\begin{array}{c}\text { At } \\
100^{\circ} \mathrm{C}\end{array}$ & $150^{\circ} \mathrm{C}$ & $200^{\circ} \mathrm{C}$ & At \\
\hline S409... & $\begin{array}{c}\text { Phosphor } \\
\text { bronze. }\end{array}$ & $\begin{array}{l}\text { P. : } \\
95.40\end{array}$ & $\begin{array}{r}\text { P. ct. } \\
4.25\end{array}$ & $\begin{array}{r}\text { P. ct. } \\
0.37\end{array}$ & $\begin{array}{c}{ }^{\circ} \mathrm{C} \\
+20-302\end{array}$ & 16.81 & 0.00359 & $\begin{array}{r}\times 10^{-0} \\
11\end{array}$ & 17.17 & 17.53 & 17.89 & 18.25 & 18.60 \\
\hline S406.... & Chain bronze & 94.86 & 4.88 & .12 & $20-301$ & 16.63 & .00367 & 13 & 17.00 & 17.36 & 17.73 & 18.10 & 18.46 \\
\hline$\$ 407 \ldots$ & Gun metal.. & 92.04 & 7.67 & .11 & $19-298$ & 16.82 & .00425 & 12 & 17.24 & 17.67 & 18.10 & 18.52 & 18.94 \\
\hline S408... & ...do .......... & 89.69 & 10.14 & .00 & $20-301$ & 17.13 & .00370 & 4 & 17.50 & 17.87 & 18.24 & 18.61 & 18.98 \\
\hline
\end{tabular}

For this series it was also found possible to derive quadratic equations showing the relation between the instantaneous coefficient at a given temperature and the copper (or tin) content of these alloys, if the comparatively small amount of phosphorus is considered negligible. The instantaneous coefficients of coldrolled copper-tin alloys ( 89.7 to 95.4 per cent copper) at every $50^{\circ}$ from 50 to $250^{\circ} \mathrm{C}$ may be calculated from the following equations, derived by the method of least squares:

$$
\begin{aligned}
& a_{50}=\left(35.492-0.32422 \mathrm{Cu}+0.0013737 \mathrm{Cu}^{2} \pm 0 . \mathrm{II}\right) \mathrm{IO}^{-6} \\
& a_{100}=\left(26.056-.1075^{2} \mathrm{Cu}+.0001793 \mathrm{Cu}^{2} \pm . \mathrm{IO}\right) \mathrm{IO}^{-8} \\
& a_{150}=\left(26.840-.11263 \mathrm{Cu}+.0001877 \mathrm{Cu}^{2} \pm . \mathrm{IO}\right) \mathrm{10}^{-6} \\
& a_{200}=\left(38.042-.342 \mathrm{I} 4 \mathrm{Cu}+.0014036 \mathrm{Cu}^{2} \pm . \mathrm{II}\right) \mathrm{IO}^{-6} \\
& a_{250}=\left(28.60 \mathrm{I}-.12544 \mathrm{Cu}+.000209 \mathrm{I} \mathrm{Cu}^{2} \pm . \mathrm{I} 2\right) \mathrm{IO}^{-6} .
\end{aligned}
$$

Fig. 33 represents graphically the instantaneous coefficients at every $50^{\circ}$ from 50 to $250^{\circ} \mathrm{C}$.

As was the case in Series II and III, the instantaneous coefficients of these alloys increase with a decrease in the copper content. 
From Fig. 33 it is seen that the curves are nearly parallel. A given increase in temperature, therefore, will cause approximately the same change in the instantaneous coefficients of alloys of this series within the range 89.7 to 95.4 per cent copper. For example, the change in the computed values of the instantaneous coefficients at 100 and $150^{\circ} \mathrm{C}$ of the alloy containing 89.69 per cent copper is $0.39 \times 10^{-6}$, and the corresponding change for the alloy containing 95.40 per cent copper is $0.37 \times 10^{-6}$. These changes are approximately the same.

The cooling curves of the specimens of this series lie below the heating curves. The maximum variation between these curves occurred at room temperature, except for $\mathrm{S}_{408}\left(\right.$ at $100^{\circ} \mathrm{C}$, deviation was -0.0 I I per cent). After cooling the specimens were found to be about 0.008 per cent shorter than before the tests.

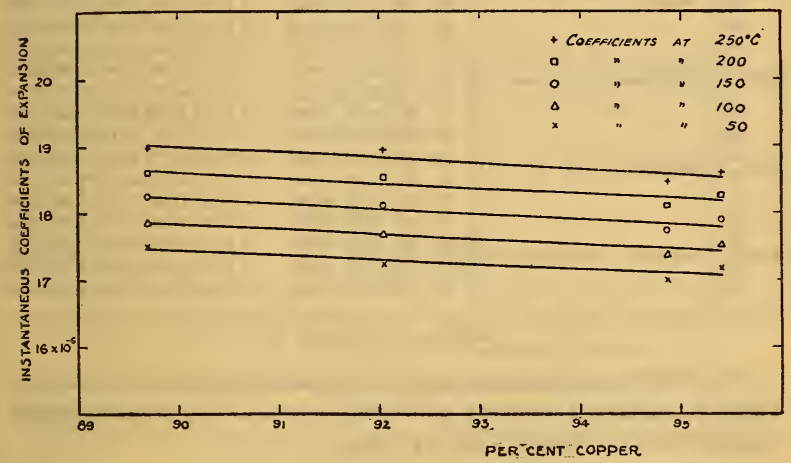

FIG. 33.-Relations between instantaneous coefficients and copper content

\section{SERIES VI: SECTIONS OF COPPER-TIN CASTINGS}

Series VI includes 16 samples cut from 4 castings ( $15 / 8$ inches) of copper-tin alloys (alpha bronzes), the compositions of which correspond to those of Series V. From each casting, four specimens (A, B, C, D) were cut similar to the sections of Series III. (See p. I I6.) The samples of Series $V$ were obtained from castings like those of Series VI, which castings were cold-rolled to twentyone thirty-seconds inch round, cold-drawn to 0.300 inch, annealed, and finished hard at one-fourth inch. S409A, S409B, S409C, and $\mathrm{S}_{409 \mathrm{D}}$ of Series VI have the same chemical composition as $\mathrm{S}_{409}$ of Series V, and in like manner for the other samples of this series. 
The composition, the temperature range of the thermal expansion test, the values of $a$ and $b$ of the general quadratic equation

$$
L_{\mathrm{t}}=L_{\mathrm{o}}\left(\mathrm{I}+a t+b t^{2}\right) \text {, }
$$

the probable error of $L_{t}$, and the instantaneous coefficients at every $50^{\circ}$ from 50 to $20^{\circ} \mathrm{C}$ are given in the following table:

TABLE 28.-Summary of Values of Series VI

\begin{tabular}{|c|c|c|c|c|c|c|c|c|c|c|c|c|c|c|}
\hline \multirow{2}{*}{\multicolumn{2}{|c|}{$\begin{array}{c}\text { Labora- } \\
\text { tory } \\
\text { number }\end{array}$}} & \multirow[b]{2}{*}{$\begin{array}{c}\text { Commercial } \\
\text { name }\end{array}$} & \multicolumn{3}{|c|}{ Composition } & \multirow{2}{*}{ 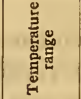 } & \multicolumn{2}{|c|}{ Coefficients } & \multirow{2}{*}{ 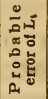 } & \multicolumn{5}{|c|}{ instantane ous coefficients $\times 10^{\circ}$} \\
\hline & & & 范 & 텸 & के & & $\stackrel{\circ}{\stackrel{\circ}{x}}$ & $\stackrel{0}{x}_{0}^{\circ}$ & & ڤึ้ & $\frac{18}{80}$ & $\begin{array}{l}\stackrel{\circ}{0}_{0} \\
\tan _{4}\end{array}$ & 总 & 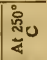 \\
\hline \multirow{5}{*}{ S409\{ } & \multirow{5}{*}{\multicolumn{2}{|c|}{$\int_{\text {bronze. }}$}} & P. ct. & P. ct. & P.ct. & $\begin{array}{c}{ }^{\circ} \mathrm{C} \\
+25-+302\end{array}$ & 16.89 & 0.00416 & $\times 10^{-6}$ & 17.31 & 17.72 & 18.14 & 18.55 & 18.97 \\
\hline & & & \multirow{2}{*}{95.40} & \multirow{3}{*}{4.25} & \multirow{2}{*}{0.37} & $21-302$ & 17.12 & .00348 & 1 & 17.47 & 17.82 & 18.16 & 18.51 & 18.86 \\
\hline & & & & & & $20-305$ & 16.77 & .00423 & 1 & 17.19 & 17.62 & 18.04 & 18.46 & 18.88 \\
\hline & & & & & & $26-299$ & 16.83 & .00452 & 2 & 17.28 & 17.73 & 18.19 & 18.64 & 19.09 \\
\hline & & & \multirow{4}{*}{94.86} & \multirow{3}{*}{4.88} & \multirow{4}{*}{.12} & $25-302$ & 16.92 & .00356 & 2 & 17.28 & 17.63 & 17.99 & 18.34 & 18.70 \\
\hline \multirow{3}{*}{ S406 } & B. & \multirow{3}{*}{ Chain bronze } & & & & $27-303$ & 16. 77 & .00415 & 2 & 17.18 & 17.60 & 18.02 & 18.43 & 18.84 \\
\hline & C. & & & & & $25-303$ & 16.91 & .00409 & 1 & 17.32 & 17.73 & 18.14 & 18.55 & 18.96 \\
\hline & D. & & & & & $24-302$ & 16. 78 & .00384 & 4 & 17.16 & 17.55 & 17.93 & 18.32 & 18.70 \\
\hline \multirow{4}{*}{ S407 } & A. & \multirow{3}{*}{ Gun metal. . } & \multirow{3}{*}{92.04} & \multirow{3}{*}{7.67} & \multirow{3}{*}{.11} & $28-303$ & 17.12 & .00347 & 2 & 17.47 & 17.81 & 18.16 & 18.51 & 18.86 \\
\hline & B. & & & & & $28-305$ & 17.02 & .00381 & 4 & 17.40 & 17.78 & 18.16 & 18.54 & 18.92 \\
\hline & C. & & & & & $25-305$ & 17.16 & .00315 & 3 & 17.48 & 17.79 & 18.10 & 18.42 & 18.74 \\
\hline & D. & \multirow{5}{*}{ Gun metal. . } & \multirow{5}{*}{89.69} & \multirow{5}{*}{10.14} & \multirow{5}{*}{.00} & $23-299$ & 17.15 & .00336 & 1 & 17.49 & 17.82 & 18.16 & 18.49 & 18.83 \\
\hline \multirow{4}{*}{ S 408} & A. & & & & & $25-305$ & 16.99 & .00520 & 2 & 17.51 & 18.03 & 18.55 & 19.07 & 19.59 \\
\hline & B. & & & & & $26-303$ & 16.98 & .00440 & 2 & 17.42 & 17.86 & 18.30 & 18.74 & 19.18 \\
\hline & c. & & & & & $22-302$ & 17.33 & .00366 & 3 & 17.70 & 18.06 & 18.43 & 18.79 & 19.16 \\
\hline & D. & & & & & $28-299$ & 17.17 & .00479 & 2 & 17.65 & 18.13 & 18.61 & 19.09 & 19.56 \\
\hline
\end{tabular}

a Results on second heating.

The derived equations giving the relation between the instantaneous coefficient at every $50^{\circ}$ from 50 to $250^{\circ} \mathrm{C}$ and the copper content of these castings are as follows:

$$
\begin{aligned}
\text { OUTSIDE SECTIONS } \\
a_{50}=\left(+37.776-0.37966 \mathrm{Cu}+0.0017247 \mathrm{Cu}^{2} \pm 0.05\right) \mathrm{IO}^{-6} \\
a_{100}=\left(+41.783-.44669 \mathrm{Cu}+.0020292 \mathrm{Cu}^{2} \pm .06\right) \mathrm{IO}^{-8} \\
a_{150}=\left(-52.360+\mathrm{I} .60752 \mathrm{Cu}-.0091195 \mathrm{Cu}^{2} \pm .13\right) \mathrm{IO}^{-6} \\
a_{200}=\left(+50.397-.59178 \mathrm{Cu}+.0026883 \mathrm{Cu}^{2} \pm .14\right) \mathrm{IO}^{-6} \\
a_{250}=\left(-92.532+2.51757 \mathrm{Cu}-.0141623 \mathrm{Cu}^{2} \pm .23\right) \mathrm{IO}^{-6} \\
\text { INSIDE SECTIONS } \\
a_{50}=\left(+33.580-0.30147 \mathrm{Cu}+0.0013695 \mathrm{Cu}^{2} \pm 0.10\right) \mathrm{IO}^{-6} \\
a_{100}=\left(-\mathrm{I} 6.009+.77588 \mathrm{Cu}-.004433 \mathrm{Cu}^{2} \pm .08\right) \mathrm{IO}^{-6} \\
a_{150}=\left(-\mathrm{I} 5.622+.77588 \mathrm{Cu}-.004433 \mathrm{Cu}^{2} \pm .07\right) \mathrm{IO}^{-6} \\
a_{200}=\left(-\mathrm{I} 5.835+.78703 \mathrm{Cu}-.0044838 \mathrm{Cu}^{2} \pm .08\right) \mathrm{IO}^{-6} \\
a_{250}=\left(-\mathrm{II} 4.19 \mathrm{I}+2.91918 \mathrm{Cu}-.0159864 \mathrm{Cu}^{2} \pm .13\right) \mathrm{IO}^{-6}
\end{aligned}
$$


Again, it should be remembered that, as in previous series, these equations are not to be applied beyond the proper limits. For this series of copper-tin castings the limits are from 89.7 to 95.4 per cent copper.

The instantaneous coefficients of the outside sections at every $50^{\circ}$ from 50 to $250^{\circ} \mathrm{C}$, and the coefficients of the inside sections are shown graphically in Figs. 34 and 35, respectively.

The experimental values of the instantaneous coefficients at 250 and $200^{\circ} \mathrm{C}$ of the outside sections deviate appreciably from the computed values, especially for the casting containing about. 92 per cent copper. The deviations of the experimental coefficients

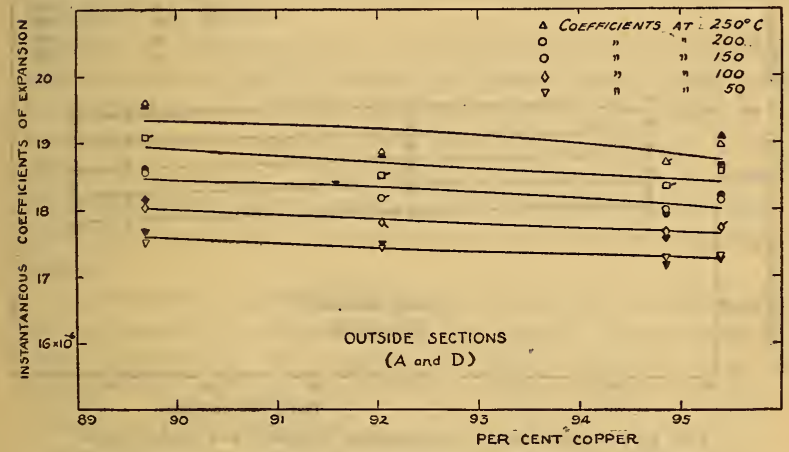

FIG. 34.-Relations between instantaneous coefficients and copper content

The light symbols represent the observed values of sections $A$, and the dark symbols those of sections $D$. Where the values of two sections $(A$ and $D)$ are equal or nearly so, a tagged symbol was employed as shown

of the inside sections are generally smaller than those of the outside sections.

The experimental values of the coefficients of sections $A$ agree with the corresponding values of sections $D$ much better than do the coefficients of sections $B$ with $C$.

The coefficients of the outside sections at 50 and $100^{\circ} \mathrm{C}$ are nearly the same as the corresponding values of the inside sections at these temperatures. However, at higher temperatures there are appreciable differences. The values of the coefficients of the inside and outside sections containing about 94 or 95 per cent copper are approximately the same, but for specimens with less copper the 
differences increase with a decrease in the copper content of the castings.

Most of the cooling curves of the specimens of Series VI lie below

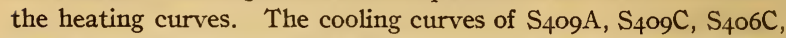
$\mathrm{S}_{408 \mathrm{~A}}$, and $\mathrm{S}_{408 \mathrm{D}}$ lie above the heating curves. The maximum variation between these curves did not exceed \pm 60 millionths per unit length except for $\mathrm{S}_{407} \mathrm{~A}$ (at $190^{\circ} \mathrm{C}$ deviation was -180 millionths per unit length). After cooling to room temperature, the average variation in length from the original lengths was \pm 0.002 per cent.

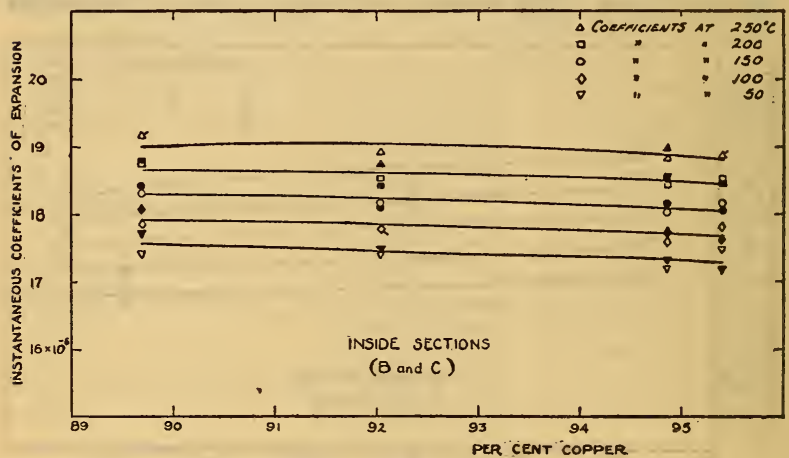

FIG. 35.-Relations between instantaneous coefficients and copper content

The light symbols represent the observed values of sections $B$, and the dark symbols those of sections $C$. Where the values of two sections ( $B$ and $C$ ) are equal, or nearly so, a tagged symbol was employed as shown

\section{SERIES VII: ALUMINUM BRONZE}

This series contains two aluminum bronzes, $\mathrm{S}_{347} \mathrm{H}$ and $\mathrm{S}_{347} \mathrm{HD}$, having the following composition: Copper, 92.17 per cent; aluminum, 7.34 per cent; zinc, 0.40 per cent; silicon, 0.09 per cent; and a trace of nickel. The first specimen was hot-rolled from 3 inches round to one-half inch diameter, and the second sample was hotrolled from 3 inches round to one-half inch diameter, cold-drawn to 0.256 inch, annealed, and finished hard at one-fourth inch.

The expansion equations derived for these bronzes are

$$
\begin{aligned}
& \mathrm{S}_{347} \mathrm{H} \quad L_{\mathrm{t}}=L_{0}\left[\mathrm{I}+\left(\mathrm{r}_{5} .57 t+0.00805 t^{2} \pm 7\right) 10^{-6}\right] . \\
& \mathrm{S}_{347} \mathrm{HD} \quad L_{\mathrm{t}}=L_{\mathrm{o}}\left[\mathrm{I}+\left(\mathrm{r} 5.79 t+.00645 t^{2} \pm 12\right) 10^{-6}\right] \text {. }
\end{aligned}
$$


These equations are applicable between 21 and $319^{\circ}$, and from I 9 to $3 \mathrm{Or}^{\circ} \mathrm{C}$, respectively.

The instantaneous coefficients at every $50^{\circ}$ from 50 to $250^{\circ} \mathrm{C}$ are given in Table $29^{\circ}$

TABLE 29

\begin{tabular}{|c|c|c|c|c|c|}
\hline \multirow{2}{*}{ Laboratory number } & \multicolumn{5}{|c|}{ Instantaneous coefficients $\times 10^{6}$} \\
\hline & At $50^{\circ} \mathrm{C}$ & At $100^{\circ} \mathrm{C}$ & At $150^{\circ} \mathrm{C}$ & At $200^{\circ} \mathrm{C}$ & At $250^{\circ} \mathrm{C}$ \\
\hline \$347H............ & 16.37 & 17.18 & 17.99 & 18.79 & 19.60 \\
\hline 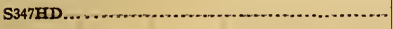 & 16.44 & 17.08 & 17.72 & -18.37 & 19.02 \\
\hline
\end{tabular}

These alloys are the only ones investigated that contain aluminum and silicon.

Below $75^{\circ}$ (approximately) the instantaneous coefficients of the drawn sample are slightly larger than those of the hot-rolled, but for higher temperatures the coefficients are less, the difference in the coefficients increasing with temperature. At $250^{\circ} \mathrm{C}$ this difference is $0.58 \times 10^{-6}$. Annealing and drawing of the hot-rolled aluminum-copper alloy caused a greater diminution in the coefficients than was observed in the case of the hot-rolled electrolytic copper.

The maximum variation between the heating and cooling curves did not exceed \pm 70 millionths per unit length. After cooling to room temperature, the variations in lengths from the original lengths of $\mathrm{S}_{347} \mathrm{H}$ and $\mathrm{S}_{347} \mathrm{HD}$ were found to be -0.002 and +0.002 per cent, respectively.

The cold-drawn aluminum-copper specimen was reheatea from 20 to $302^{\circ} \mathrm{C}$. The equation

$$
L_{\mathrm{t}}=L_{\mathrm{o}}\left[\mathrm{I}+\left(\mathrm{r} 6.17 t+0.00523 t^{2} \pm 10\right) \mathrm{10}^{-6}\right]
$$

was found to fit the observations on the second heating. The last term of the parentheses represents the probable error of $L_{t}$ at any temperature within the range. The following comparison gives the instantaneous coefficients on the first and second heatings:

TABLE 30

\begin{tabular}{|c|c|c|c|c|c|}
\hline \multirow{2}{*}{ 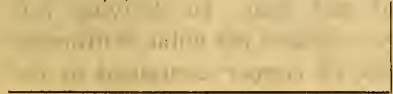 } & \multicolumn{5}{|c|}{ Instantaneous coefflcients $\times 10^{\circ}$} \\
\hline & At $50^{\circ} \mathrm{C}$ & At $100^{\circ} \mathrm{C}$ & At $150^{\circ} \mathrm{C}$ & At $200^{\circ} \mathrm{C}$ & At $250^{\circ} \mathrm{C}$ \\
\hline 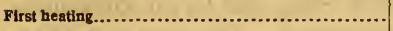 & 16.44 & 17.08 & 17.72 & 18.37 & 19.02 \\
\hline 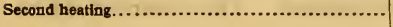 & 16.69 & 17.22 & 17.74 & 18.26 & 18.78 \\
\hline
\end{tabular}

$20183-21-4$ 
At about $150^{\circ} \mathrm{C}$ the coefficients are equal. Below this temperature the coefficients on the second heating are greater than those of the first, but at higher temperatures the reverse is true. The maximum difference in the coefficients is $0.25 \times 10^{-6}$.

\section{RELATION OF DENSITY TO THERMAL EXPANSION}

In order to find a possible relation between thermal expansion and density, it was decided to examine the densities of a number of samples of Series II and III.

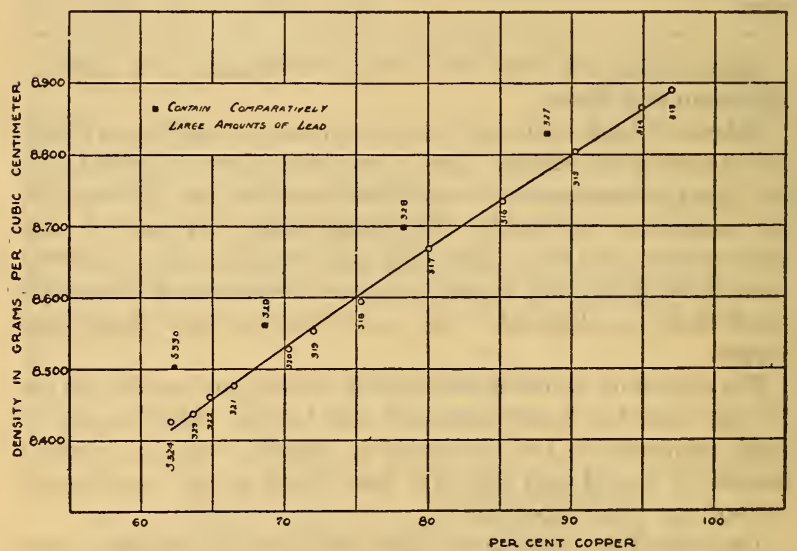

FIG. 36.-Relation between density and copper content of cold-rolled copper-zinc alloys

The densities of 16 samples of 2-inch cold-rolled copper-zinc alloys of Series II were determined ${ }^{13}$ after the thermal expansion tests, and are plotted in Fig. 36. The empirical equation

$$
D_{15}=7.3605+0.019147 \mathrm{Cu}-0.00003509 \mathrm{Cu}^{2}
$$

gives the density of a cold-rolled copper-zinc alloy containing from 62. I to 97 per cent copper, and the remainder zinc with comparatively small percentages of lead and iron. In deriving this equation, where $D_{15}$ is the density in grams per cubic centimeter at $15^{\circ} \mathrm{C}$ and $\mathrm{Cu}$ is the percentage of copper contained in the alloy the four specimens $\left(\mathrm{S}_{32} 7, \mathrm{~S}_{32} 8, \mathrm{~S}_{329}\right.$, and $\left.\mathrm{S}_{33} \mathrm{O}\right)$, containing appreciable amounts of lead, were ignored. The observed densi-

${ }^{20} \mathrm{By}$ E. L. Peffer of this Bureau. 
ties of these four alloys are considerably greater than those computed from the formula, on account of the comparatively large density of the lead constituent. The following table shows a comparison between the observed and computed densities:

TABLE 31.-Densities of Cold-Rolled Copper-Zinc Alloys

\begin{tabular}{|c|c|c|c|c|c|c|c|}
\hline \multirow{2}{*}{ Laboratory number } & \multicolumn{4}{|c|}{ Composition } & \multicolumn{2}{|c|}{ Density } & \multirow{2}{*}{$\begin{array}{c}\text { Resld- } \\
\text { uals }\end{array}$} \\
\hline & Copper & Zinc & Lead & Iron & Observed & $\begin{array}{l}\text { Com- } \\
\text { puted }\end{array}$ & \\
\hline & Per cent & Per cent & Per cent & Per cent & & & \\
\hline s313................................ & 97.00 & 2.97 & 0.01 & 0.02 & 8.890 & 8.888 & 0.002 \\
\hline S314... & 94.87 & 5.11 & .01 & .01 & 8.866 & 8.861 & .005 \\
\hline S315................................... & 90.26 & 9.70 & .01 & .03 & 8.804 & 8.803 & .001 \\
\hline s316............................. & 85.21 & 14.76 & .01 & .02 & 8.734 & 8.737 & -.003 \\
\hline s317.................... & 80.02 & 19.89 & .05 & .03 & 8.667 & 8.668 & -.001 \\
\hline \$ $318, \ldots \ldots \ldots \ldots \ldots \ldots \ldots \ldots \ldots \ldots \ldots \ldots$ & 75.31 & 24.64 & .02 & .03 & 8.594 & 8.604 & -.010 \\
\hline s319..................................... & 72.02 & 27.95 & .01 & .02 & 8.553 & 8.558 & -.005 \\
\hline S320................... & 70.28 & 29.66 & .03 & .03 & 8.528 & 8.533 & -.005 \\
\hline s321........................... & 66.50 & 33.43 & .04 & .03 & 8.476 & 8.479 & -.003 \\
\hline S322................................ & 64.81 & 34.92 & .24 & .03 & 8.460 & 8.454 & +.006 \\
\hline S323............................... & 63.63 & 36.17 & .17 & .03 & 8.437 & 8.437 & .000 \\
\hline s324................................ & 62.10 & 37.71 & .17 & .02 & 8.426 & 8.414 & .012 \\
\hline s327........................... & 88.30 & 10.00 & 1.68 & .02 & 8.830 & (8.778) & $(.052)$ \\
\hline 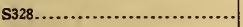 & 78.28 & 20.01 & 1.68 & .03 & 8.698 & $(8.644)$ & $(.054)$ \\
\hline s329............................... & 68.65 & 29.67 & 1.65 & .03 & 8.562 & $(8.510)$ & $(.052)$ \\
\hline s330............................... & 62.33 & 35.04 & 2.57 & .06 & 8.503 & $(8.418)$ & $(.085)$ \\
\hline
\end{tabular}

The probable error above is \pm 0.004 .

From the relations existing between expansion and copper content and between density and copper content, it is possible to predict the expansion of a cold-rolled copper-zinc alloy from a density determination. By substituting the observed density in the previous equation the copper content may be found. The instantaneous coefficient of expansion-for example, at $100^{\circ} \mathrm{C}$ may be determined by substituting this value of the copper content in the equation (p. I 13 )

$$
a_{100}=\left(24.673-0.08794 \mathrm{Cu}+0.0001252 \mathrm{Cu}^{2} \pm 0.05\right) \mathrm{IO}^{-6} \text {. }
$$

The densities (in grams per milliliter at $18^{\circ} \mathrm{C}$ ) of the sections of four castings of Series III were also determined. The results were found to be as follows: 
TABLE 32.-Densities of Sections of Some Copper-Zinc Castings

\begin{tabular}{|c|c|c|c|c|c|}
\hline \multirow{3}{*}{ Laboratory number } & \multirow{3}{*}{ Copper } & \multicolumn{4}{|c|}{ Density } \\
\hline & & \multicolumn{2}{|c|}{ Outside sections } & \multicolumn{2}{|c|}{ Inside sections } \\
\hline & & $\mathbf{A}$ & D & $\mathbf{B}$ & C \\
\hline S317.... & $\begin{array}{r}\text { Per cent } \\
80.02\end{array}$ & 8.626 & 8.612 & 8.612 & 8.480 \\
\hline S318................ & 75.31 & 8.571 & 8.569 & 8.479 & 8.486 \\
\hline \$321........ & 66.50 & 8.442 & 8.443 & 8.434 & 8.415 \\
\hline 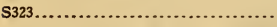 & 63.63 & 8.410 & 8.413 & 8.392 & 8.419 \\
\hline
\end{tabular}

On cutting through the surfaces of $\mathrm{S}_{31} \mathrm{C}, \mathrm{S}_{32} \mathrm{C}$, and $\mathrm{S}_{32} \mathrm{~B}$, inclosed pores and cavities were found to exist. This accounts for the comparatively low values of the densities of these sections.

In general the density increases with an increase in the copper content of the casting, but no definite relation could be found for this series of castings. The densities of the cold-rolled alloys (Series II) of corresponding composition are greater than the densities of these castings. In this case cold-rolling evidently closed the pores and cavities in the casting and produced a more compact alloy.

\section{COMPARISON OF RESULTS}

A discussion of each particular series of samples has already been given at the close of each series. In this section, however, it is proposed to compare the various series and indicate the more obvious relations or differences.

The curves of instantaneous coefficients of Series II and III were plotted on the same scale and are shown in Fig. 37. Since the curves for the inside sections are slightly below those for the outside sections, they were omitted in order to avoid confusion. An examination of this figure yields important facts, showing the differences produced in copper-zinc castings (Series III) if cold-rolled, cold-drawn, annealed, and finished hard (Series II).

In the case of alloys containing 62 per cent copper, it was found that the coefficients did not materially differ in cast and cold-rolled specimens, and for alloys containing 90 per cent copper a similar agreement existed. For alloys with a copper content from about 62 to 90 per cent, the cold-rolled alloys give greater coefficients than the castings, and for alloys containing more than 90 per cent copper the reverse is true. In the former case, the maximum 
deviations occur at about 75 per cent copper (except at $250^{\circ} \mathrm{C}$ ), and in the latter case at 97 per cent copper; that is, the coefficients of expansion of castings containing 75 or 97 per cent copper, if cold-rolled, cold-drawn, annealed, and finished hard, change more than the coefficients of castings containing other percentages of copper between 62 and 97 per cent. The maximum deviations between the coefficients of Series II and those of Series III (over the range 62 to 97 per cent copper) occur in alloys with a copper content of 97 per cent (except at $250^{\circ} \mathrm{C}$ ). The differences between the computed coefficients of a casting (Series III, outside

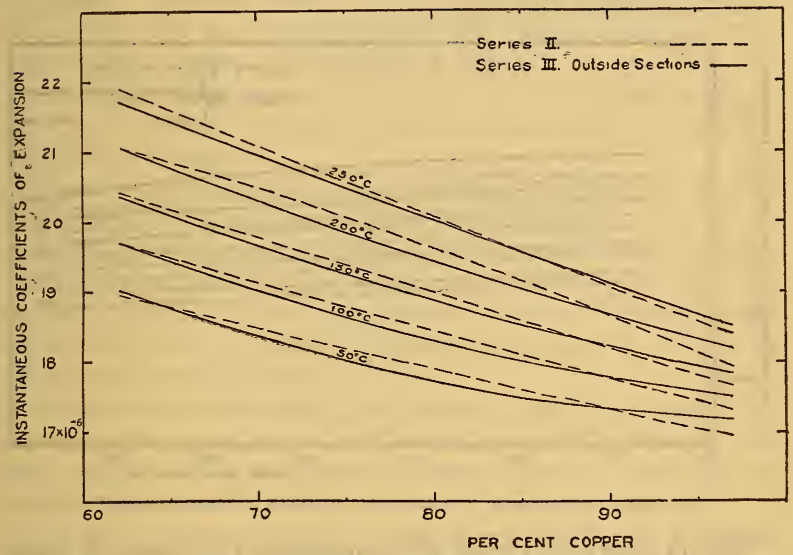

FIG. 37.-Comparison of instantaneous coefficients of Series II and III

sections) containing 97 per cent copper, and of a cold-rolled copperzinc alloy (Series II) of the same composition, are shown in the following comparison:

TABLE 33

\begin{tabular}{|c|c|c|c|c|}
\hline 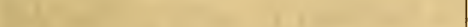 & \multicolumn{4}{|c|}{ Instantaneous coefficients $\times 10^{6}$} \\
\hline 17 & At $50^{\circ} \mathrm{C}$ & At $100^{\circ} \mathrm{C}$ & At $150^{\circ} \mathrm{C}$ & At $200^{\circ} \mathrm{C}$ \\
\hline Series III (outside sections)........ & 17. 18 & 17.51 & 17.84 & 18.20 \\
\hline Serles II.......................... & 16.95 & 17.32 & 17.67 & 17.93 \\
\hline 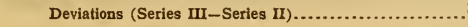 & .23 & .19 & .17 & .27 \\
\hline
\end{tabular}


The corresponding deviations between the two series for alloys containing 75 per cent copper are given in Table 34 .

TABLE 34

\begin{tabular}{|c|c|c|c|c|}
\hline & \multicolumn{4}{|c|}{ Instantaneous coefficients $\times 10^{\circ}$} \\
\hline 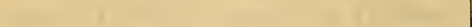 & $50^{\circ} \mathrm{C}$ & $100^{\circ} \mathrm{C}$ & $150^{\circ} \mathrm{C}$ & $200^{\circ} \mathrm{C}$ \\
\hline Series III (outside sections)......... & 18.01 & 18.64 & 19.26 & 19.86 \\
\hline 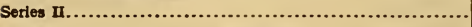 & 18.19 & 18. 78 & 19.39 & 20.07 \\
\hline Devlations (Series III-Series II).................... & -.18 & -.14 & -.13 & -.21 \\
\hline
\end{tabular}

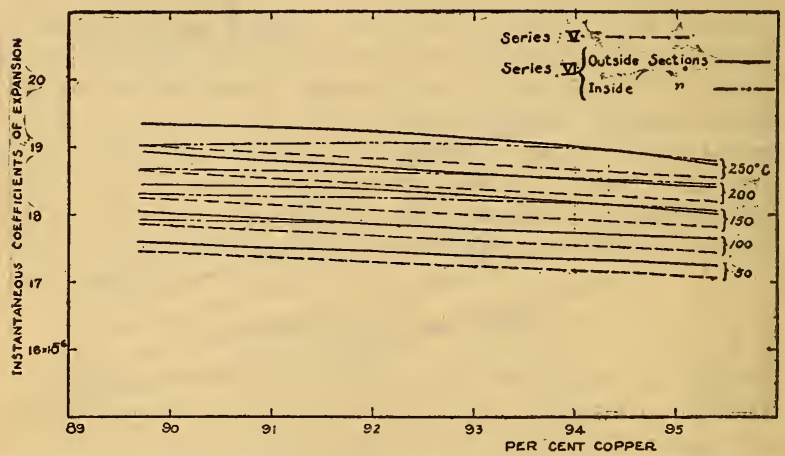

FIG. 38.-Comparison of instantaneous coefficients of Series $V$ and VI

Fig. 38 shows the curves of instantaneous coefficients of Series $\mathrm{V}$ and VI. The curve for the instantaneous coefficients of the inside sections at $50^{\circ}$ was omitted to avoid confusion, for it is very close to the corresponding curve for the outside sections.

Some of the essential differences produced in copper-tin castings (Series VI), if cold-rolled, cold-drawn, annealed, and finished hard (Series V), are as follows:

I. The coefficients of the cold-rolled tin alloys are less than those of the castings; that is, cold rolling and drawing cause a diminution in the values of the instantaneous coefficients. In general, the difference between the instantaneous coefficients of the outside sections and the cold-rolled specimens increases as the temperature increases. 
2. The instantaneous coefficients of the inside sections and the cold-rolled alloys, both containing 90 per cent copper, are approximately equal. For specimens containing from 90 to 95 per cent copper, the difference between these coefficients generally increases with increase of copper content.

The following five figures (Figs. 39 to 43 , inclusive) give a general graphical résumé of the instantaneous coefficients of the seven series of alloys investigated.

The curves derived from the observations of Series II, III, V, and VI are shown, except several which are omitted to avoid confusion. The curves of the inside sections of Series III are not shown, for they nearly coincide with the corresponding curves of the outside sections. The curve of Series V at $150^{\circ}$ and the curve of the inside sections of Series VI at $50^{\circ}$ were also omitted, for they are close to those of Series II and Series VI (outside sections), respectively.

There do not seem to be great differences between the curves of Series II and V and Series III and V, respectively. The maximum deviation $\left(0.12 \times 10^{-6}\right)$ between the curves of instantaneous coefficients of Series II and V occurs at $200^{\circ} \mathrm{C}(95.4$ per cent copper), and the greatest difference $\left(0.12 \times 10^{-6}\right)$ between the curves of Series III (outside sections) and Series V, at $250^{\circ} \mathrm{C}$ (about 95 per cent copper).

For the curves of Series II and Series VI (outside sections) the maximum variation $\left(0.36 \times 10^{-8}\right)$ occurs at $250^{\circ} \mathrm{C}$ (about 93 per cent copper). The differences between Series III and VI are considerably less.

At $50^{\circ}$ the instantaneous coefficients of $\mathrm{S}_{347} \mathrm{H}$ and $\mathrm{S}_{347} \mathrm{HD}$, which contain about 7 per cent aluminum, are considerably below the values of Series II, III, V, and VI. With increasing temperature, to about $200^{\circ} \mathrm{C}$, the values of the instantaneous coefficients approach those of the alloys of these series containing the same amount of copper. At $250^{\circ}$ the instantaneous coefficient of $\mathrm{S}_{347} \mathrm{H}$ is greater than any copper alloy of these series containing about 92 per cent copper. The aluminum evidently has a great effect on the rate of expansion.

At $50^{\circ} \mathrm{C}$ the values of the instantaneous coefficients of $\mathrm{S}_{34} \mathrm{OH}$ and $\mathrm{S}_{34} \mathrm{OHD}$ (99.97 per cent copper) lie slightly below the extrapolated curve of Series II. As the temperature increases, these values gradually approach this curve, and then with further increase in temperature there is a tendency to depart more and more above this curve. The values of the coefficients of the 


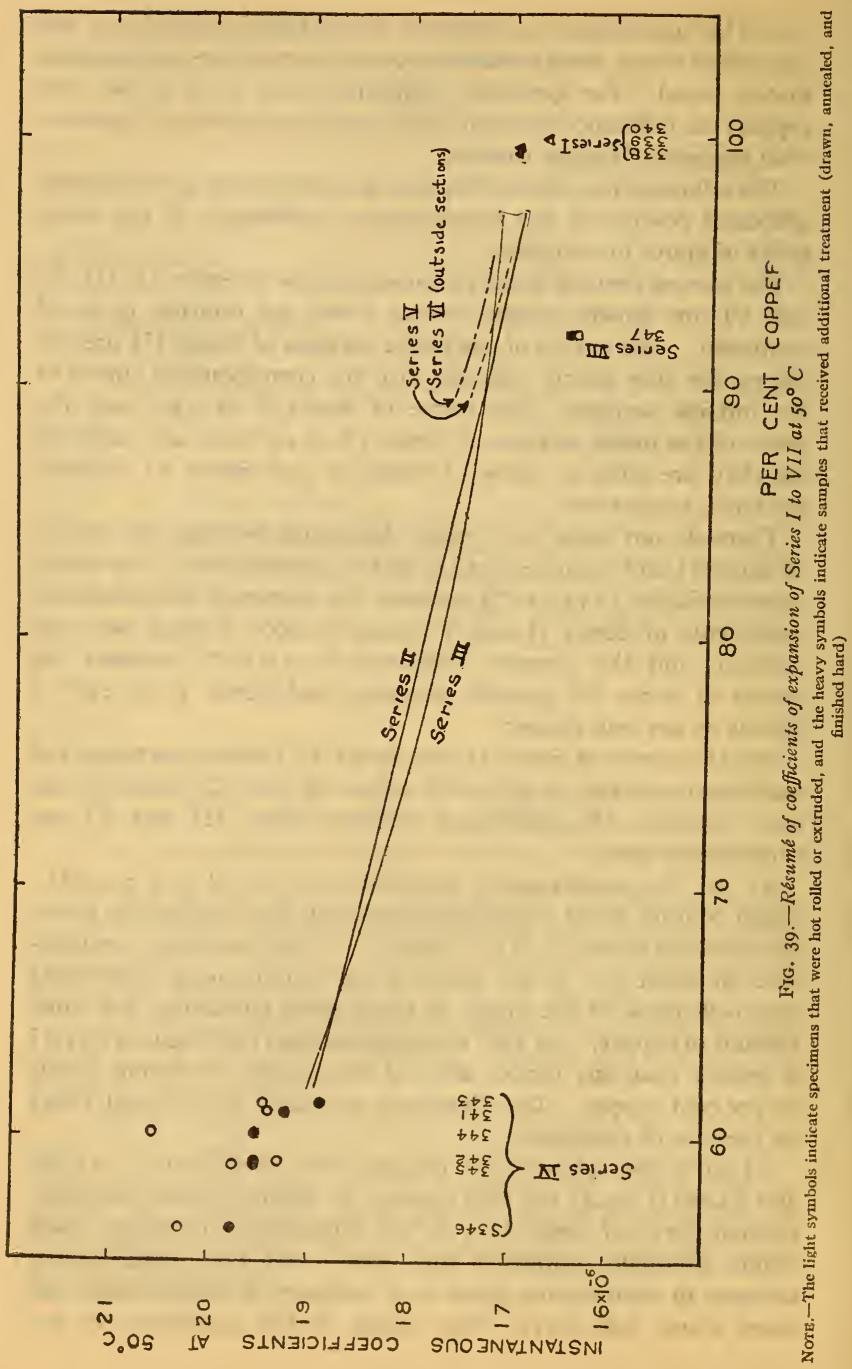




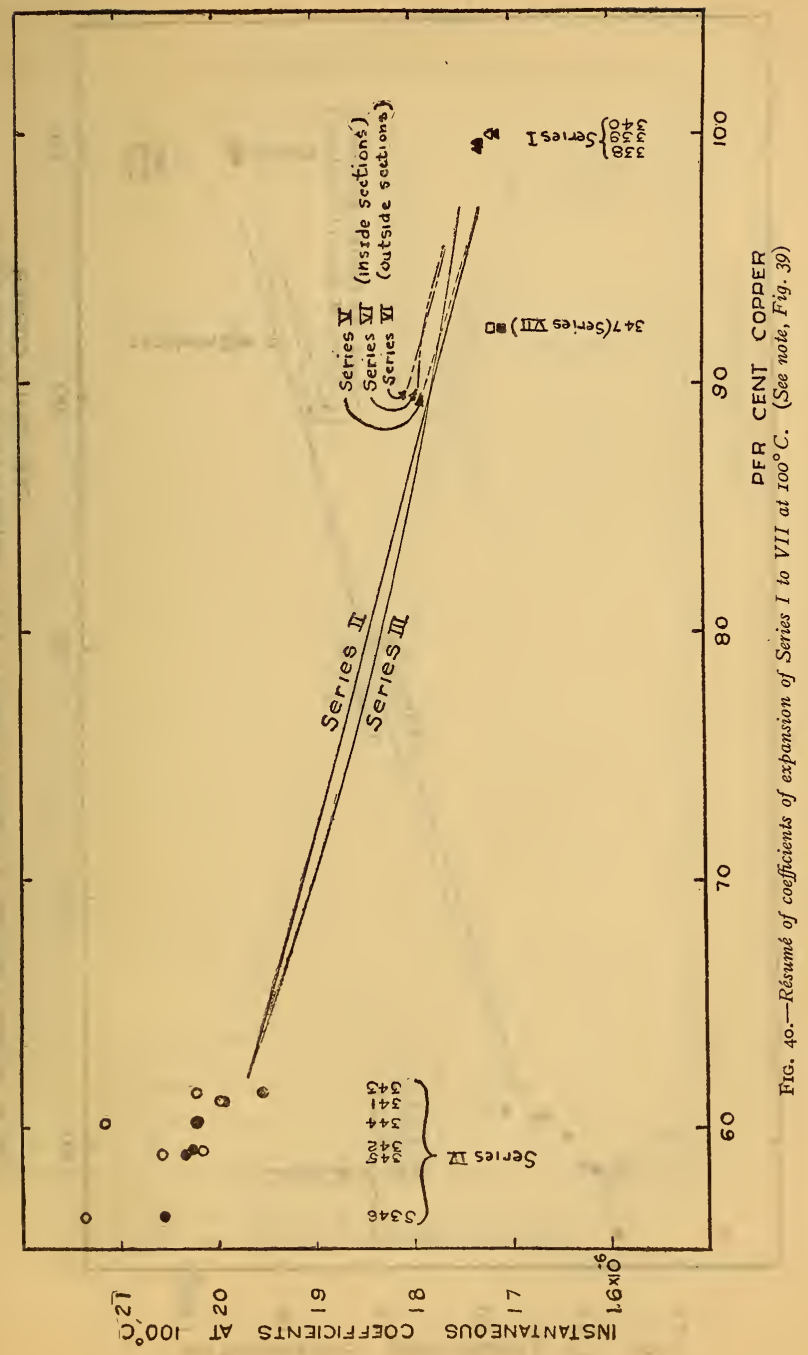




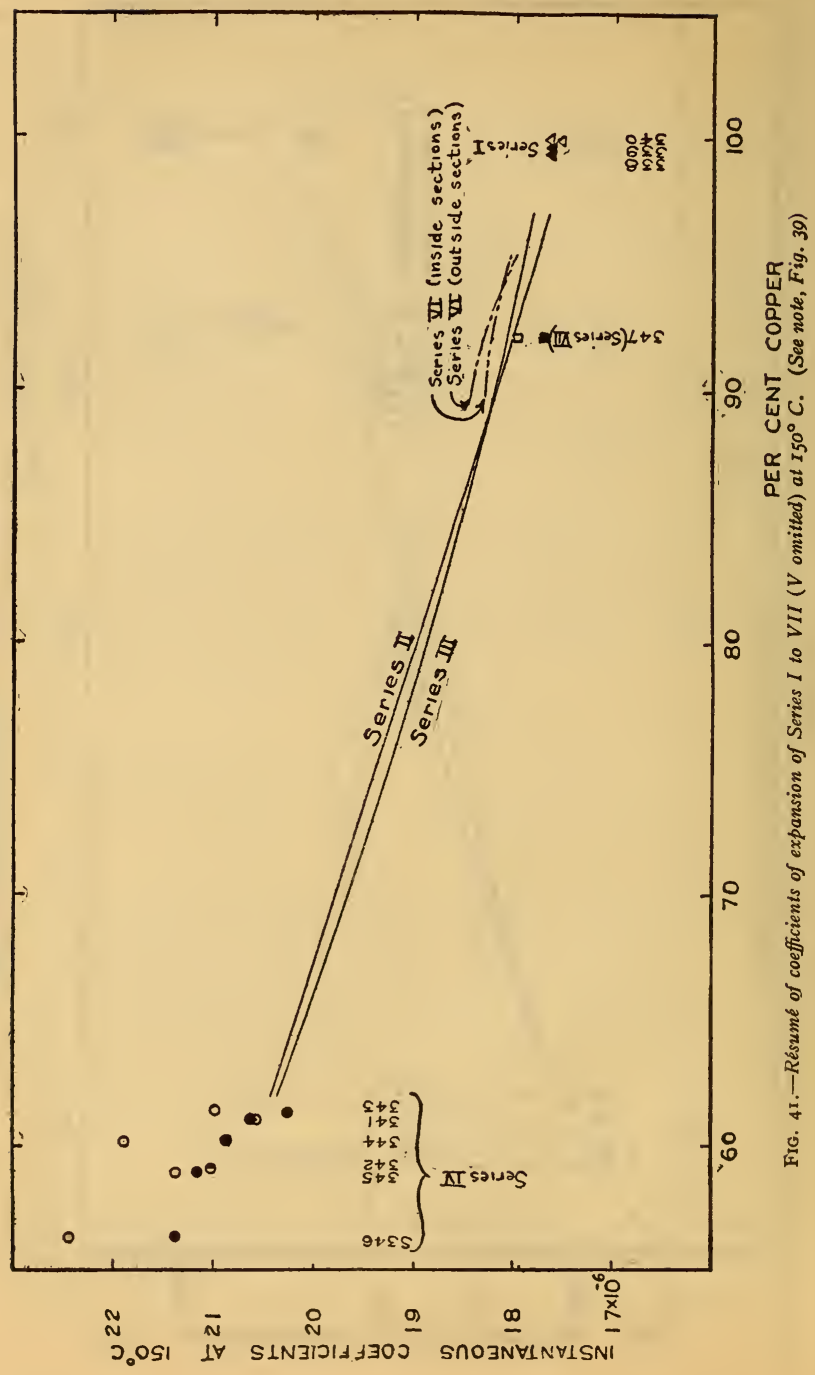




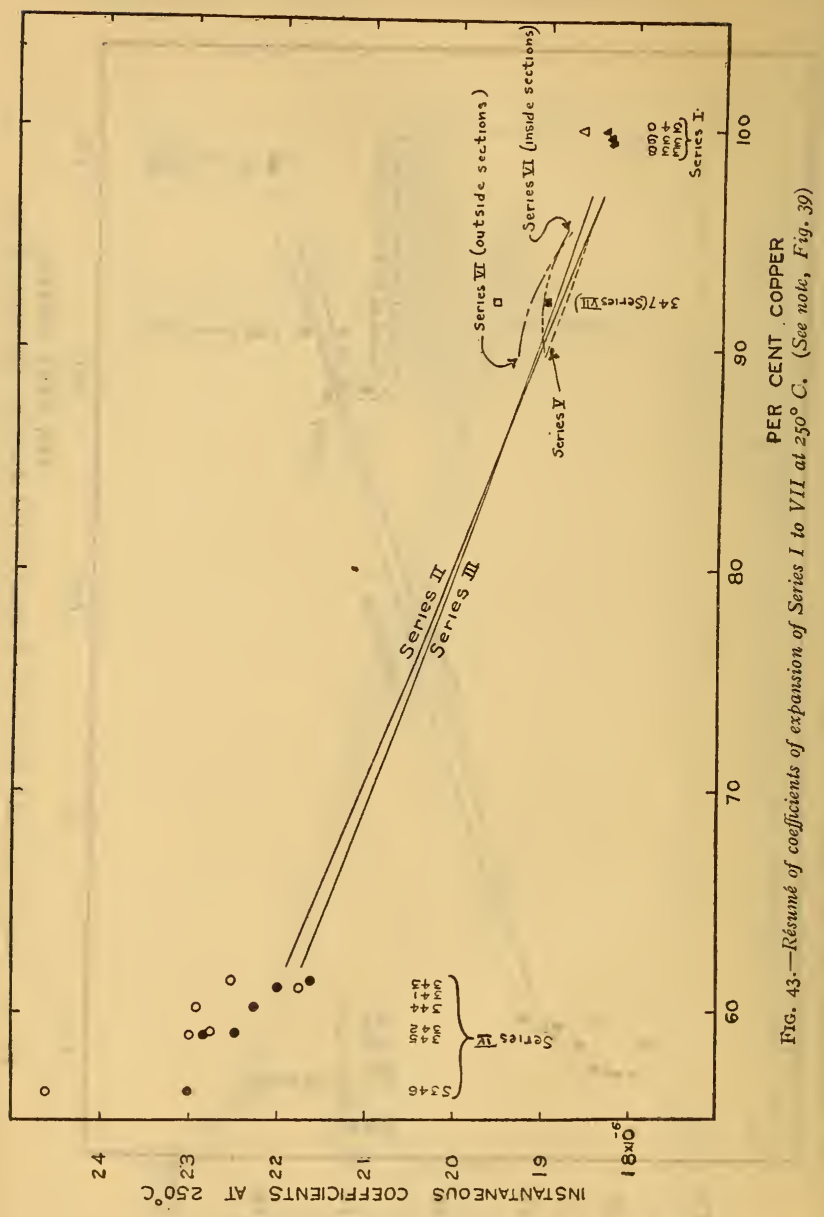


nickeliferous and arsenical copper lie near the extrapolated curves of Series III and above those of Series II.

The instantaneous coefficients of the hot-rolled and extruded alloys containing from 56.4 to 61.4 per cent copper, are scattered more or less, on account of the comparatively large number of varying factors. In general, these values lie above the extrapolated curves of Series II and III.

\section{SUMMARY AND CONCLUSIONS}

In the present investigation data on the thermal expansion of I 28 samples of copper and its important industrial alloys of various compositions, heat treatments, mechanical treatments, etc., are presented. The alloys contained from 56 to roo per cent copper and were prepared in a number of ways-cast, cast and cold-rolled, extruded, extruded and cold worked, hot-rolled, and hot-rolled and cold worked. Most of the samples were examined from room temperature to about $300^{\circ} \mathrm{C}$. (Several specimens were cooled to $-50^{\circ} \mathrm{C}$ and then heated to $+300^{\circ} \mathrm{C}$.)

Practically all available information on the thermal expansion of copper and its alloys is briefly reviewed.

A description of the apparatus and the preparation of the samples, etc., are given.

Definite mathematical relations were found to exist between the instantaneous coefficients of expansion and the copper content of most of the alloys investigated. (See Series II, III, V, VI.) In general, the coefficient of expansion increases with a decrease in the copper content. The addition of lead or tin has a decided effect on the coefficient; the former element generally decreases, and the latter increases, the coefficient.

SERIES II AND III (COPPER-ZINC ALLOYS).-In the case of alloys containing 62 per cent copper, it was found that the coefficients did not materially differ in cast or cold-rolled specimens, and for alloys containing 90 per cent copper a similar agreement existed. For alloys with a copper content from about 62 to 90 per cent, the cold-rolled alloys have greater coefficients than the castings, and for alloys containing more than 90 per cent copper the reverse is true. The coefficients of the inside sections of the castings are generally slightly less than those of the outside sections. A relation exists between the density and thermal expansion of the cold-rolled copper-zinc alloys of Series II.

SERIES V ANd VI (COPPER-TIN AlLOYS).-The coefficients of the cold-rolled tin alloys are less than those of the castings. Cold- 
rolling and drawing therefore cause a diminution in the values of the coefficients.

SERIES I, IV, ANd VII (Hot-Rolled ANd ExTruded SPECIMENS).-Owing to the large number of varying elements in the hot-rolled and extruded samples, it was impossible to determine the exact effect of each constituent element. In general, however, the coefficients are greater than the extrapolated values obtained from the quadratic equations of Series II and III.

The differences between the various series of samples are discussed in the preceding section and presented graphically in Figs. 39 to 43 .

The appendix gives average coefficients of expansion of all the samples investigated.

Acknowledgement is due to L. A. Fischer, W. H. Souder, and H. S. Rawdon, Bureau of Standards, for valuable suggestions to the author during this investigation. R. L. Coleman, jr., and J. O. Eisinger, Bureau of Standards, aided in making the tests, computations, drawings, etc.

WASHINGTON, October 9, 1920. 


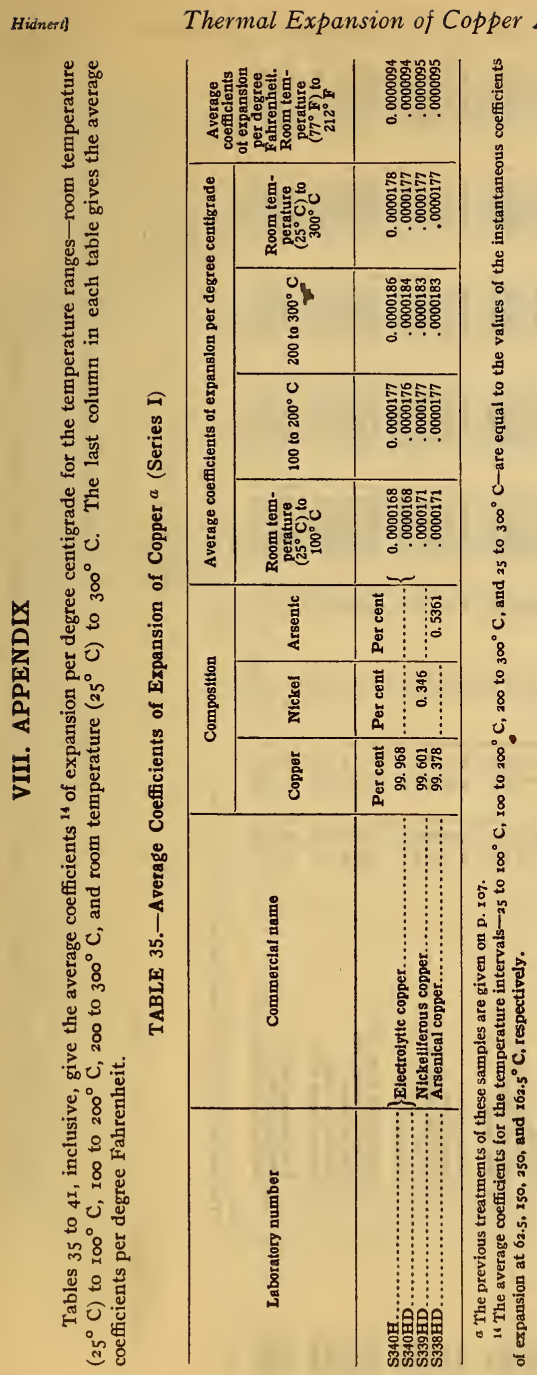




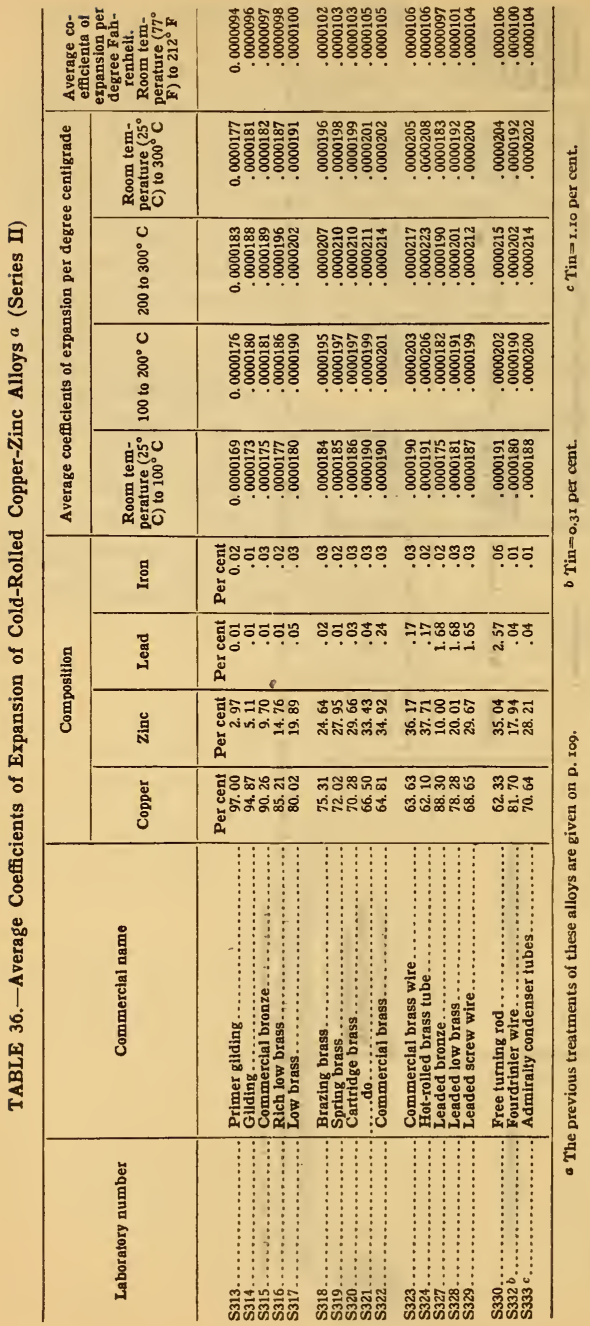


Hidneri] Thermal Expansion of Copper Alloys

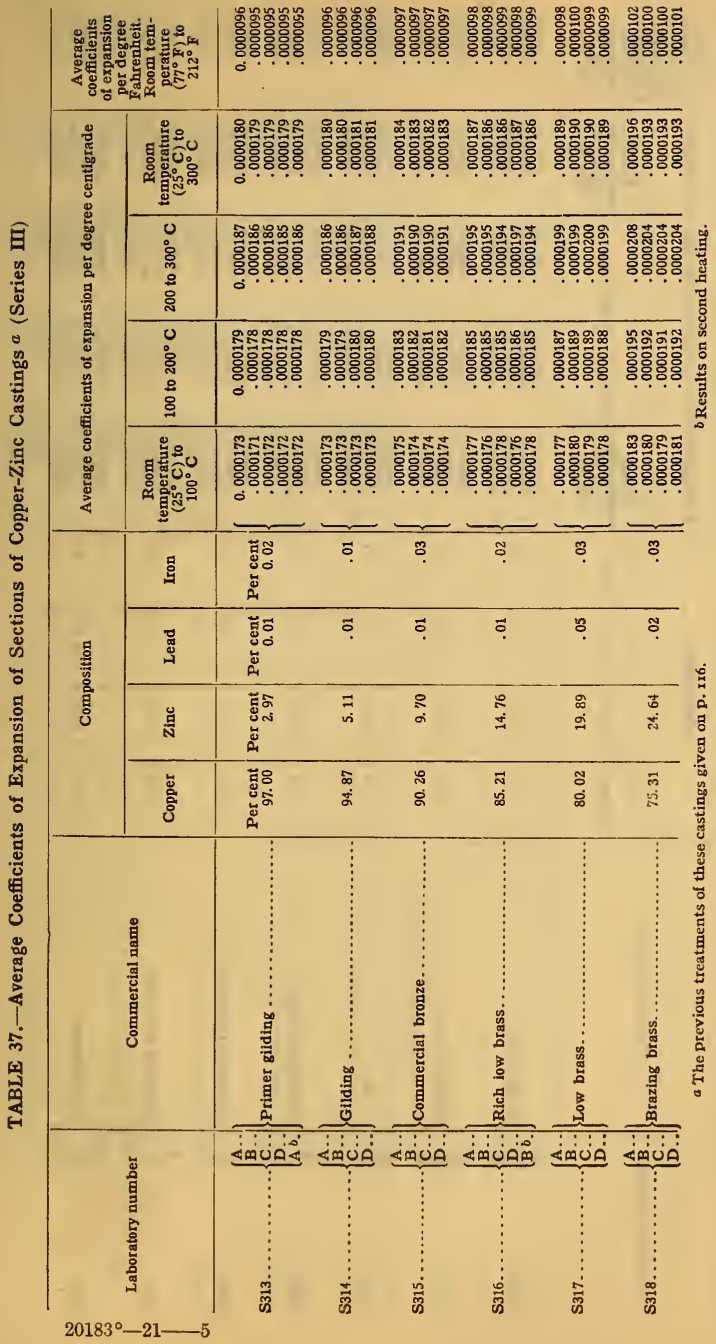




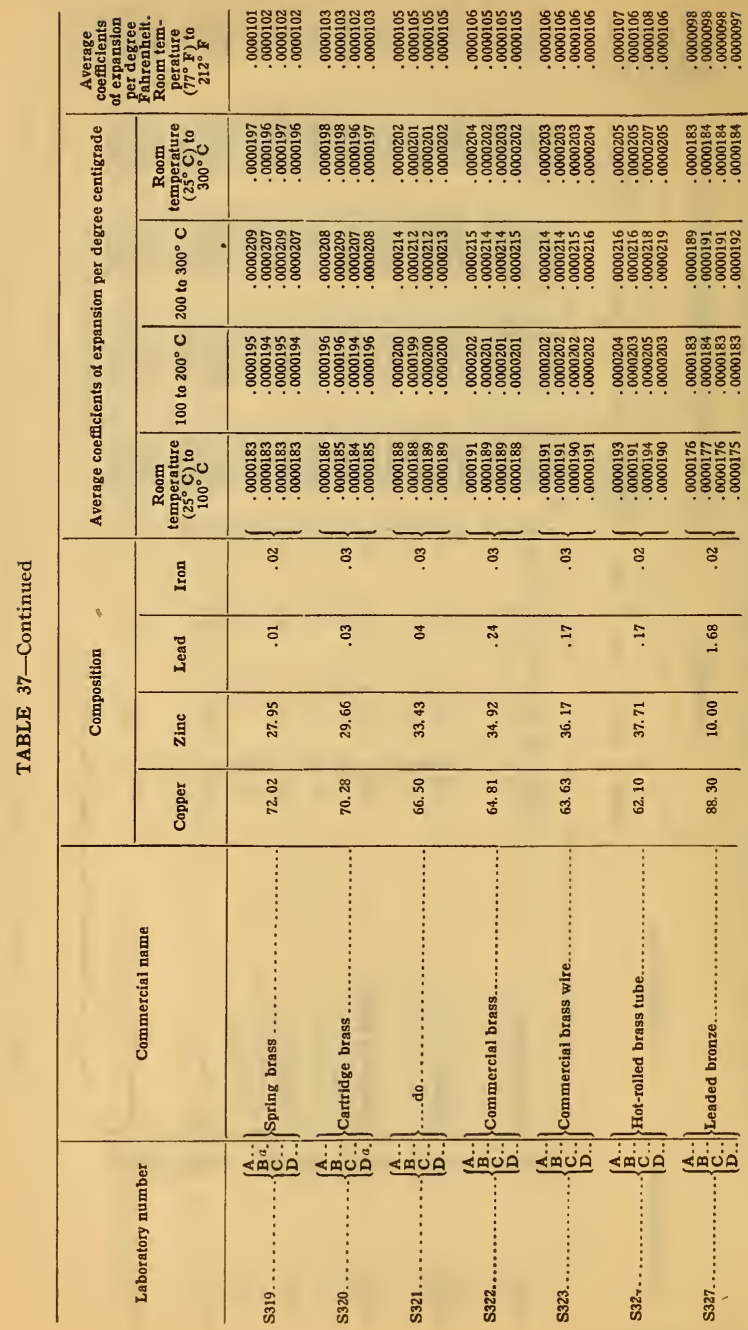



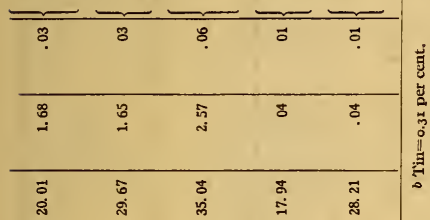

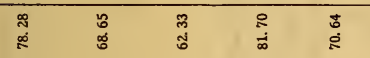

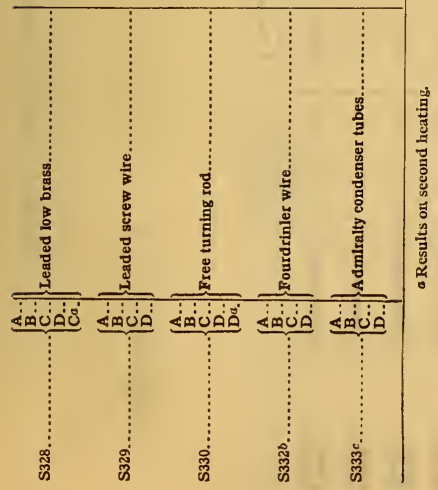




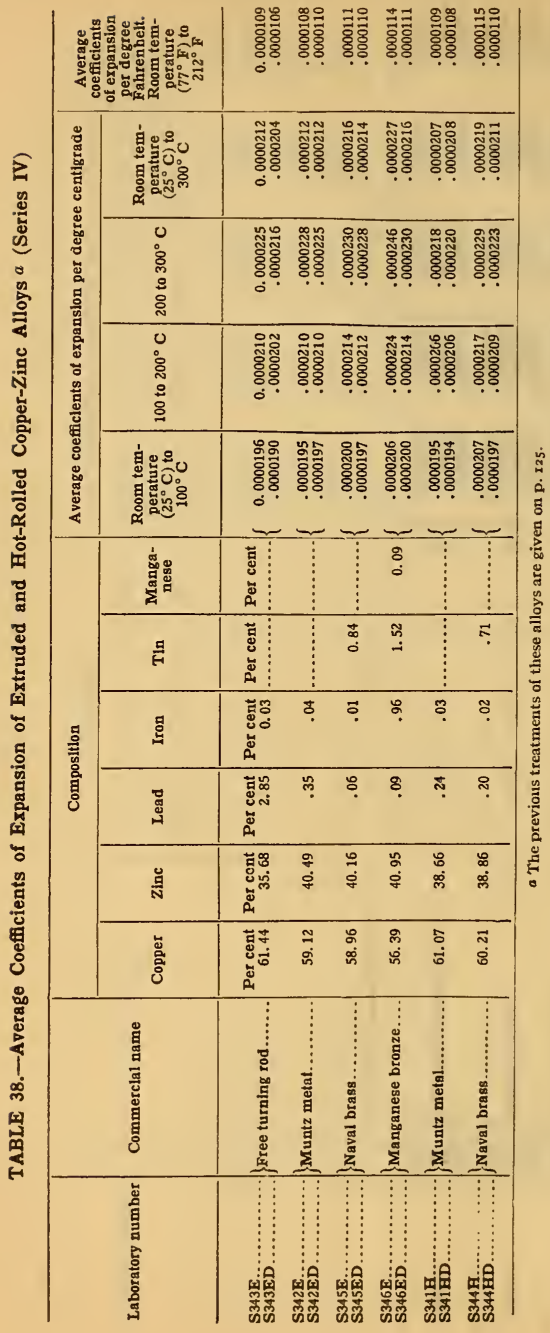




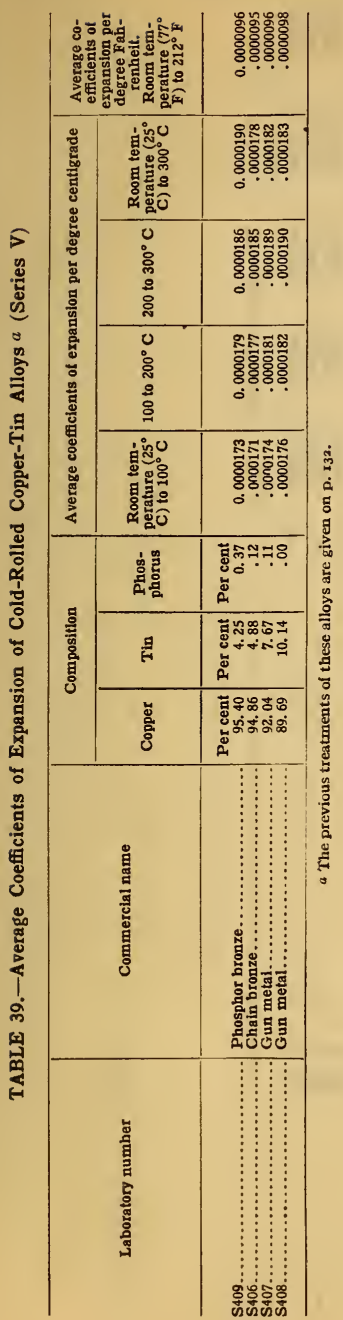




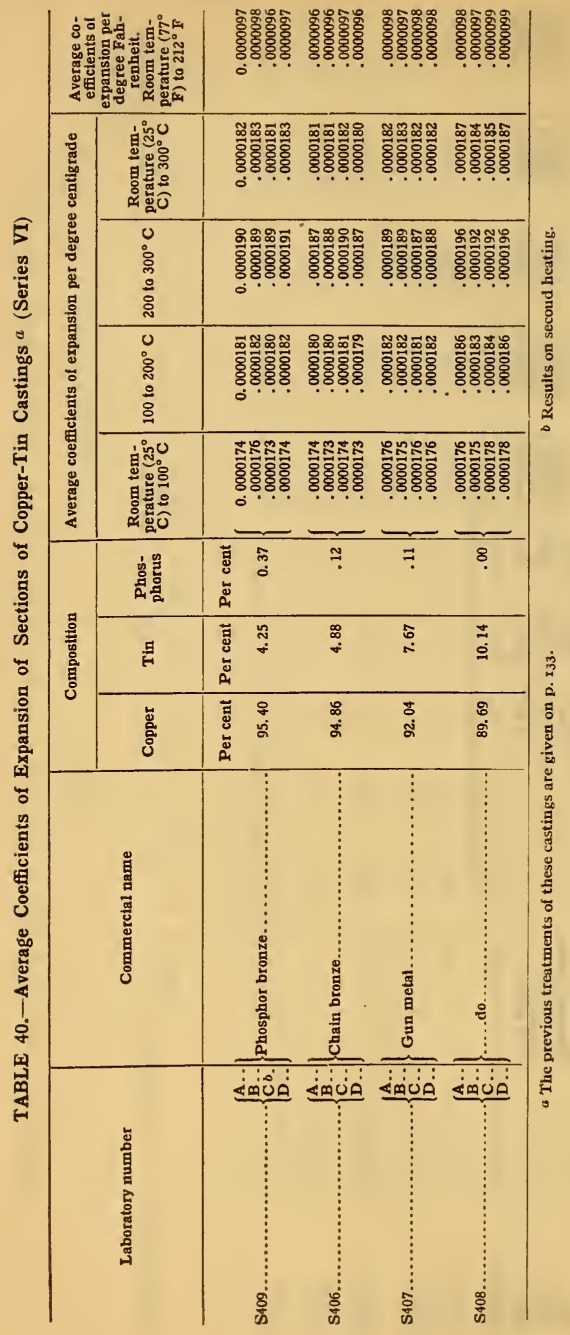




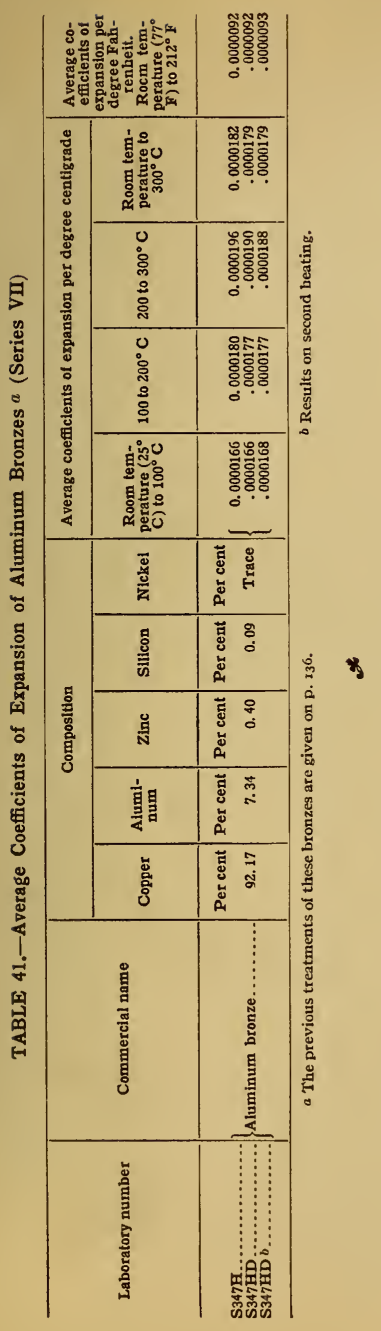

